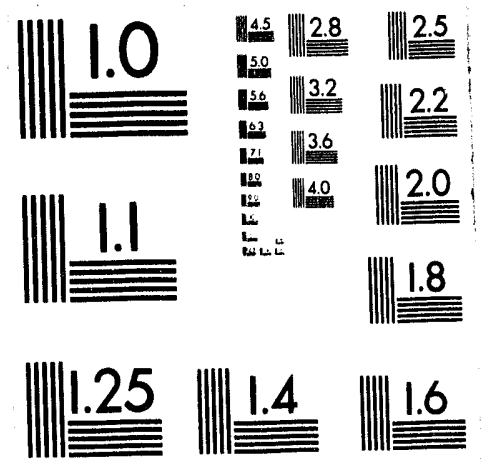




$$
\frac{\vec{o}}{\omega}
$$




\section{Performance Objectives and}

Criteria for

Conducting DOE Environmental Audits

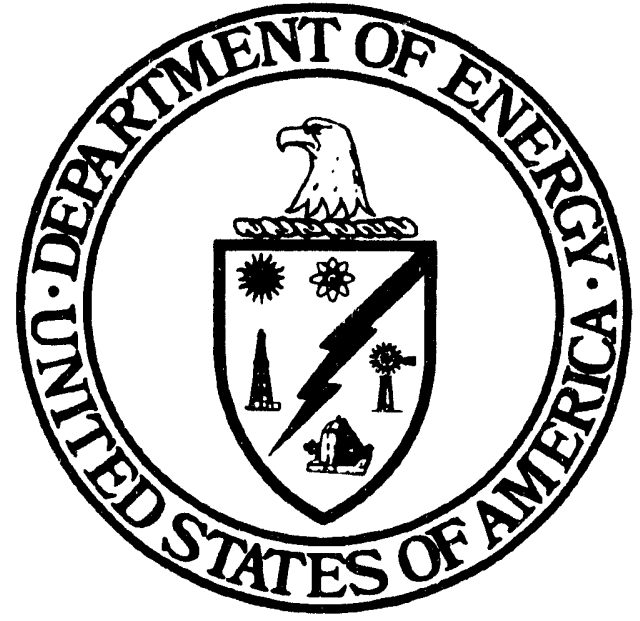

\section{U.S. Department of Energy} Office of Environmental Audit 


\section{TABLE OF CONTENTS}

Title

Page





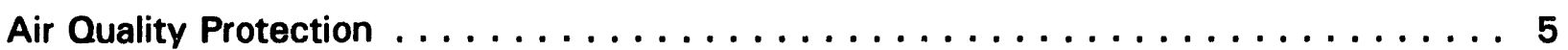

Surface Water and Drinking Water Quality . . . . . . . . . . . . . . 25



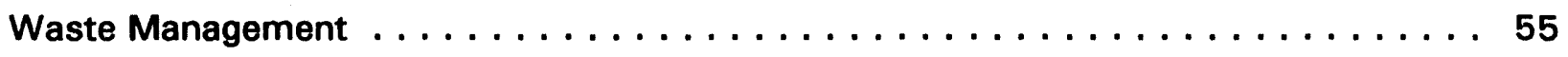

Toxic and Chemical Materials $\ldots \ldots \ldots \ldots \ldots \ldots \ldots \ldots$

Inactive Waste Sites and Releases $\ldots \ldots \ldots \ldots \ldots$. . . . . . . . . . . 103

Environmental Radiation Protection $\ldots \ldots \ldots \ldots \ldots \ldots \ldots \ldots \ldots$

Ecological and Cultural Resources $\ldots \ldots \ldots \ldots \ldots \ldots \ldots \ldots$

Environmental Quality Assurance $\ldots \ldots \ldots \ldots \ldots \ldots \ldots \ldots \ldots \ldots$

National Environmental Policy Act $\ldots \ldots \ldots \ldots \ldots \ldots \ldots \ldots$

Environmental Management Systems $\ldots \ldots \ldots \ldots \ldots \ldots \ldots \ldots \ldots$ 
This page intentionally left blank. 


\section{Introduction}

This document contains the Performance Objectives and Criteria (POC) that have been developed for environmental audits and assessments conducted by the Office of the Assistant Secretary for Environment, Safety and Health. The Environmental POC can serve multiple purposes. Primarily, they are to serve as guidelines for the technical specialists conducting the audits and assessments, and for the team management. The POC can also serve as supporting documents for training of technical discipline specialists and Team Leaders and as bases for DOE programs and field offices and contractors conducting audit or assessment activities or improving environmental protection programs. It must be recognized that not all of the POC will necessarily apply to all DOE facilities. The users of this document must rely upon their knowledge of the facility and their professional judgemient, or the judgement of qualified environmental professionals to determine the applicability of each POC.

The POC cover eleven technical disciplines: air; surface water and drinking water quality; groundwater; waste management; toxic and chemical materials; radiation; quality assurance; inactive waste sites and releases; ecological and cuitural resources; the National Environmental Policy Act (NEPA); and environmental management systems. The performance objectives for each discipline describe component parts of a comprehensive program to conduct the environmental protection activities associated with that discipline. Each performance objective contains a concise statement of that objective followed by brief summaries of the regulatory citations that support it. This is then followed by the criteria that must generally be satisfied in order to achieve the objective. The performance objectives are broad and themselves not directly measurable, while the criteria are measurable, although in some cases the measurement will by necessity be somewhat subjective. The POC are designed to provide direction to technical and management personnel, and are not intended to replace audit checklists and protocols, the professional expertise of the technical specialists, or reference to DOE Orders and environmental regulations. Because of the complex nature of environmental protection and the DOE system, the criteria may not recessarily address all activities associated with a performance objective. Consequently, there may be cases where a facility satisfies a literal interpretation of the criteria, but still fails to achieve the performance objective. Conversely, it may be possible for the performance objective to be achieved even though not all of the criteria have been met. For this reason the emphasis is on the performance objectives, and the criteria should be viewed as aids in evaluating them.

The POC have been developed on a "programmatic" basis. That is, they are intended to guide assessment team members in evaluating the effectiveness of the programs and systems used by a facility to establish and implement environmental protection standards. This requires not only evaluations of compliance with environmental regulations, DOE Orders, and conformance to accepted industry practices, but also whether the programs and systems are sufficient to provide reasonable assurances that environmental protection can be achieved. Such an approach is especially beneficial for assessments of large or complex facilities where it would be impractical to conduct a compliance assessment that would cover all operations and locations. Further, a conventional compliance assessment is a "snapshot in time," and is not an effective predictor of future compliance status. The programmatic approach focuses on the formal systems and programs used by the facility management to establish and implement environmental protection activities. Evaluations of these programs and systems by experienced environmental professionals should provide 
a reasonably accurate assessment of whether they are sufficient to provide environmental protection that goes beyond compliance and proactively address environmental issues.

The POC for each technical discipline address the key elements necessary for effective programmatic control, and will include such issues as technical aspects, formality of the programs, training, and quality assurance. The POC are written at a level that emphasizes policies and programs. It must be understood by all users that the POC are not amenable to yes or no answers. The mere existence of a formal program is not sufficient to satisfy a performance objective, nor can it be concluded that one of the criteria has been satisfied simply because it is addressed in the program documentation. Rather it will be first necessary for the discipline specialist to evaluate whether the objectives and criteria are addressed in such a way, and with a sufficient degree of formality, that they will be satisfied if the programs are effectively implemented. This requires a detailed critical review of the formal policies, standards, procedures, and other documents that define the program. It is further necessary to evaluate all program implementing procedures to determine whether they are sufficiently comprehensive and detailed to fulfill their purpose. It is then necessary to evaluate the effectiveness of the implementation, that is, the extent to which the environmental activities are consistent with regulatory requirements and best. management practices. These reviews must also include an assessment of the adequacy of internal control and oversight.

The level of knowledge and understanding of environmental protection that is necessary to effectively conduct a programmatic assessment is clearly not directly provided by the information contained in the POC. The POC must be supplemented by the knowledge and experience of the technical specialists, audit checklists and protocols such as the DOE Environmental Audit Manual (DOE/EH-0125), the Protocols for Conducting Environmental Management Assessments of DOE Organizations (DOE/EH-0326), DOE Orders, regulations and associated preambles, DOE and regulatory guidance documents, and other pertinent documents. The proper use of the POC is for the specialists to utilize them to focus or direct their attention to the key discipline elements that must be evaluated in an assessment. It is the responsibility of the individual specialist to use this direction to develop and implement a site-specific assessment plan and lines of inquiry.

Finally, the users of these POC must recognize that this is a living document. That is, revisions are to be expected as regulations change, and as the POC are put into widespread use. Experience in the use of the POC may reveal weaknesses, identify redundancies, or suggest needs for additional performance objectives or criteria. Recommended changes and additions, as well as general comments on the utility of the POC should be directed to the DOE Office of Environmental Audit. 


\section{Significant Revisions}

This document is a revision of the first edition of the Performance Objectives and Criteria for Conducting DOE Environmental Audits (DOE/EH-0229). Among the many updates and changes to the previous edition are the following significant revisions:

- New assessment/audit disciplines added:

- Ecological and Cultural Resources

$-\quad$ NEPA

- New POC added to existing disciplines:

- Management of Nonhazardous Waste (WM.12) has been added to the Waste Management discipline.

- Management arıd Control of Asbestos (TCM.6), Pollution Prevention Awareness Program (TCM.7) (The Office of Environmental Audit is currently working with the Waste Reduction Steering Committee and various field organizations to develop detailed pollution prevention assessment protocols that go beyond pollution prevention awareness. These protocols are expected to be completed in 1994 and will be distributed throughout the DOE complex when finalized), and Explosives Management and Control (TCM.8) have been added to the Toxic and Chemical Materials discipline.

- Removal Actions and Interim Removal Actions (IWS.6) and Remedial Action Design and Construction (IWS.7) have been added to the Inactive Waste Sites discipline.

- $\quad$ Environmental Planning and Risk Management (EM.8) has been added to the Environmental Management Systems discipline.

- Existing POC moved or significantly altered:

- $\quad$ Floodplain and Wetlands Protection Program (formerly SW.7) has been moved to the Ecological and Cultural Resources discipline (ECOL.2).

- Surface Water and Drinking Water Protection Programs (SW.3) has been replaced with 3 POC: Oil Pollution Prevention (SW.6), Drinking Water Protection Program (SW.7), and Surface Water Protection Program (SW.8).

Accumulation, Transfer and Storage (WM.3) has been replaced with Satellite and Temporary Accumulation Areas (WM.3). 
- $\quad$ Portions of Treatment/Recycling (WM.4) have been combined with Disposal (WM.5) in a new POC, Treatmerit, Storage and Disposal Facilities (WM.4).

- $\quad$ The remainder of WM.4 has been combined with Minimization/ Reduction (WM.7) in a new POC, Minimization and Recycling (WM.6).

- Management and Control of Petroleum and Petroleum Products in Aboveground Storage Tanks (TCM.4) has been merged into Drinking Water Protection Program (SW.7).

- Release Reporting (formerly IWS.2) has been moved to the Toxic and Chemical Materials discipline (TCM.9).

- $\quad$ Culture and Attitude (EM.2) has been replaced with Environmental Commitment (EM.2).

- Staffing and Resources (EM.6) and Staff Development and Training (EM.7) have been combined in a new POC, Staff Resources, Training and Development (EM.6).

The elements of Environmental Program Documentation (EM.9) have been separated and placed within appropriate disciplines throughout this document. 


\section{PERFORMANCE OBJECTIVES AND CRITERIA FOR AIR QUALITY PROTECTION}

\section{Overview}

The responsibility of the air specialist is to determine whether the site operations and other activities comply with applicable Federal, state, and local statutes, regulations, ordinances, or any other legally enforceable requirements that relate to the emission of pollutant substances to the atmosphere.

These requirements are included in the United States Code of Federal Regulations, state statutes and regulations, and local ordinances. Specific DOE Orders and segments of the Code of Federal Regulations (CFR) that are pertinent to the air assessment are shown in Table A-1. Air specialists must also identify and determine compliance with any legally enforceable requirements, such as permits, court orders, consent orders, Federal Facility Compliance Agreements, or state requirements which establish standards or practices for the site. In addition, air specialists identify areas of the site operations and activities which, in their judgement, do not satisfy mandatory DOE procedural requirements as identified in DOE Orders. Air specialists also review site activities for adherence to best management practices (BMPs). BMPs are typically evaluated when statutes or regulations do not exist, do not apply, do not describe specific actions that may be required to achieve the statutory or regulatory goals, or do not go far enough to achieve protection of human health and the environment. Most BMPs complement existing regulations and provide an added degree of protection when prudently employed. When used, BMPs are normally described in appropriate site operations documents such as procedures manuals.

The general approach to the air portion of an assessment or audit includes the following information collection activities: (1) review of documentation, including policy statements, program plans, standard operating procedures, operating records, and previous audits and assessments; (2) examination of facilities and sources of air-contaminant emissions and any devices or techniques used to measure and control emissions; and (3) interviews with DOE and site contractor personnel, and Federal/state regulators. While the scope and depth of the information collection process is not intended to identify every compliance problem at a site, it is intended to compile a representative sampling of information for use in developing a broad understanding and awareness of the compliance status of the site on the programmatic level in order to define the range of compliance issues and problems that may exist.

In conducting these activities the air specialist will work closely with a number of other specialists. In particular, regarding NESHAP issues the radiation specialist will be a key resource. In addition, the toxic and chemical materials specialist can be consulted regarding the generation of airborne pollution. Control of air emissions from waste treatment, storage, and disposal facilities will be examined with the assistance of the waste management specialist.

Because of the complexity of many of the DOE sites and the myriad environmental regulations and requirements, a series of Performance Objectives and Criteria (POC) documents has been developed to guide the air specialist in conducting a programmatically oriented assessment or audit. A list of POC developed for the air specialty is shown in 
Table A-2. Each of the POC includes a stated objective; citations of applicable DOE Orders, regulations, and requirements that provide the basis for the POC; and criteria that should be used in evaluating the site's performance against the programmatic objective. 


\begin{tabular}{|c|c|c|}
\hline & $\begin{array}{c}\text { TABLE A-1 } \\
\text { LIST OF AIR } \\
\text { REGULATIONS/REQUIREMENTS/GUIDELINES }\end{array}$ & \\
\hline Reguriationst?: & Sectionsmitilo & Authority \\
\hline DOE 5400.1 & General Environmental Protection Program & DOE \\
\hline DOE 5400.2A & Environmental Compliance Issue Coordination & DOE \\
\hline DOE 5400.5 & $\begin{array}{l}\text { Radiation Protection of the Public and the } \\
\text { Environment }\end{array}$ & DOE \\
\hline DOE 5480.1 & Conduct of Operations & DOE \\
\hline DOE 5482.1B & Environmental Health and Safety Appraisals & DOE \\
\hline DOE 5484.1 & $\begin{array}{l}\text { Environmental Protection, Safety and Health } \\
\text { Protection Information and Reporting Requirements }\end{array}$ & DOE \\
\hline DOE 6430.1A & General Design Criteria & DOE \\
\hline DOE/EH-0173T & $\begin{array}{l}\text { Environmental Regulatory Guide for Radiological } \\
\text { Effluent and Environmental Surveillance }\end{array}$ & DOE \\
\hline 40 CFR 51 & $\begin{array}{l}\text { State Implementation Plan as Required by the } \\
\text { Clean Air Act }\end{array}$ & EPA \\
\hline 40 CFR 52.21 & $\begin{array}{l}\text { Prevention of Significant Deterioration of Air } \\
\text { Quality }\end{array}$ & EPA \\
\hline 40 CFR 60 & $\begin{array}{l}\text { Clean Air Act Regulations for New Source } \\
\text { Performance Standards }\end{array}$ & EPA \\
\hline 40 CFR 61 & $\begin{array}{l}\text { National Emission Standards for Hazardous Air } \\
\text { Pollutants (NESHAP) }\end{array}$ & EPA \\
\hline 40 CFR 80 & Regulation of Fuels and Fuel Additives & EPA \\
\hline 40 CFR $260-271$ & Hazardous Waste Incinerators & EPA \\
\hline $\begin{array}{l}40 \text { CFR } \\
264.250(\mathrm{c})(3) \text {, } \\
264.301(\mathrm{i}), \text { and } \\
264.273(\mathrm{f})\end{array}$ & $\begin{array}{l}\text { Resource Conservation and Recovery Act (RCRA) } \\
\text { Requirements for Particulate Emissions from } \\
\text { Permitted Waste Piles, Landfills, and Land } \\
\text { Treatment Units }\end{array}$ & EPA \\
\hline
\end{tabular}


TABLE A-2

PERFORMANCE OBJECTIVES AND CRITERIA FOR AIR QUALITY PROTECTION

A.1 Air-Effluent-Source Monitoring Program

A.2 Airborne Effluent Control Program

A.3 Ambient Air Surveillance Monitoring Program

A.4 Meteorological Monitoring Program

A.5 Program to Obtain and Maintain Permits for Air Emission Sources and Air Pollution Control Devices

A.6 Program to Ensure Awareness of Federal, State, and Local Air Pollution Rules and Regulations

A.7 Program to Ensure Compliance with Notification and Reporting Requirements

A.8 Program for Reduction of Emissions from Motor Vehicle Operations

A.9 Program to Minimize Emissions to the Air of Pollutants from Hazardous Waste Treatment, Storage, and Disposal Facilities 


\section{A.1 AIR-EFFLUENT-SOURCE MONITORING PROGRAM}

\section{PERFORMANCE OBJECTIVE}

A program should be in effect to characterize and monitor gases or air streams exhausted or yented to the outside atmosphere from any site, facility, or process for all regulated pollutants or hazardous substances, including both radioactive and nonradioactive materials.

DOE 5400.1, General Environmental Protection Program, Chapter IV, contains requirements and guidance for environmental monitoring programs concerned with measuring and monitoring effluents from DOE operations. An air effluent monitoring program shall be cunducted at all DOE sites where radionuclides may be released to the atmosphere, or as required by applicable Federal, state, or local regulations.

DOE 5400.1, Chapter IV, Section 1.b, specifies that all requirements of Chapter IV associated with the development of an environmental monitoring plan and implementation of an environmental monitoring program, including air-effluent-source monitoring, shall be accomplished no later than November 9, 1991, unless otherwise required by other DOE Orders, or by applicable Federal, state, or local legislation or regulation. The environmental monitoring plan shall be reviewed annually and updated as needed.

DOE 5400.1, Chapter IV, Section 4, requires a written environmental monitoring plan that includes a program for monitoring air-effluent sources.

DOE 5400.5, Radiation Protection of the Public and the Environment, requires the use of informaticn obtained from monitoring in calculations to demonstrate that exposures are as low as reasonably achievable (ALARA).

DOE/EH-0173T, Environmental Regulatory Guide for Radiological Effluent Monitoring and Environmental Surveillance, Chapter III, sets forth an objective that all DOE operations properly and accurately measure radionuclides in their effluents, and provides specific guidance for use in establishing and operating an effluent monitoring program for atmospheric emissions.

An EH-232 Memorandum dated August 5, 1991 provides "Guidance on Achieving Compliance with the NESHAP Emission Monitoring and Test Procedures of 40 CFR 61.93(b)."

40 CFR 60, Standards of Performance for New Stationary Sources, and 40 CFR 61 , National Emission Standards for Hazardous Air Pollutants (NESHAP) require performance tests and monitoring for specified pollutants and sources.

ANSI N13.1-1969, American National Standard Guide to Sampling Airborne Radioactive Materials in Nuclear Facilities, and ANSI N42.18-1980, Specification and Performance of On-site Instrumentation for Continuously Monitoring Radioactivity in Effluents, provide guidelines for monitoring of gaseous effluent streams. 
Source inventorying and monitoring may be required by state or local air pollution control agencies.

Federal Facility Compliance Agreements, consent orders, etc., may also require that air effluent monitoring be conducted; specific program requirements may be prescribed in those documents.

\section{CRITERIA}

A. Responsibility and authority have been assigned for the preparation of a plan for aireffluent-source monitoring, as part of an environmental monitoring plan.

B. A plan for monitoring air-effluent sources that addresses the elements listed in DOE 5400.1 , Chapter IV, Section 4 has been formalized in a document and has received appropriate review and approval.

C. The responsibility and authority for operation of the air-effluent-monitoring program has been delineated.

D. The plan has identified all potential air-effluent sources, has defined all those that require characterization and/or effluent monitoring or sampling, and has documented the basis for not monitoring or sampling specific sources.

E. Radiological air-effluent monitoring is conducted in accordance with the requirements of 40 CFR 61.93 (b), DOE Orders in the 5400 series, and DOE guidance document DOE/EH-0173T.

F. Nonradiological air-effluent monitoring is conducted in accordance with the requirements of applicable Federal, state, or local regulations.

G. The monitoring or sampling design is sufficiently detailed to assure that representative, quality assured samples are obtained.

H. Detailed operating procedures for monitoring or sampling equipment and laboratory analyses that are appropriate for the pollutant being monitored have been developed, reviewed, and bear appropriate approval signatures.

I. Operators of monitoring or sampling equipment and laboratory analysts have been trained or have received refresher training, and records of training are maintained.

J. Records of calibration and maintenance activities are kept and calibration stickers that are dated and signed are in place.

K. Data generated by monitoring or sampling activities are reviewed and quality control checks are conducted to provide early warning of malfunctions.

L. A plan is in place that describes corrective actions to be implemented during malfunctions of monitoring equipment. 
M. Radiological effluent monitoring data are used to evaluate the effectiveness of the ALARA program. 


\section{A.2 AIRBORNE EFFLUENT CONTROL PROGRAM}

\section{PERFORMANCE OBJECTIVE}

An effective program should be in place to ensure that emissions to the atmosphere of pollutants or hazardous substances are maintained at levels that are below allowable standards and, in the absence of specific standards, that appropriate management methods are utilized to minimize emissions. In the case of radionuclides, the program should ensure that emissions are controlled to the extent that potential exposures to members of the public are as low as reasonably achievable (ALARA).

DOE 5400.5, Radiation Protection of the Public and the Environment, requires the development of a program and implementation of a process (ALARA Process) that is an approach to radiation protection which is intended to control or manage exposures and releases of radioactive material to the environment with an objective of attaining dose levels from radionuclide releases as far below applicable limits as practicable.

DOE 6430.1A, General Design Criteria, provides standards and requirements for control devices for radionuclide emissions and air pollution control in general.

40 CFR 51 describes State Implementation Plans for meeting Clean Air Act requirements. Based upon these plans, state or local air pollution control agencies and state or local air emission standards frequently require specific emission control technologies or administrative procedures as part of their programs to attain and maintain air quality standards, and in construction permits issued pursuant to prevention of significant deterioration requirements or nonattainment area new source review requirements.

40 CFR 60, Standards of Performance for New Stationary Sources, prescribes emission standaras for any stationary source that includes an affected facility for which construction or modification commenced on or after the date of publication of an applicable st andard. IEmission standards are also prescribed in 40 CFR 61 , National Emission Standards for Hazardous Air Pollutants (NESHAP), for specified substances and processes. The NESHAP apply to new sources and, 90 days after the effective date of a standard, to existing sources. Attainment of both the new source standards and the NESHAP requires the application of suitable engineering or administrative controls to minimize emissions of air pollutants.

NSPS 4A, CFR 60.11, states that at all times, including during upsets, sources of air pollution should be operated in a manner consistent with good air pollution control practices for minimizing emissions.

Documents such as Federal Facility Compliance Agreements and consent orders, may also require installation of specific emission control technologies or implementation of prescribed administrative controls.

\section{CRITERIA}

A. A formal, documented plan has been developed to identify sources that need to have emission controls implemented, and to identify controls that are appropriate. 
B. Responsibilities and authorities have been assigned for the development and implementation of an airborne effluent control program.

C. All existing exhaust stacks and vents as well as sources of fugitive emissions have been inventoried and evaluated to determine which sources need engineering and/or administrative controls to minimize emissions to the atmosphere. This inventory and evaluation have been fully documented, including the basis for a decision to not control specific sources.

D. Emission control systems or administrative controls are in place and are being operated in a manner that assures effective control of emissions to the atmosphere.

E. Standard operating procedures are available that adequately describe operational requirements for emission-control equipment, or that detail steps required to be taken to implement administrative controls.

F. Operational logbooks are kept that provide permanent records of the operational status of emission control equipment, including records of outages, maintenance performed, and periodic readings from gauges or instruments that provide performance indicator data.

G. Periodic efficiency tests are conducted to evaluate the performance of the emission control equipment (see also POC A.1).

H. Control of radiological airborne effluents is addressed as a part of a formal ALARA program.

I. Quality assurance requirements and procedures have been established in formal documents, and procedures have been implemented to ensure that emission controls provide the required protection of the environment. 


\section{A.3 AMBIENT AIR SURVEILLANCE MONITORING PROGRAM}

\section{PERFORMANCE OBJECTIVE}

A program of environmental surveillance monitoring should be in place to ascertain the effects of airborne emissions of pollutants or hazardous materials from DOE activities on onsite and offsite environmental and natural resources and public health.

DOE 5400.1, General Environmental Protection Program, Chapter IV, Section 5.b, requires that environmental surveillance be conducted at DOE sites where radionuclides may be released to the atmosphere, or as required by Federal, state, or local regulations to monitor the effects of DOE activities on the environment. An environmental surveillance program shall be implemented no later than November 9, 1991, unless otherwise required by other DOE Orders, or by applicable Federal, state, or local legislation or regulation (Chapter IV, Section 1.b). The environmental monitoring plan shall be reviewed annually and updated as needed. A critical element of monitoring is quality assurance and verification (Chapter IV, Section 1.a) (see also POC QA.1 and QA.4).

DOE 5400.1, Chapter IV, Section 4, requires a written environmental monitoring plan that includes a program for ambient air surveillance monitoring for radionuclides and, if required by Federal, state, or local regulations, for significant pollutants or hazardous materials emitted in airborne effluents from the facility.

DOE 5400.5, Radiation Protection of the Public and the Environment, Chapter I, Paragraph 8.a, states that it is the intent of DOE that monitoring and surveillance programs for DOE activities, facilities, and locations be of high quality.

DOE 5400.5, requires all DOE Operations to maintain exposures to the public and environment to levels that are as low as reasonably achievable (ALARA) below the appropriate dose limits.

DOE/EH-0173T, Environmental Regulatory Guide for Radiological Effluent Monitoring and Environmental Surveillance, Chapter V, sets forth an objective to properly and accurately measure radionuclides in ambient environmental media, and provides specific guidance for use in establishing and operating an environmental surveillance program.

40 CFR 50 provides reference methodologies for ambient air surveillance of criteria pollutants.

40 CFR 51, State Implementation Plan requirements may specify ambient air surveillance monitoring under the authority of state or local air pollution control agencies. Such monitoring is designed to ensure attainment and maintenance of the National Ambient Air Quality Standards.

40 CFR 58 provides guidance on monitoring criteria and quality assurance requirements for prevention of significant deterioration monitoring. 
Pre-construction ambient air surveillance monitoring may be required to obtain a prevention of significant deterioration (PSD) permit to construct and post-construction monitoring may be specified in a PSD permit.

Federal Facility Compliance Agreements, consent orders, and similar documents may also require that ambient air surveillance monitoring be conducted. Specific program requirements may be prescribed as part of those documents.

\section{CRITERIA}

A. Responsibility and authority have been assigned for the preparation of a plan for air surveillance monitoring, as part of an environmental monitoring plan.

B. A plan for air surveillance monitoring that addresses the elements listed above and in DOE 5400.1, Chapter IV, Section 4 has been formalized in a document and has received appropriate review and approval.

C. The responsibility and authority for operation of the air surveillance monitoring program have been delineated.

D. The plan has identified all pollutants and hazardous materials emitted from the facility, has defined all those that require surveillance monitoring, and has documented the basis for not monitoring specific pollutants.

E. The monitoring plan, including the basis for monitor location is consistent with DOE Orders and/or EPA guidance and is sufficiently detailed to ensure that representative samples are obtained. For example, monitor locations have been selected objectively based on the purpose for the data to be generated (e.g., resolution of maximum concentrations or determination of background concentrations.).

F. Some facilities may not be explicitly exempted from the monitoring program by the DOE Order, but their operations are such that monitoring may not be necessary. For these facilities, an objective evaluation of the facility operations and emissions has been performed, documented, and submitted to DOE EH-1 for a monitoring exemption request.

G. Detailed operating procedures for monitoring equipment and laboratory analyses that are appropriate for the pollutant being monitored have been developed, reviewed, and bear appropriate approval signatures.

H. Operators of monitoring or sampling equipment and laboratory analysts have been trained or refresher trained, and records of training are maintained.

I. Records of calibration and maintenance activities are kept and calibration stickers that are dated and signed are in place.

J. Data generated by monitoring or sampling activities are reviewed and quality control checks are conducted to provide early warning of malfunctions. 
K. Environmental data are used in the evaluation of the effectiveness of the ALARA program.

L. Quality assurance activities are sufficient to ensure that monitoring or sampling activities yield representative and defensible data.

M. A plan is in place that describes corrective actions to be implemented during malfunctions of monitoring equipment. 


\section{A.4 METEOROLOGICAL MONITORING PROGRAM}

\section{PERFORMANCE OBJECTIVE}

A program to obtain and maintain representative meteorological data is required to support environmental monitoring activities and to comply with regulations and DOE Orders requiring the assessment of the impact of airborne releases.

DOE 5400.1, General Environmental Protection Program, requires that a meteorological monitoring program be implemented at DOE facilities where radionuclides may be released to the atmosphere, or as required by applicable Federal, state, or local regulations, to obtain representative meteorological data in support of environmental monitoring activities (Chapter IV. Section 6), and that implementation of the program shall be accomplished no later than November 9, 1991 (Chapter IV, Section 1.b). The environmental monitoring plan shall be reviewed annually and updated as needed.

DOE 5400.1, Chapter IV, Section 6.a, requires the development of a meteorological data acquisition or monitoring program as part of the facility environmental monitoring plan.

DOE/EH-0173T, Environmental Regulatory Guide for Radiological Effluent Monitoring and Environmental Surveillance. Chapter IV, sets forth specific guidance for use in establishing and operating a meteorological monitoring program.

Meteorological monitoring programs that provide input to EPA models should be conducted in accordance with the EPA guidance document, On-site Meteorological Program Guidance for Regulatory Modeling Applications, (EPA-450/4-87-013).

\section{CRITERIA}

A. Where required, responsibility and authority have been assigned for the preparation of a plan for meteorological monitoring, as part of an environmental monitoring plan. The meteorological monitoring plan addresses conditions that would be applicable for both continuous releases and accidental releases, as necessary. This would likely include characterizing upper air (at least throughout the mixing layer) and surface conditions.

B. A plan for meteorological monitoring has been formalized in a document and has received appropriate review and approval. The plan identifies the types of meteorological information required to support all environmental protection activities (both routine and nonroutine) and addresses the regulations applicable to assessing impacts of airborne releases.

C. The meteorological monitoring program shall assure that representative meteorological information shall be available at or in the vicinity of DOE facilities to:

1. Provide data to characterize atmospheric transport, diffusion conditions, and other climatic conditions of importance in the vicinity of the DOE facility for assessments of the impacts of airborne releases (both routine and nonroutine) on public health and safety; 
2. Provide data to characterize conditions important to environmental surveillance activities such as air quality and radiation monitoring;

3. Provide data to confirm compliance with and implementation of applicable regulations and DOE Orders; and

4. Provide a consistent data base upon which decisions can be made concerning airborne releases and appropriate control activities.

D. The responsibility and authority for operation of the meteorological monitoring program have been delineated.

E. The meteorological monitoring approach is consistent with DOE Orders and other applicable guidance.

F. Detailed operating procedures for monitoring equipment have been developed, reviewed, and bear appropriate approval signatures.

G. Operators of monitoring equipment have been trained or refresher trained, and records of training are maintained.

H. Records of calibration and maintenance activities are kept and calibration stickers that are dated and signed are in place.

I. Data generated by monitoring activities are reviewed and quality control checks are conducted to provide early warning of malfunctions. 


\section{A.5 PROGRAM TO OBTAIN AND MAINTAIN PERMITS FOR AIR EMISSION SOURCES AND AIR POLLUTION CONTROL DEVICES}

\section{PERFORMANCE OBJECTIVE}

A program should be in effect to ensure that permits to construct and permits to operate various air pollutant sources and air pollutant control devices are obtained or renewed on a timely basis.

DOE 5400.1, General Environmental Protection Program, recognizes that DOE environmental management activities ". . . are extensively, but not entirely, regulated by EPA and state or local environmental agencies. Where these agencies clearly exercise environmental protection authority through permitting and compliance administrative procedures applicable to DOE, they establish and regulate required performance for environmental protection" (see Subparagraph 6b).

DOE 5400.1, Chapter III, Section 2.c, requires each field organization to prepare an Environmental Protection Plan that includes an assignment of responsibility for complying with requirements of all Federal, state, and local environmental laws and regulations.

Either 40 CFR 52.21, Prevention of Significant Deterioration of Air Quality, or an approved State Implementation Plan as detailed in 40 CFR 52, Subparts B through FFF, may require construction permits prior to start of construction of a new source or major modification.

Permits to construct and permits to operate may be required under rules and regulations promulgated by the EPA and state and local air pollution control agencies.

\section{CRITERIA}

A. A program is in effect to ensure that permits to construct and permits to operate are obtained or renewed for all sources of air pollutants and air pollutant control devices on a timely basis.

B. A current Environmental Protection Implementation Plan exists that assigns responsibility for complying with all requirements of Federal, state, and local environmental laws and regulations, and specifically assigns responsibility for the air permits program.

C. Current permits to construct and permits to operate exist, where required, for all air pollutant sources and air pollutant control devices.

D. Applications for permits to construct and permits to operate, including original applications and applications for renewal, are maintained as part of the permits file.

E. Where required by state or local regulations, current permits to construct or permits to operate are posted prominently at or near the permitted source or control device.

F. A tracking system is in place to provide a timely alert of permits requiring renewal. 


\section{A.6 PROGRAM TO ENSURE AWARENESS OF FEDERAL, STATE, AND LOCAL AIR POLLUTION RULES AND REGULATIONS}

\section{PERFORMANCE OBJECTIVE}

A program should be in place with assigned responsibilities to maintain awareness of applicable Federal, state, and local rules and regulations and their frequent updates to ensure compliance with all requirements.

The Clean Air Act Amendments of 1990, Title V, require all states to implement an operating permit program by 1995 . This program may require modeling analyses and monitoring of sources.

DOE 5400.1, General Environmental Protection Program, and other DOE environmental protection directives provide requirements for satisfying externally imposed regulations. The Order expects that activities, documentation, and special planning to meet these legal requirements will be used to the maximum extent (see Subparagraph 6b).

\section{CRITERIA}

A. An effective program has been implemented to ensure awareness of applicable Federal, state, and local air pollution laws, rules, and regulations and their frequent updates. The program includes assignments of specific responsibility.

B. An up-to-date file of DOE Orders is maintained.

C. A library of pertinent and current volumes of the Code of Federal Regulations is maintained.

D. A periodic review of the Federal Register and similar state and local sources is conducted to maintain awareness of proposed and new regulatory requirements.

E. Up-to-date files of state and local air pollution control laws, rules, and regulations are maintained.

F. A program is in place that ensures that changes to laws and regulations are systematically reviewed with facility emission inventories and operations to identify potential implications.

G. Modeling analyses are updated and source monitoring is implemented if required by state or local air pollution control agencies. 


\section{A.7 PROGRAM TO ENSURE COMPLIANCE WITH \\ NOTIFICATION AND REPORTING \\ REQUIREMENTS}

\section{PERFORMANCE OBJECTIVE}

A program should be in effect to ensure that required notices and reports relative to air programs are prepared and submitted on a timely basis.

DOE 5400.1, General Environmental Protection Program, recognizes that DOE environmental management activities ". . . are extensively, but not entirely, regulated by EPA and state or local environmental agencies. Where these agencies clearly exercise environmental protection authority through permitting and compliance administrative procedures applicable to DOE, they establish and regulate the required performance for environmental protection" (see Subparagraph 6b).

DOE 5400.1, Chapter II, establishes requirements for notification and follow-up of environmental occurrences, and periodic reporting of significant environmental protection information. Requirements for the following notices and reports are detailed:

(1) Notification to the Emergency Operations Center of significant nonroutine releases of any pollutant or hazardous substance,

(2) Semi-annual submission (by May 1 and December 15) of 5-year plans for pollution abatement projects as required by Office of Management and Budget Circular A-106,

(3) Annual Site Environmental Report by June 1, and

(4) Annual reports to Waste Information Systems Branch, EG\&G Idaho, Inc., on Radioactive Effluent and On-site Discharge Data by April 1.

40 CFR 61 specifies notification and reporting requirements for hazardous air pollutants as part of National Emission Standards for Hazardous Air Pollutants. The pollutants include, but are not limited to, radionuclides (Subpart H), asbestos (Subpart M), and beryllium (Subpart C).

Notification and reporting may be required by state or local air pollution control agencies as specified in regulations and in air operating permits.

Releases of reportable quantities of hazardous substances, including releases to the atmosphere, are addressed in POC IWS.2.

\section{CRITERIA}

A. A program is in place to ensure that notifications and reports, which are required by DOE, the U.S. EPA, or state or local air pollution control agencies, are prepared and submitted on a timely basis. 
B. Procedures have been developed that describe by whom, how, to whom, and how quickly reports of nonroutine releases of pollutants or hazardous substances to the atmosphere are to be made.

C. Procedures have been developed that address the notification and reporting requirements for the following hazardous air pollutants:
(1) asbestos,
(2) radionuclides except radon from DOE facilities, and
(3) beryllium 


\section{A.8 PROGRAM FOR REDUCTION OF EMISSIONS FROM MOTOR VEHICLE OPERATIONS}

\section{PERFORMANCE OBJECTIVE}

A program should be in place that minimizes pollutant emissions to the atmosphere from motor vehicle operations and from gasoline storage and dispensing operations.

The Clean Air Act Amendments of 1990, Title I, may require implementation of transportation controls and clean fuel vehicle programs.

40 CFR 51, State Implementation Plans, may authorize state or local air pollution control agencies to require Phase I or Phase II emission controls at gasoline dispensing facilities.

40 CFR 80.22 and .27 prescribe requirements applicable to gasoline retailers and wholesale purchaser-consumers.

State or local air pollution control agencies may require that vehicles be subjected to periodic emission inspection and maintenance programs to minimize emissions.

\section{CRITERIA}

A. Gasoline dispensing facilities are in compliance with the requirements of 40 CFR 80.22 and .27 .

B. A program for vehicular emission inspection and maintenance is in place, if required by state or local air pollution control regulations.

C. Proper emission controls are in place at gasoline dispensing facilities, if required by state or local air pollution control regulations.

D. In ozone severe areas, mandator y transportation control programs are in place, such as reduced commuting, parking restrictions, and clean fuel vehicles, if required by state or local air pollution control regulations. 


\section{A.9 PROGRAM TO MINIMIZE EMISSIONS TO THE AIR OF POLLUTANTS FROM HAZARDOUS WASTE TREATMENT, STORAGE, AND DISPOSAL FACILITIES}

\section{PERFORMANCE OBJECTIVE}

A program should be in place to ensure compliance with regulations and emission standards prescribed to minimize emissions of air pollutants from hazardous waste treatment, storage, and disposal facilities (TSDF).

40 CFR 264, Subpart L, Waste Piles, addresses the design and operation of waste piles to control dispersal of waste by wind, and provides special requirements for ignitable or reactive wastes.

40 CFR 264, Subpart M, Land Treatment, requires that the treatment zone must be managed to control wind dispersal of particulates, and requires weekly inspections to detect improper functioning of wind dispersal controls. Also specified are closure and post-closure requirements. Special requirements relate to certain specified hazardous wastes.

40 CFR 264, Subpart N, Landfills, addresses the control of wind dispersal of particulate matter, and has special requirements for certain specified hazardous wastes.

40 CFR 264, Subpart O, Incinerators, delineates performance standards and emission limits for hazardous waste incinerators.

40 CFR 264, Subpart X, Miscellaneous Units, requires prevention of any release that may have adverse effects on human health or the environment due to migration of waste constituents in the air.

40 CFR 264, Subpart AA, Air Emission Standards for Process Vents, and Subpart BB, Air Emission Standards for Equipment Leaks, both relate to organic air emissions at hazardous waste treatment, storage, and disposal facilities (TSDF) that require a permit under subtitle C of the Resource Conservation and Recovery Act (RCRA).

\section{CRITERIA}

A. Responsibilities and authorities have been assigned to ensure that releases of pollutants to the atmosphere from TSDF are minimized.

B. Standard operating procedures have been developed that specifically address actions to be taken to minimize releases to the atmosphere from TSDF.

C. Operators of TSDF have been trained in the required procedures.

D. Compliance with emission standards specified in 40 CFR 264, Subpart AA and Subpart BB, has been demonstrated using methodologies specified in those Subparts. 


\section{PERFORMANCE OBJECTIVES AND CRITERIA FOR PROTECTION OF \\ SURFACE WATER AND DRINKING WATER QUALITY}

\section{Overview}

The responsibility of the surface water and drinking water specialist is to determine whether site activities comply with applicable Federal, state, and local statutes and regulations, DOE Orders, permits, agreements, and other legally enforceable requirements that relate to surface water and drinking water quality.

An evaluation of surface water and drinking water issues at all DOE facilities is primarily based on compliance with requirements mandated by the Clean Water Act (CWA), as amended, and the Safe Drinking Water Act (SDWA), as amended. These two acts provide the statutory basis for rules and regulations promulgated by the Environmental Protection Agency (EPA) to protect the waters of the United States and all public water systems. In turn, EPA has permitted most states to formulate their own water pollution control regulations, so long as they provide equivalent protection of the environment and of drinking water sources. Specific DOE Orders and segments of the Code of Federal Regulations (CFR) that are pertinent to the surface and drinking water assessment are shown in Table SW-1.

Protection of surface water is accomplished through the National Pollutant Discharge Elimination System (NPDES) permit program, wherein all effluent discharges, whether directly to receiving streams or indirectly via Publicly-Owned Treatment Works (POTWs), must attain certain definite water quality levels prior to release. Dischargers to POTWs are not required to obtain NPDES permits, but must comply with all requirements established by the local sanitary authority. If expressly incorporated into a NPDES permit, facilities are required to develop formal best management practices (BMP) plans for controlling toxic and hazardous materials, whether they are raw materials awaiting use or waste products awaiting treatment or disposal. In addition, sites storing oils in large quantities are required to have an effective Spill Prevention, Control, and Countermeasure (SPCC) Plan. Moreover, the EPA and most state agencies have recently begun to investigate the impact of storm water discharges upon receiving streams. The current activity is focusing on point source discharges of storm water, but non-point sources will also be involved in the future. Permit application procedures have been put in place for point source discharges associated with industrial activity. The submission deadline for individual permit applications was October 1, 1992.

Potable drinking water issues involve the treatment, storage, and distribution of drinking water on site. Even sites that depend on outside utility companies to supply drinking water must take steps to protect the integrity of the supply through an aggressive backflow prevention program. For those sites that practice their own water treatment, rigid quality control, sampling, and analytical requirements apply, as outlined in the Safe Drinking Water Act and implementing regulations. Underground sources of drinking water must be protected from contamination, as must treatment and storage lagoons and tanks. Proper notification must be given in the event certain parameters are present at levels greater than those stipulated in regulations. Levels vary from state to state, but requirements are very specific within a state. 
The general approach to the surface and drinking water portion of an assessment or audit includes the following information collection activities: (1) review of documentation, including SPCC, BMP and other plans, permits and permit applications, standard operating procedures, training, operation and maintenance records, and earlier audit and assessment reports; (2) observation of site conditions, site operations, and routine procedures, including wastewater treatment plant operations, sampling activities if at all possible, and laboratory QA/OC procedures; and (3) interviews with DOE and site contractor personnel, and Federal/state regulators.

Many of the issues within the surface and drinking water assessment cross functional area boundaries. The reviewer should coordinate with the appropriate specialists to ensure adequate coverage of the POC and to avoid duplication of effort. For example, the quality assurance specialist should be consulted on sampling and analysis activities, and input should be obtained from the toxic and chemical materials specialist on oil storage issues. Coordination should also occur with the inactive waste sites specialist, who typically examines spill response activities.

A series of Performance Objectives and Criteria (POC) documents have been developed to provide general guidance to the surface and drinking water specialist for conducting the assessment or audit and to ensure that relevant aspects of environmental laws and regulations and DOE Orders are considered. A list of the POC is shown in Table SW-2. Each of the POC includes a stated objective; citations of applicable DOE Orders, regulations, and requirements that provide the basis for the POC; and criteria that should be used in evaluating the site's performance against the programmatic objective. 


\begin{tabular}{|c|c|c|}
\hline \multicolumn{3}{|c|}{$\begin{array}{l}\text { TABLE SW-1 } \\
\text { LIST OF SURFACE WATER AND DRINKING WATER } \\
\text { REGULATIONS/REQUIREMENTS/GUIDELINES }\end{array}$} \\
\hline 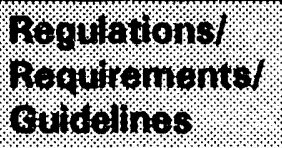 & Sogetrongrifilo. & Aviliority \\
\hline DOE 5000.3A & $\begin{array}{l}\text { Occurrence Reporting and Processing of } \\
\text { Operations Information }\end{array}$ & DOE \\
\hline DOE 5400.1 & General Environmental Protection Program & DOE \\
\hline DOE 5480.19 & $\begin{array}{l}\text { Conduct of Operations Requirements for DOE } \\
\text { Facilities }\end{array}$ & DOE \\
\hline DOE 6430.1A & General Design Criteria & DOE \\
\hline 29 CFR 1910 & Occupational Safety and Health Standards & OSHA \\
\hline 40 CFR 110 & Discharge of Oil & EPA \\
\hline 40 CFR 112 & Oil Pollution Prevention & EPA \\
\hline 40 CFR 121 & $\begin{array}{l}\text { State Certification of Activities Requiring a } \\
\text { Federal License or Permit }\end{array}$ & EPA \\
\hline 40 CFR 122 & $\begin{array}{l}\text { National Pollutant Discharge Elimination } \\
\text { System }\end{array}$ & EPA \\
\hline 40 CFR 141 & National Primary Drinking Water Regulations & EPA \\
\hline 40 CFR 143 & $\begin{array}{l}\text { National Secondary Drinking Water } \\
\text { Regulations }\end{array}$ & EPA \\
\hline 40 CFR 403 & $\begin{array}{l}\text { General Pretreatment Regulations for Existing } \\
\text { and New Sources of Pollution }\end{array}$ & EPA \\
\hline
\end{tabular}


TABLE SW-2

\section{PERFORMANCE OBJECTIVES AND CRITERIA FOR \\ PROTECTION OF \\ SURFACE WATER AND DRINKING WATER QUALITY}

SW.1 Discharge Permits

SW.2 Compliance with Applicable Permit Requirements

SW.3 Monitoring, Sampling, and Analysis Programs

SW.4 Special Certification Requirements for Water-Related Operations

SW.5 Wastewater Collection System and Treatment Plant Design, Operation, and Maintenance

SW.6 Oil Pollution Prevention

SW.7 Drinking Water Protection Program

SW.8 Surface Water Protection Program 


\section{SW.1 DISCHARGE PERMITS}

\section{PERFORMANCE OBJECTIVE}

\section{A system should be in place to ensure that liquid effluent discharges have received necessary permits from the appropriate Federal, state, or local agencies.}

40 CFR 122.1 contains requirements for discharge permits. The NPDES program requires permits for the discharge of "pollutants" from any "point source" into "waters of the United States." The terms "pollutant", "point source", and "waters of the United States" are defined in 40 CFR 122.2. Requirements for NPDES permits for storm water discharges associated with industrial activity are contained in 40 CFR 122.26.

40 CFR 123 contains requirements that a state must meet in order to be able to administer an NPDES program instead of the EPA. Basically, the state program must be at least as stringent as the Federal regulations. The Federal regulations for NPDES permits contained in 40 CFR 122 only address discharges to surface water. However, many states, in enacting the legislation needed to obtain authority to administer the NPDES program, included groundwaters in their definition of waters of the state.

40 CFR 144.11 requires permits for discharges to groundwaters through injection wells. "Any underground injection, except as authorized by permit or rule issued under the UIC program, is prohibited." Requirements, criteria, and standards for Underground Injection Control (UIC) programs are contained in 40 CFR 144, 145, and 146.

40 CFR 403.8 requires Publicly-Owned Treatment Works (POTWs) to "Control through permit, order, or similar means, the contribution to the POTW by each Industrial User to ensure compliance with applicable Pretreatment Standards and Requirements." DOE facilities may be subject to various categorical pretreatment standards, and it is DOE's responsibility to comply with National Pretreatment Standards as promulgated in local sanitary authority regulations.

\section{CRITERIA}

A. There is a formal, documented process in place to make certain that discharge permits have been obtained, or applied for, prior to commencing construction of a facility for which a discharge permit will be required.

B. The responsibility, authority, and accountability for obtaining required permits are clearly defined.

C. The facility has a National Pollutant Discharge Elimination System/State Pollutant Discharge Elimination System (NPDES/SPDES) permit for existing discharges (including storm waters if appropriate) to surface waters pursuant to 40 CFR 122 and 123.

D. The facility has a permit for any discharges to groundwaters through injection wells under either a Federal or state Underground Injection Control (UIC) program pursuant to 40 CFR 144, 145, and 146. 
E. The facility has a permit from the local sanitary authority for discharges, other than domestic sanitary waste (for which no permit is required), to the POTW.

F. There are formal requirements and schedules in place to periodically make documented physical inspections of the premises to detect any discharges to surface waters, groundwater, or POTWs not covered by a permit.

G. There are formal requirements and schedules for the documented periodic inspection of drain lines and sewers to ascertain that wastes are directed to the correct discharge point.

H. The facility has a written procedure for providing proper notification and reporting of any unpermitted discharges if and when they may occur.

I. Documentation of all past discharges and reporting details are on file at the facility. 


\section{SW.2 COMPLIANCE WITH APPLICABLE PERMIT REQUIREMENTS}

\section{PERFORMANCE OBJECTIVE}

A program should be in effect to ensure that all discharge limitations mandated by sitespecific NPDES or SPDES permits, or pretreatment requirements established by local sanitary authorities, are being complied with on a consistent basis.

DOE 5400.1, General Environmental Protection Program, provides for establishment of an environmental protection program to assure "compliance with applicable Federal, state and local environmental protection laws and regulations, Executive Orders, and internal Department policies." Chapter I of the Order delineates standards that apply to DOE facilities, including specific standards that pertain to this performance objective.

DOE 5400.1. Chapter IV, contains general environmental monitoring requirements, which emphasize that monitoring be conducted to verify compliance with applicable permit requirements. Section $8 \mathrm{c}$ provides details pertaining to compliance with Clean-Water-Actrelated NPDES requirements, and also points out that permits typically contain "specific and legally enforceable effluent limitations and self-monitoring requirements for flow measurement and sampling."

In addition to permit requirements or pre-treatment standards, Federal Facility Compliance Agreements, consent orders, multi-party compacts, or other contractual obligations may also establish permit-type requirements which must be met.

\section{CRITERIA}

A. A formal, documented plan has been developed for implementing permit requirements and responsibilities, authorities, and accountabilities have been clearly defined.

B. Copies of this plan and the permits are made available for use by wastewater treatment plant operators, sampling crews, and other environmental staff involved in ensuring or assessing compliance.

C. Wastewater treatment plant operators have the necessary education, training, and in those states where required, proper certification to ensure that treatment systems are operated in such a manner that compliance with requirements becomes routine (see POC SW.4).

D. Proper operation and maintenance of wastewater treatment equipment and related appurtenances are conducted and records are maintained (see POC SW.5).

E. Calibration and maintenance of monitoring and flow measurement equipment is conducted on a regularly scheduled basis and records of these events are maintained for three years. 
F. Compliance schedules or construction dates mandated by the permit have been met. In the event of any schedule slippage, proper notification has been given to the regulatory agency at the earliest time for negotiation of an amended schedule.

G. Copies of all reports required by the permit and data used to generate the reports are maintained for three vears.

H. Appropriate laboratory controls and quality assurance procedures are used (see POC SW.3).

1. Specific reporting requirements given in permits have been followed.

J. Reports have been certified in compliance with permit requirements. When designated staff members change, the agency is notified that new certification will appear in the next report.

K. Special permit requirements have been met in a timely fashion.

L. Permit reapplications have been completed in a timely manner as specified in the existing permit.

M. The regulatory agency has been notified in a timely manner of all alterations or additions to the facility which could change the nature or increase the quantity of pollutants released. 


\section{SW.3 MONITORING, SAMPLING, AND ANALYSIS PROGRAMS}

\section{PERFORMANCE OBJECTIVE}

\section{DOE facilities should have approved Environmental Monitoring Plans (EMP) to address required wastewater and surface water monitoring and reporting needs and to ensure that all data gathered and reported by DOE are of high quality.}

DOE 5400.1, General Environmental Protection Program, provides guidance for establishing appropriate water and wastewater monitoring programs and developing EMPs.

DOE 5400.5, Radiation Protection of the Public and the Environment, requires all DOE Operations to maintain exposures to the public and environment to levels that are as low as reasonably achievable (ALARA) below the appropriate dose limits.

DOE 5700.6C, Quality Assurance, requires use of proper procedures to ensure the quality of data obtained under the surface water environmental monitoring program, and maximum use of quality assurance (QA) practices that effectively support program needs and objectives. New quality assurance programs (QAP) require approval by DOE prior to the commencement of work and existing QAPs are required to be revised to conform to DOE 5700.6C and submitted to DOE for approval by February 21, 1992.

DOE/EH-0173T, Regulatory Guide for Radiological Effluent Monitoring and Environmental Surveillance, contains detailed guidance for the development and implementation of effluent monitoring and environmental surveillance programs.

40 CFR 122.41 requires that surface water and wastewater sampling and analysis be performed in accordance with the techniques prescribed in 40 CFR 136, unless otherwise specified in 40 CFR 503. 40 CFR 122.41 also requires that all samples and measurements taken for the purpose of monitoring must be representative of the monitored activity.

This POC should be coordinated with the radiation and quality assurance specialists to avoid duplication of effort and ensure adequate coverage of the POC.

\section{CRITERIA}

A. Environmental Monitoring Plans developed in response to DOE 5400.1 are clear, concise, and contain all the information necessary for users to understand and perform their activities effectively.

B. Responsibilities, authorities, and accountabilities are clearly assigned.

C. Plans are reviewed in detail by environmental management to ensure that all permit requirements have been addressed in full.

D. In the event that permit requirements are changed, EMPs are revised to reflect the changes.

E. Internal assessments are performed by persons not directly involved in the 
monitoring and reporting programs to ensure that the program is following the plan and that the plan adequately addresses all permit requirements.

F. The facility has developed and implemented a formalized sampling and analysis (S\&A) plan for the collection, analysis, and reporting of data. The S\&A plan contains sufficient detail regarding sampling locations, sampling frequencies, sample types, and preservation techniques, if appropriate.

G. Sampling locations have been selected with care and adequately documented, and sampling procedures have been written and are performed in the field in a manner representative of the monitored activity.

H. All reports required by the facility's NPDES/SPDES or pretreatment permits, as well as any other legal requirements, are submitted on time following thorough review for accuracy and completeness.

1. Radiological monitoring data are used to evaluate the effectiveness of the ALARA program (see POC RAD.3). 


\section{SW.4 SPECIAL CERTIFICATION REQUIREMENTS FOR WATER-RELATED OPERATIONS}

\section{PERFORMANCE OBJECTIVE}

DOE facilities should provide properly trained and certified operators and utility department maintenance workers to meet agency requirements governing the operation of water and wastewater treatment plants, and the inspection and maintenance of backflow prevention devices and cross-connection controls.

DOE 5400.1, General Environmental Protection Program, delegates heads of DOE field organizations to "Establish and maintain liaison and cooperative programs with appropriate Federal, state, and local environmental officials so as to facilitate effective environmental management." Unless certification requirements are mandated by specific permits or wellpublicized laws, the need for certification can best be determined through direct communication with regulatory agencies. State regulations, and county and local ordinances are the major sources of rules pertaining to certification of water-related technical personnel.

\section{CRITERIA}

A. Environmental management has identified, in formal documents, the need for certification wherever it is required, whether for water or wastewater treatment plant operators, or for utility department inspectors.

B. Certification requirements have been posted so that all interested candidates may be aware of all steps to be taken to acquire certification.

C. Time and financial resources are made available to qualified candidates to aid in attaining certification.

D. In the event that certification requirements include the need for follow-up training with refresher courses, these are scheduled in such a way that all qualified operators may maintain their skills, thus ensuring a steady pool of certified operators.

E. Coordination between plant management and bargaining units is considered when vacancies occur that must be filled with certified operators. 


\section{SW.5 WASTEWATER COLLECTION SYSTEM AND TREATMENT PLANT DESIGN, OPERATION, AND MAINTENANCE}

\section{PERFORMANCE OBJECTIVE}

Each DOE facility that generates wastewaters should have effective means for treating such wastewaters prior to release to the surface water environment, and thus, minimize the impacts from wastewater discharges. Wastewater treatment plants should be properly designed, efficiently operated, and effectively maintained to ensure maximum pollutantload reductions.

DOE 5400.1, General Environmental Protection Program, requires that all DOE operations must be conducted in a manner that minimizes the risks to the environment and to public health. This requirement applies to the design, operation, and maintenance of treatment plants installed to control pollutants from DOE activities that produce wastewaters.

DOE 5400.5, Radiation Protection of the Public and the Environment, invokes the ALARA process in the management and control of radioactive materials in liquid discharges, and states that the Best Available Technology (BAT) is the prescribed level of treatment required prior to discharge of liquid effluents.

\section{CRITERIA}

A. Wastewater treatment plant design is in conformance with good engineering practices with respect to provision of adequate equalization capacity, pump sizes, sufficient retention times, treatment process monitoring equipment, and ability to operate with minimal operator attention. Plant design also incorporates features considered to be Best Available Technology (BAT) for treating wastewaters from the appropriate industrial subcategory or non-industrial processes discharging wastewaters to the treatment plant. The treatment plant is able to control all discharges to the extent necessary to maintain compliance with NPDES/SPDES or pretreatment permit requirements.

B. Provisions are included to provide holding capacity or alternative methods of treatment in the event of loss or failure of treatment components (including loss of electrical power) until normal operations are restored.

C. All treatment plant operations are performed under the direction of trained plant operators. Where local requirements include certification of operators, such certification is maintained (also see POC SW.4).

D. Operation and Maintenance (O\&M) procedures are formalized in writing, updated periodically, and made readily available to appropriate supervisors and staff. The concepts of the ALARA process have been incorporated in all such procedures and in the conduct of operations. Where O\&M procedures are required by regulation or by the facility's permit, procedures meet the applicable requirements.

E. Preventive maintenance is aggressively practiced so that equipment failures are minimized or avoided. Regular inspections are conducted and documented. 
Sufficient spare parts are maintained on site so that turn-around times can be made as brief as possible.

F. Controls are in place to prevent the by-pass or overflow of untreated or partially treated wastewater.

G. Operators maintain detailed and accurate records of all plant operations by use of log books and charts listing chemical usage, water flows in and out of treatment, operating equipment maintenance activities, results of control testing, sampling, and any other pertinent information on plant operations. Records are retained for a minimum of three years.

H. Procedures are established to ensure that the wastewater treatment plant operators receive timely notice of accidental spills or releases to the wastewater collection system from operations using oils, acids, alkalis, or any other toxic or hazardous materials.

1. A program is in place to reduce and eventually eliminate all exfiltration/infiltration out of or into the wastewater collection system and the effluent discharge lines. The program includes regular inspections with in-line video camera methods or other advanced techniques to locate problem areas within pipelines. Corrective action follows within a reasonable time. 


\section{SW.6 OIL POLLUTION PREVENTION}

\section{PERFORMANCE OB.JECTIVE}

An effective program should be in place to manage the storage of oils, fuels, and other petroleum products to prevent or minimize damage to the surface water environment.

DOE 5400.1, General Environmental Protection Program, Attachment 1-1, Mandatory Environmental Protection Standards, states "To the extent legally applicable to a particular activity, standards contained in the following legislation, regulations, and Executive Orders are mandatory for DOE Operations." All major laws/regulations are listed. Regulations applicable to petroleum and petroleum products include the Clean Water Act as amended; specifically, 33 CFR 153-157, ."Control of Pollution by Oil and Hazardous Substances," 40 CFR 110, "Discharge of Oil," and 40 CFR 112, "Oil Pollution Prevention."

DOE 6430.1A, General Design Criteria, contains specific requirements for providing containment of oil-filled electrical equipment in accordance with 40 CFR 112 (Division 16 , Section 1630-2.3.5, Oil-Filled Equipment).

40 CFR 112 requires that surface water receptors be protected from release of oils by implementation of aggressive Spill Prevention, Control, and Countermeasure (SPCC) plans addressing each potential source. It also requires that aboveground storage tanks that contain petroleum products (above specific quantities) have adequate secondary containment or diversionary structures or equipment to prevent the release of these materials to surface waters.

If required by the NPDES/SPDES permits, best management practices (BMP) plans must be developed following the guidance provided in 40 CFR 125 to address potential releases of toxic or hazardous materials and wastes.

This POC should be coordinated with the toxic and chemical materials specialist to ensure adequate coverage of the POC and to avoid duplication of effort.

\section{CRITERIA}

A. A Spill Prevention Control and Countermeasure (SPCC) Plan has been developed and certified by a Professional Engineer if threshold quantities of petroleum products have been exceeded.

B. A best management practices (BMP) plan has been prepared if required by the NPDES/SPDES Permit.

C. Responsibilities and authorities for the program have been clearly defined and communicated.

D. SPCC plans are reviewed and recertified at least every three years, as well as reviewed and amended at any time when substantive changes may occur. 
E. SPCC and BMP plans, or spill contingency plans, contain specific spill reporting instructions as required by the applicable regulation.

F. The SPCC or BMP plan clearly defines the notification responsibilities and identifies appropriate deadlines for reporting. Environmental management is involved in determining if and when reporting to regulatory agencies is required.

G. For spill plans that involve emergency responses and notification, up-to-date contact names and telephone numbers are provided at all times.

H. Training is provided and documented to all site personnel who may be involved in responding to spills.

I. Appropriate containment or diversionary structures or equipment have been provided.

J. Containment capacity has been certified to meet regulatory requirements and dike integrity is routinely inspected.

K. Drainage from diked storage areas is controlled and documented.

L. Periodic inspections for leaks are made and documented.

M. Periodic inspections of rainwater run-off are performed.

N. Periodic integrity testing of all tanks is conducted and documented.

0. Tanks are equipped with high liquid-level alarms or liquid level sensing devices that are routinely tested.

P. Procedures are in place to immediately correct leaks.

Q. Storage areas are protected against tampering or trespassers where necessary. 


\section{SW.7 DRINKING WATER PROTECTION PROGRAM}

\section{PERFORMANCE OBJECTIVE}

Each DOE operation should have effective programs designed to maintain the integrity and quality of the drinking water supply.

The Safe Drinking Water Act requires that certain public water suppliers routinely test their water supplies for contaminants outlined in 40 CFR 141 and report those results to the State. The testing requirements vary depending on the type and size of the public water supply system.

DOE 6430.1A, General Design Criteria, also contains specific sections relating to environmental protection and worker health. Relevant sections include:

- Division 1, General Requirements, Section 0110-7 - Environmental Protection and Pollution Control.

- Division 2, Site and Civil Engineering, Section 0266 - Water Distribution Systems.

- Division 15, Mechanical, Section 1540 - Plumbing/Service Piping.

Protection of potable water distribution systems is most often subject to state or local health department jurisdiction. In particular, backflow prevention and cross-connection control requirements have been routinely defined by state, county, or city rules. The auditor is encouraged to investigate these on a case-by-case basis.

\section{CRITERIA}

A. Required programs for protection of the drinking water system have been developed in formal documents following guidelines established in the applicable regulations or local rules.

B. Responsibilities, authority, and accountability for these activities have been clearly defined.

C. Program elements have been reviewed by environmental management for completeness.

D. Copies of the programs are available for use by parties most involved in provision of potable water for employee use.

E. Appropriate testing of the water supply is conducted in accordance with the requirements of 40 CFR 141 and timely submissions are made to the state.

F. Public notifications are made when there is a failure to comply with Maximum Contaminant Levels, treatment techniques, or other requirements of any schedule prescribed pursuant to a variance or exemption. 
G. All potable water treatment plant operations are performed under the direction of trained plant operators (see POC SW.4).

H. Operation and Maintenance (O\&M) procedures are formalized in writing, updated periodically, and made readily available to appropriate supervisors and staff.

1. Preventive maintenance is aggressively practiced at the potable water plant so that equipment failures are minimized or avoided.

J. Operators maintain detailed and accurate records of all potable water plant operations by use of log books and charts listing chemical usage, water flows in and out of treatment, operating equipment maintenance activities, results of control testing, sampling, and any other pertinent information on plant operations. Records are retained as required by state or local regulation agencies.

K. A Backflow Prevention/Cross Connection Control (BFP/CCC) program exists to prevent contamination of the drinking water supply from non-potable sources.

L. The BFP/CCC programs address inspections and modifications of existing water distribution systems as well as the design and maintenance of new and replacement systems. 


\section{SW.8 SURFACE WATER PROTECTION PROGRAM}

\section{PERFORMANCE OBJECTIVE}

\section{Each DOE operation should have effective programs designed to prevent or minimize damage to the surface water environment.}

DOE 5400.1, General Environmental Protection Program, provides for the establishment of an environmental protection program. It requires the establishment of effluent monitoring and environmental surveillance programs that assure compliance with applicable Federal, state, and local environmental protection laws and regulations, and monitor the effect of DOE activities on onsite and offsite environmental and natural resources.

DOE 5400.5, Radiation Protection of the Public and the Environment, establishes requirements for radiation exposures from water pathways, and defines controls for the release of effluent. In addition, this Order invokes the ALARA process in the management and control of radioactive materials in liquid discharges, and states that the Best Available Technology (BAT) is the prescribed level of treatment required prior to discharge of liquid effluent. The auditor should coordinate these efforts with the radiation specialist.

DOE 6430.1A, General Design Criteria, Division 13, Special Facilities, Section 1323, outlines requirements for radioactive liquid waste facilities.

\section{CRITERIA}

A. Required programs for the protection of surface water have been developed in formal documents following guidelines established in the applicable regulations or local rules. Such programs include effluent monitoring, environmental surveillance, application of the principles of ALARA for radionuclides, and incorporation of design concepts equivalent to Best Available Technology (BAT).

B. Responsibility, authority, and accountabılity for these activities have been clearly defined.

C. Program elements have been reviewed by environmental management for completeness.

D. Copies of the programs are available for use by parties most involved in environmental protection.

E. The effluent monitoring program incorporates NPDES or pretreatment permit requirements to assure compliance with applicable laws and regulations (see also POC SW.2).

F. The environmental surveillance program requirements have been determined on a site specific basis and include a screening program to determine the need for a permanent surveillance program. 


\section{PERFORMANCE OBJECTIVES AND CRITERIA FOR PROTECTION OF GROUNDWATER}

\section{Overview}

The responsibility of the groundwater specialist is to determine whether site operations are in compliance with the comprehensive program for groundwater protection mandated by DOE Orders, and with legally enforceable requirements.

These requirements are found in the EPA regulations based on the Resource Conservation and Recovery Act (RCRA) and the Comprehensive Environmental Response Compensation, and Liability Act (CERCLA), the Safe Drinking Water Act, the Clean Water Act, state statutes and regulations, and local ordinances. State and local statutes and regulations may include specific requirements for vaste discharge, storm water permits, underground injection, and aquifer and recharge zone protection. In addition, requirements for well construction and abandonment may be included. These regulations vary from state to state and must be considered at each facility. Permits, court orders, consent orders, Federal Facility Compliance Agreements, or other compliance agreements may also create legally enforceable requirements for a particular site.

DOE Orders and RCRA regulations set requirements for planning and implementation of a Groundwater Protection Management Program, including groundwater monitoring, which must exist at all DOE field operation sites. [Note: groundwater protection management programs are not necessary at strictly administrative sites, e.g., SPR administrative offices in Metarie, Louisiana.] The DOE requirements apply whether or not contaminant releases to the environment are known to have occurred, and whether or not RCRA facilities or CERCLA actions that involve groundwater monitoring are present. Specific DOE Orders, segments of the Code of Federal Regulations (CFR), and other Federal guidance that are pertinent to the groundwater assessment are shown in Table GW-1.

Groundwater specialists also review site activities for adherence to best management practices (BMPs). BMPs are typically used when, in the absence of specific requirements from DOE Orders or regulations, progress toward meeting a deadline appears insufficient, or documentation or procedures appear inadequate. BMPs can also be identified in technical guidance documents that detail acceptable procedures for the conduct of groundwater protection and monitoring programs.

The general approach to the groundwater portion of an assessment or audit includes the following information collection activities: (1) review of documentation, especially program plans, standard operating procedures, quality assurance documents, and reports of investigations; (2) observation of site conditions, site operations, and routine procedures; and (3) interviews with DOE and site contractor personnel, and Federal/state regulators.

In conducting these activities, the groundwater specialist will need to coordinate with other specialists. In particular, the groundwater specialist will work closely with the radiation specialist to assess site programs related to radiological impacts to groundwater; with the inactive waste site specialist to address groundwater monitoring and characterization programs at inactive waste sites; and with the quality assurance specialist 
to assess procedures for sample collection, handling and analysis, data management, and records management.

Performance Objectives and Criteria (POC) documents have been prepared to provide a framework that should be used when conducting a programmatic assessment. A list of POC developed for the groundwater specialty is shown in Table GW-2. Each Performance Objective includes the applicable DOE Orders or other requirements that serve as the basis for the objective. Each of the POC includes a stated objective; citations of applicable DOE Orders, regulations, and requirements that provide the basis for the POC; and criteria that should be used in evaluating the site's performance against the programmatic objective. 


\begin{tabular}{|c|c|c|}
\hline & $\begin{array}{c}\text { TABLE GW-1 } \\
\text { LIST OF GROUNDWATER } \\
\text { REGULATIONS/REQUIREMENTS/GUIDELINES }\end{array}$ & \\
\hline $\begin{array}{l}\text { Regulations/ } \\
\text { Rogtutromantel } \\
\text { Ruidolines }\end{array}$ & sectlons/Titla & Authority \\
\hline DOE 5400.1 & General Environmental Protection Program & DOE \\
\hline DOE 5400.4 & $\begin{array}{l}\text { Comprehensive Environmental Response, } \\
\text { Compensation, and Liability Act } \\
\text { Requirements }\end{array}$ & DOE \\
\hline DOE 5480.1 & Conduct of Operations & DOE \\
\hline 40 CFR 110 & Discharge of Oil & EPA \\
\hline 40 CFR 112 & Oil Pollution Prevention & EPA \\
\hline 40 CFR 121 & $\begin{array}{l}\text { State Certification of Activities Requiring a } \\
\text { Federal License or Permit }\end{array}$ & EPA \\
\hline 40 CFR 122 & $\begin{array}{l}\text { National Pollutant Discharge Elimination } \\
\text { System }\end{array}$ & EPA \\
\hline 40 CFR 141 & National Primary Drinking Water Regulations & EPA \\
\hline 40 CFR 143 & $\begin{array}{l}\text { National Secondary Drinking Water } \\
\text { Regulations }\end{array}$ & EPA \\
\hline 40 CFR 144 & Underground Injection Control Program & EPA \\
\hline $\begin{array}{l}40 \text { CFR } 264 \text { and } \\
265\end{array}$ & $\begin{array}{l}\text { Standards and Interim Status Standards for } \\
\text { Owners and Operators of Hazardous Waste } \\
\text { Treatment, Storage, and Disposal Facilities }\end{array}$ & EPA \\
\hline 40 CFR 300 & $\begin{array}{l}\text { National Oil and Hazardous Substances } \\
\text { Pollution Contingency Plan }\end{array}$ & EPA \\
\hline $\begin{array}{l}\text { OSWER Directive } \\
9283.1-2\end{array}$ & $\begin{array}{l}\text { Guidance on Remedial Actions for } \\
\text { Contaminated Groundwater at Superfund } \\
\text { Sites }\end{array}$ & EPA \\
\hline $\begin{array}{l}\text { OSWER Directive } \\
9502.00-60\end{array}$ & RCRA Facility Investigation (RFI) Guidance & EPA \\
\hline $\begin{array}{l}\text { OSWER Directive } \\
9950.1\end{array}$ & $\begin{array}{l}\text { RCRA Groundwater Monitoring Technical } \\
\text { Enforcement Guidance Document Guidance } \\
\text { for Conducting Remedial Investigations }\end{array}$ & EPA \\
\hline SW-846 & Test Methods for Evaluation of Solid Waste & EPA \\
\hline
\end{tabular}




\section{TABLE OW-2}

\section{PERFORMANCE OBJECTIVES AND CRITERIA FOR PROTECTION OF GROUNDWATER}

$\begin{array}{ll}\text { GW.1 } & \text { Groundwater Protection Management Program } \\ \text { GW.2 } & \text { Groundwater Monitoring Program } \\ \text { GW.3 } & \begin{array}{l}\text { Sitewide Groundwater Monitoring Well Network and Hydrogeologic } \\ \text { Characterization }\end{array}\end{array}$

GW.4 Hydrogeologic Characterization of Active and Inactive Waste Sites 


\section{OW.1 GROUNDWATER PROTECTION MANAGEMENT PROGRAM}

\section{PERFORMANCE OBJECTIVE}

A formal groundwater protection management program should be in place.

DOE 5400.1, General Environmental Protection Program, Chapter III, Environmental Protection Program Plans, in a statement of policy, establishes requirements for DOE operations to develop and implement specific program plans.

DOE 5400.1, Chapter III, Section 4.a, requires that a specific program plan, the Groundwater Protection Management Program Plan, be in place by May 9, 1990. This plan must be reviewed annually and updated every three years.

\section{CRITERIA}

A. A formal, documented Plan prepared by May 9, 1990 describes a Program to develop, or cause to happen, all the elements that comprise a Groundwater Protection Management Program, as specified in DOE 5400.1, Chapter III, Section 4.a.

B. The Plan incorporates procedural requirements to conduct annual reviews and to update the plan and program every three years, or as needed.

C. The Plan includes a description of the hydrogeologic setting for the site, summaries of prior investigations, and plans for future studies.

D. All elements of the Groundwater Protection Management Program have been identified, and responsibilities for each element have been defined by organizational unit, or individual position. Such elements include well installation, health and safety, sampling and analysis, data evaluation and reporting, and quality assurance. Organization charts showing clear lines of authority have been prepared.

E. All pertinent documents, such as hydrogeological characterization studies, sampling plans, analytical methods, quality assurance documents, and standard operating procedures, have been referenced.

F. The plan includes a description of the existing well network and references to the details of construction and abandonment.

G. The Groundwater Protection Management Program described in this Plan includes the Groundwater Monitoring Program discussed in Performance Objective GW.2. Although actual implementation of the Groundwater Monitoring Program was not required until November 9,1991 , the monitoring program should have been documented by May 9, 1990, in the management program plan.

H. The Plan presents details of the design and implementation for any upgrading of the monitoring system required to meet the November 9, 1991, specifications. 
I. Formal, written procedures are in place to ensure that all facility operations, including planning and construction of new production facilities, closure of existing waste management units, design, construction and operation of new waste management units, and decontamination and decommissioning of facilities contaminated with radioactive materials, are coordinated with, and consistent with the Groundwater Protection Management Program Plan.

J. Specific Safe Drinking Water ACt, CERCLA, or RCRA actions that have occurred on site are described in the Plan. 


\section{GW.2 GROUNDWATER MONITORING PROGRAM}

\section{PERFORMANCE OBJECTIVE}

\section{A Groundwater Monitoring Program should be implemented to monitor groundwater both on site and in the vicinity of the facility.}

DOE 5400.1, General Environmental Protection Program, Chapter IV', Section 9.b, lists specific requirements for a Groundwater Monitoring Program.

DOE 5400.1, Chapter II, Section 4, requires that the environmental data from the Groundwater Monitoring Program be preserited in the Annual Site Environmental Report.

DOE 5400.1, Chapter IV. Section 1.b, requires that the Groundwater Monitoring Program be developed and implemented by November 9, 1991.

DOE 5400.1 also includes by reference guidance documents which establish standard procedures for groundwater monitoring. These documents include OSWER-9950.1, RCRA Groundwater Monitoring Technical Enforcement Guidance Document (TEGD); SW-846, Test Methods for Evaluating Solid Waste; SW-611, Procedures Manual for Groundwater Monitoring at Solid Waste Facilities; NEIC Manual for Groundwater/Surface Investigations; NWWA Manual of Groundwater Sampling Procedures; and Standard Methods for the Examination of Water and Wastewater.

40 CFR 264 (Subpart F) and 265 (Subpart F) specify the requirements for groundwater monitoring at hazardous waste management facilities. 40 CFR 264 and 265 also specify unit-based monitoring requirements during operation, closure, and post-closure.

\section{CRITERIA}

A. The Groundwater Monitoring Program is documented in a Groundwater Monitoring Plan (GMP). The GMP is a specific element of the Environmental Monitoring Plan required by DOE Order 5400.1, Chapter IV, Section 4.

B. The GMP identifies all DOE requirements and Federal, state, and local regulations applicable to groundwater protection, explains the current site-specific monitoring strategy, and specifies all elements of the Groundwater Monitoring Program. The rationale or purpose for selecting these elements is explained.

C. A sampling and analysis plan fully describes all elements identified and defined in the Groundwater Protection Management Plan. These elements include well installation, health and safety, sampling, and analysis.

D. Approved standard operating procedures are in place detailing step-by-step instructions for sampling and analysis. These procedures cover various aspects of the program, such as well purging, disposal of purge water, sample collection, sample preservation, sample documentation, and analytical methods. 
E. Training of the sampling team and lab analysts has been conducted and documented.

F. If RCRA-regulated units exist on site, applicability of and compliance with RCRA groundwater monitoring requirements are fully documented (see POC WM.8). 


\section{GW.3 SITEWIDE GROUNDWATER MONITORING WELL NETWORK AND HYDROGEOLOGIC CHARACTERIZATION}

\section{PERFORMANCE OBJECTIVE}

A sitewide groundwater monitoring well network should be in place to characterize site hydrogeology and determine the effects of operations on groundwater quality.

DOE 5400.1, General Envirormental Protection Program, Chapter IV, Sections 1.b and 9, require that groundwater iilat is or could be affected by DOE activities be monitored. The monitoring well network and associated monitoring program must be in place by November 9, 1991 .

\section{CRITERIA}

\section{Monitoring Well Network}

A. The monitoring well network consists of sufficient stations to determine the quality of groundwater entering and leaving the site. Comparisons between upgradient and downgradient conditions in all established or defined hydrostratigraphic units provide an adequate and sound analysis of potential onsite and offsite releases of contaminants.

B. Well locations and depths must be supported by an adequate characterization of the overall hydrogeologic setting of the site.

C. Construction of all monitoring wells is fully documented and is in accordance with applicable guidelines and regulations.

D. Plugging and abandonment of all onsite wells and boreholes are performed in accordance with applicable guidelines and regulations, and the location and status of all existing and abandoned wells are fully documented.

E. Well inspection and maintenance records are documented and available for review.

F. Standard operating procedures exist for borehole drilling, well construction, disposal of borehole cuttings and drilling fluids, well inspection and maintenance, and well abandonment.

\section{Hydro,jeologic Characterization}

A. Tie surface and subsurface geology, stratigraphy, and hydrology have been defined and described including regional setting and site-specific conditions. The descriptions include identification of aquifers, surface water/groundwater relationships, and local water-use factors.

B. The direction of groundwater flow has been defined for each aquifer or hydrostratigraphic unit. Contour maps showing the configuration of the piezornetric surface of each unit are available. 
C. If intermediate depth or deep aquifers are present, the vertical gradient between aquifers and intervening confining units has been determined.

D. Hydrogeologic characteristics such as hydraulic conductivity, transmissivity, saturated thickness, and effective porosity are available and based on results of aquifer tests and field permeability tests. Calculations for reported values have been verified. Estimated values are based on credible references.

E. A baseline study has been conducted to define the rate and extent of groundwater contamination, both that which is attributable to the facility and that which affects the facility. The study has accounted for the offsite migration of facility contaminants as well as the impact of contaminants from potential offsite sources.

F. Where groundwater flow models have been used to establish or to evaluate the monitoring well network, the model assumptions and input are appropriate to site conditions. Model documentation, including code testing and field verification, where applicable, is available. 


\section{GW.4 HYDROGEOLOGIC CHARACTERIZATION OF ACTIVE AND INACTIVE WASTE SITES}

\section{PERFORMANCE OBJECTIVE}

Actions should be in progress for hydrogeologic characterization of individual Solid Waste Management Units (SWMUs) and inactive waste sites identified either through a RCRA Facility Assessment (RFA), a CERCLA Preliminary Assessment/Site Inspection (PA/SI), or a related investigation.

DOE 5400.1 includes by reference guidance documents which establish standard procedures for groundwater monitoring. These documents include OSWER-9950.1, RCRA Groundwater Monitoring Technical Enforcement Guidance Document (TEGD); SW-846, Test Methods for Evaluating Solid Waste; SW-611. Procedures Manual for Groundwater Monitoring at Solid Waste Facilities; NEIC Manual for Groundwater/Surface Investigations; NWWA Manual of Groundwater Sampling Procedures; and Standard Methods for the Examination of Water and Wastewater.

DOE 5400.3, Hazardous and Radioactive Mixed Waste Program, requires compliance with RCRA.

DOE 5400.4, Comprehensive Environmental Response, Compensation, and Liability Act Requirements, requires DOE facilities to comply with applicable portions of CERCLA.

40 CFR 264 (Subpart F) and 265 (Subpart F) specify the requirements for groundwater monitoring at hazardous waste management facilities. 40 CFR 264 and 265 also specify unit-based monitoring requirements during operation, closure, and post-closure.

\section{CRITERIA}

A. A written plan for hydrogeologic characterization has been prepared and contains specific goals for each phase of the site characterization. The goals are related to obtaining data from tests, measurements, and analyses needed to design and implement a Groundwater Protection Strategy.

B. All onsite sources or potential sources of contamination have been identified based on RFA, PA/SI, or related investigations of both production and waste management operations. Offsite contamination resulting from onsite sources has also been identified.

C. The contaminants of concern have been defined as a result of specific studies of SWMUs or inactive waste sites or from routine sampling based on the site environmental monitoring program. Routine analysis of groundwater samples includes defined site specific contaminants of concern.

D. The rate and extent of groundwater contamination attributed to the facility or affecting the facility have been defined, including potential offsite sources or offsite migration of contaminants. 
E. Groundwater monitoring plans and procedures are in place, adhere to applicable guidelines and regulations, and are consistent with those in place for sitewide monitoring.

F. Hydrogeologic characterization of active waste sites (e.g., SWMUs) and inactive waste sites adheres to requirements and compliance schedules set forth in existing consent decrees, orders or permit requirements from local, state, or Federal regulatory agencies. 


\section{PERFORMANCE OBJECTIVES AND CRITERIA FOR WASTE MANAGEMENT}

\section{Overview}

The responsibility of the waste management specialist is to determine whether all site activities related to the management of nonhazardous, hazardous, radioactive, and mixed wastes comply with applicable Federal and state statutes and regulations, DOE Orders, agreements, permits, and other relevant policy guidance.

The primary statutes and regulations that address the waste management program are the Resource Conservation and Recovery Act (RCRA), DOE 5400.1 for waste minimization, DOE 5400.3 for hazardous and radioactive mixed wastes, DOE 5820.2A for radioactive and mixed wastes, DOE 5480.19 for conduct of operations, DOE 5700.6C for quality assurance and training, and state statutes and regulations. Specific DOE Orders, segments of the Code of Federal Regulations (CFR), and other Federal guidance that are pertinent to the waste management assessment are shown in Table WM-1. In addition, the waste management specialist must evaluate how any Federal Facility Compliance Agreements or consent orders apply to waste management activities at the site. Finally, the waste management specialist also reviews all activities for adherence to best management practices (BMPs). BMPs are typically evaluated when statutes or regulations do not describe specific actions that may be required to achieve the statutory or regulatory goals, or do not go far enough to achieve protection of human health and the environment. For waste management, most BMPs are found in procedures or guidance manuals. These procedures or guidance manuals often are state or region specific, although many Federal manuals (e.g., Guidance on Conducting RCRA Facility Investigations) also exist.

The general approach of the waste management specialist conducting an environmental assessment or audit includes the following information collection activities: (1) study of the management structure of the DOE organizations that provide oversight, as well as the contractor organization(s) that conduct waste management operations; (2) review of available documentation, including agreements, court orders or decrees, program plans, specific site action plans, EPA and state documents related to specific site activities, the results of previous site audits, assessments, or inspections, and actual waste analysis records and other site-specific documentation; (3) examination of all major waste management activities underway at the site, including field visits and inspections of waste generation, treatment, storage, and disposal sites; and (4) interviews with DOE, site contractor, and regulatory personnel. The scope of the waste management audit is extremely broad, covering such areas as underground storage tanks and waste minimization as well as all activities associated with the generation, transportation, treatment, storage, and disposal of nonhazardous, hazardous, radioactive, and mixed wastes.

In conducting these activities, the waste management specialist always will need to work closely with the radiation specialist. The waste management specialist and inactive waste sites specialist may need to jointly examine inactive waste sites that may require closure or other actions under regulations generally associated with active waste management. The toxic and chemical materials specialist can be consulted on issues of transportation of hazardous materials. The groundwater and surface water specialists can provide 
assistance on environmental monitoring as it pertains to waste management facilities, and coordination with the air specialist is required for many waste treatment processes,

including incineration.

Because of the potentially broad scope and complexity of waste management issues across DOE sites, a series of Performance Objectives and Criteria (POC) documents has been developed to assist the waste management specialist in conducting a programmatically oriented assessment or audit. A list of the POC developed for the waste management assessment is shown in Table WM-2. Each of the POC includes a stated objective; citations of applicable DOE Orders, statutes, and regulations; and criteria that should be used in evaluating the site's performance against the programmatic objective. A POC for storage and disposal of PCBs is included under the Toxic and Chemical Materials section (see POC TCM.2). 


\begin{tabular}{|c|c|c|}
\hline \multicolumn{3}{|c|}{$\begin{array}{c}\text { TABLE WM-1 } \\
\text { LIST OF WASTE MANAGEMENT } \\
\text { REGULATIONS/REQUIREMENTS/GUIDELINES }\end{array}$} \\
\hline $\begin{array}{l}\text { nequlationst } \\
\text { Requitomentst } \\
\text { euidelines }\end{array}$ & Sectionshitio & Authority \\
\hline CERCLA & Section 7 - Liability & EPA \\
\hline DOE 5400.1 & General Environmental Protection Program & DOE \\
\hline DOE 5400.3 & $\begin{array}{l}\text { Hazardous and Radioactive Mixed Waste } \\
\text { Program }\end{array}$ & DOE \\
\hline DOE 5400.5 & $\begin{array}{l}\text { Radiation Protection of the Public and the } \\
\text { Environment }\end{array}$ & DOE \\
\hline DOE 5480.19 & $\begin{array}{l}\text { Conduct of Operations Requirements for } \\
\text { DOE Facilities }\end{array}$ & DOE \\
\hline DOE 5480.3 & $\begin{array}{l}\text { Safety Requirements for the Packaging and } \\
\text { Transportation of Hazardous Materials, } \\
\text { Hazardous Substances, and Hazardous } \\
\text { Wastes. }\end{array}$ & DOE \\
\hline DOE 5700.6C & Quality Assurance & DOE \\
\hline DOE $5820.2 \mathrm{~A}$ & Radioactive Waste Management & DOE \\
\hline $\begin{array}{l}\text { Implementation } \\
\text { Guidance for DOE } \\
5400.1\end{array}$ & $\begin{array}{l}\text { Waste Minimization Plan and Waste } \\
\text { Reduction Reporting of DOE Hazardous, } \\
\text { Radioactive and Radioactive Mixed Wastes }\end{array}$ & DOE \\
\hline 40 CFR 260 & $\begin{array}{l}\text { Hazardous Waste Management System: } \\
\text { General }\end{array}$ & EPA \\
\hline 40 CFR 261 & $\begin{array}{l}\text { Identification and Listing of Hazardous } \\
\text { Waste }\end{array}$ & EPA \\
\hline 40 CFR 262 & $\begin{array}{l}\text { Standards Applicable to Generators of } \\
\text { Hazardous Waste }\end{array}$ & EPA \\
\hline 40 CFR 263 & $\begin{array}{l}\text { Standards Applicable to Transporters of } \\
\text { Hazardous Waste }\end{array}$ & \\
\hline 40 CFR 264 & $\begin{array}{l}\text { Standards for Owners and Operators of } \\
\text { Hazardous Waste Treatment, Storage, and } \\
\text { Disposal Facilities }\end{array}$ & EPA \\
\hline 40 CFR 265 & $\begin{array}{l}\text { Interim Status Standards for Owners and } \\
\text { Operators of Hazardous Waste Treatment, } \\
\text { Storage, and Disposal Facilities }\end{array}$ & EPA \\
\hline
\end{tabular}




\begin{tabular}{|c|c|c|}
\hline \multicolumn{3}{|c|}{$\begin{array}{c}\text { TABLE WM-1 } \\
\text { LIST OF WASTE MANAGEMENT } \\
\text { REGULATIONS/REQUIREMENTS/GUIDELINES }\end{array}$} \\
\hline $\begin{array}{l}\text { Requilitionsl: } \\
\text { Requirements/ } \\
\text { Cuidelines }\end{array}$ & Sections gritlo & Authonity \\
\hline 40 CFR 266 & $\begin{array}{l}\text { Standards for the Management of Specific } \\
\text { Hazardous Wastes and Specific Types of } \\
\text { Hazardous Waste Management Facilities }\end{array}$ & EPA \\
\hline 40 CFR 268 & Land Disposal Restrictions & EPA \\
\hline 40 CFR 270 & $\begin{array}{l}\text { EPA Administered Permit Programs: The } \\
\text { Hazardous Waste Permit Program }\end{array}$ & EPA \\
\hline 40 CFR 280 & $\begin{array}{l}\text { Technical Standards and Corrective Action } \\
\text { Requirements for Owners and Operators of } \\
\text { Underground Storage Tanks (UST) }\end{array}$ & EPA \\
\hline $\begin{array}{l}49 \text { CFR } 172,173 \\
178, \text { and } 179\end{array}$ & Shipping Hazardous Materials & DOT \\
\hline $\begin{array}{l}52 \text { Federal Register } \\
25056, \text { June } 12 \\
1989\end{array}$ & $\begin{array}{l}\text { Draft Guidance to Hazardous Waste } \\
\text { Generators on the Elements of a Waste } \\
\text { Minimization Program }\end{array}$ & EPA \\
\hline
\end{tabular}


TABLE WM-2

\section{PERFORMANCE OBJECTIVES AND CRITERIA FOR WASTE MANAGEMENT}

WM.1 Characterization/Certification

WM.2 Transportation

WM.3 Satellite and Temporary Accumulation Areas

WM.4 Treatment, Storage, and Disposal Facilities (TSDFs)

WM.5 Planning, Recordkeeping and Tracking

WM.6 Minimization and Recycling

WM.7 Offsite Facility Evaluations

WM.8 Monitoring

WM.9 Permit Applications and Notifications

WM.10 Contingency Planning

WM.11 Underground Storage Tank Management

WM.12 Management of Nonhazardous Waste 


\section{WM. 1 CHARACTERIZATION/CERTIFICATION}

\section{PERFORMANCE OBJECTIVE}

A program should be in place to ensure that the physical, chemical, anci radiological characteristics of all wastes managed at the facility are adequately determined, and that waste characterization related activities are performed in accordance with all applicable DOE, Federal, state, and local requirements.

DOE 5400.1, General Environmental Protection Program, requires a waste minimization plan that quantifies changes in waste quantity, volume, and toxicity.

DOE 5400.3, Hazardous and Radioactive Mixed Waste Program, requires that nixed wastes be managed in accordance with the requirements of Subtitle C of RCRA and of the Atomic Energy Act (AEA). RCRA applies to the extent that it is not inconsistent with the AEA.

DOE 5480.19, Conduct of Operations Requirements for DOE Facilities, requires that operations at DOE facilities be managed with a consistent and auditable set of requirements, standards, and responsibilities.

DOE 5700.6C, Quality Assurance, establishes quality assurance requirements for DOE.

DOE 5820.2A, Radioactive Waste Management, specifies the requirements for characterization of radioactive high-level waste (HLW), transuranic waste (TRU), and lowlevel waste (LLW) and for certification of radioactive TRU waste.

40 CFR 262.11 requires that any person who generates a solid waste as defined in 40 CFR 261.2 determine whether that waste is a hazardous waste. This may be done by sampling and analysis or by process knowledge.

40 CFR 264.13 and 265.13 require that owners and operators of permitted or interim status hazardous waste management facilities develop and follow a waste analysis plan.

\section{CRITERIA}

A. There is a formal, facility-wide waste characterization program in place that describes procedures and roles and responsibilities for identifying and characterizing all solid, hazardous, radioactive, and mixed waste streams.

B. The waste characterization program is: documented, regularly evaluated and updated; includes requirements of all waste analysis plans for treatment, storage and disposal facilities used by the site; and is implemented through standard operating procedures, including appropriate sampling and analysis procedures.

C. The waste characterization program includes overall quality assurance and quality control mechanisms, such as inspections, audits, and updates, which are conducted on a regular basis. It is recharacterized after production processes change (see POC QA.2). 
D. Personnel implementing the waste characterization program use test methods and process knowledge to determine whether waste streams are RCRA-hazardous wastes, low-level wastes, transuranic wastes, high-level wastes, or mixed wastes.

E. All analytical procedures used to determine the nature of solid, hazardous, radioactive, and mixed wastes are subject to a level of quality assurance and quality control required for the procedures. A formal mechanism exists to determine when waste streams should be retested (see POC QA.3 and QA.4).

F. The results of waste characterization are documented and maintained to ensure compliance and determine facility generator status. All applicable records (e.g., lab reports, manifests, land-disposal-restricted notifications and certifications) are kept on site as part of the operating record.

G. There is a formal training program for personnel involved in waste characterization activities addressing all aspects of the waste characterization process, quality assurance and quality control, documentation, and roles and responsibilities. All training is documented. 


\section{WM.2 TRANSPORTATION}

\section{PERFORMANCE OBJECTIVE}

A program should be in place to ensure that wastes are safely transported using adequate packaging, placarding, marking, and labeling, means of transport, and with proper documentation. Waste transportation related activities are performed in accordance with all applicable DOE, Federal, state, and local requirements.

DOE 5400.3, Hazardous and Radioactive Mixed Waste Program, requires that mixed wastes be managed in accordance with the requirements of Subtitle C of RCRA and of the Atomic Energy Act (AEA). RCRA applies to the extent that is not inconsistent with the AEA.

DOE 5400.5, Radiation Protection of the Public and the Environment, requires all DOE Operations to maintain exposures to the public and environment to levels that are as low as reasonably achievable (ALARA) below the appropriate dose limits.

DOE 5480.3, Safety Requirements for the Packaging and Transportation of Hazardous Materials, Hazardous Substances, and Hazardous Wastes, specifies the requirements for the transportation and packaging of radioactive wastes and the quality assurance requirements for the fabrication and testing of radioactive waste offsite shipping containers and transportation procedures.

DOE 5700.6C, Quality Assurance, establishes quality assurance requirements for DOE.

DOE 5820.2A, Radioactive Waste Management, specifies the requirements for the transportation of transuranic (TRU) waste, low-level waste (LLW), and Naturally Occurring and Accelerator Produced Radioactive Material (NARM) and the packaging of TRU waste.

40 CFR 262 specifies the requirements for hazardous waste generators for preparing hazardous waste for transport (including placarding, marking, and labeling requirements), and for manifesting hazardous wastes.

40 CFR 263 specifies the requirements for transporters of hazardous wastes for hazardous waste manifesting, recordkeeping associated with hazardous waste transport, and responding to releases of hazardous waste while in transport.

49 CFR 172, 173, 178, and 179 specify the requirements for packaging, labeling, and placarding vehicles used in offsite transport of hazardous waste.

\section{CRITERIA}

A. Procedures are in place to ensure that packages or containers used for transportation both within and outside of the facility are appropriate for the contents being shipped.

B. There is a program in place at the facility that ensures that actual packaging of wastes is in compliance with Federal and state regulations and DOE Orders, and 
occurs in a manner that is protective of workers, the public, and the environment. This program includes regular inspections of waste packaging.

C. Procedures are in place to ensure that all packages and containers are correctly labeled for internal and external shipment. In addition, these procedures ensure that packages have proper markings and placards prior to shipment.

D. Paperwork associated with transportation (e.g., manifests and packing lists) is completed correctly and maintained in a central location, and appropriate follow-up actions are taken when discrepancy reports are received, or when manifests are not returned within regulatory deadlines.

E. There are quality assurance and quality control measures in place to ensure that all aspects of transporting solid, hazardous, radioactive, and mixed wastes occur in compliance with 40 CFR 262 and 263 (see POC QA.3).

F. Responsibilities, authority, and accountability have been clearly defined for all activities associated with the transportation of solid, hazardous, and radioactive wastes, including classified waste shipments and hazardous waste manifests.

G. There is a training program for personnel involved in the transportation of solid, hazardous, radioactive, and mixed wastes, including security, and other personnel who may be responsible for reviewing accompanying waste documents. This training includes all aspects of transportation, including emergency response procedures. All training is documented.

H. Transportation of radioactive and mixed wastes is considered in a formal ALARA program.

I. There is a program in place to determine the qualifications of any subcontractors used for transportation of hazardous wastes off site. Periodic oversight of transporters is conducted (see POC OA.1). 


\section{WM.3 SATELLITE AND TEMPORARY ACCUMULATION AREAS}

\section{PERFORMANCE OBJECTIVE}

A program should be in place to ensure that wastes are safely accumulated, using adequate facilities with a minimum potential for release of contaminants to the environment, and that the associated activities are performed in accordance with all applicable DOE, Federal, state, and local requirements.

DOE 5400.3, Hazardous and Radioactive Mixed Waste Program, requires that mixed wastes be managed in accordance with the requirements of Subtitle C of RCRA and of the Atomic Energy Act (AEA). RCRA applies to the extent that it is not inconsistent with the AEA.

DOE 5400.5, Radiation Protection of the Public and the Environment, requires all DOE Operations to maintain exposures to the public and environment to levels that are as low as reasonably achievable (ALARA) below the appropriate dose limits.

DOE 5480.19, Conduct of Operations Requirements for DOE Facilities, requires that operations at DOE facilities be managed with a consistent and auditable set of requirements, standards, and responsibilities.

DOE 5700.6C, Quality Assurance, establishes quality assurance requirements for DOE.

40 CFR 262.34(c) specifies the requirements for accumulation of up to 55 gallons of hazardous waste at or near the point of generation (Satellite Accumulation Areas).

40 CFR 261.5, 262.34(d), and 262.(a) contains requirements for the temporary accumuiation of greater than $\mathbf{5 5}$ gallons of hazardous waste for conditionally exempt small quantity generators, small quantity generators, and generaturs, respectively (Temporary Accumulation Area).

\section{CRITERIA}

A. There is an inventory of all satellite and temporary accumulation areas, and it is clearly understood by DOE and the operating contractor which regulatory requirements apply to each area based on location, the types and volumes of wastes maintained, and the length of time wastes may be stored in the area.

B. All plans, reports, and other documents (e.g., emergency preparedness plans, and contingency plans) required for the operation of accumulation areas are maintained and adequate. The provisions of such operating documents are incorporated into prastices and procedures for operating the areas.

C. Roles and responsibilities for the management, operation, and oversight of each satellite and temporary accumulation area are clearly specified in plans and other standard operating procedures. Evaluation of the appropriateness and effectiveness of these roles and responsibilities occurs on a regular basis. 
D. Procedures are in place to ensure that the technical and administrative standards for each area where wastes are accumulated are met both for the area and for all drums, containers, or packages placed in the area. These standards include compliance with waste acceptance criteria, waste inventory documentation requirements (additions and removals), accumulation timeframes, correct container labeling, inspections, and facility design and operation, as well as contingency plans and emergency preparedness plans.

E. There is a training program for all personnel responsible for managing, operating, and overseeing waste accumulation areas, and all training is documented.

F. There are quality assurance and quality control measures in place to ensure that all aspects of operations of accumulation areas are effective, in compliance with regulatory requirements, and appropriately documented (see POC OA.3).

G. Regular inspections of satellite and temporary accumulation areas are conducted in accordance with formal procedures, and comprehensive records are maintained.

H. There is a system in place to investigate nonconformances, develop and implement corrective actions, and track both nonconformances and actions.

1. The handling of radioactive and mixed wastes is conducted in accordance with a formal ALARA program.

J. A contingency plan has been prepared that describes actions to be taken by facility personnel in response to any fire, explosion, or unplanned sudden or non-sudden release of hazardous waste or hazardous waste constituent to air, soil, or surface water (see POC WM.10). 


\section{WM.4 TREATMENT, STORAGE, AND \\ DISPOSAL FACILITIES (TSDFs)}

\section{PERFORMANCE OBJECTIVE}

A program should be in place to ensure that wastes are safely and effectively stored, treated, and disposed of with a minimum potential for release of contaminants to the environment, and that these operations are performed in accordance with all applicable DOE, Federal, state, and local requirements.

DOE 5400.3, Hazardous and Radioactive Mixed Waste Progiam, requires that mixed wastes be managed in accordance with the requirements of Subtitle C of RCRA and of the Atomic Energy Act (AEA). RCRA applies to the extent that it is not inconsistent with the AEA.

DOE 5400.5, Radiation Protection of the Public and the Environment, requires all DOE Operations to maintain exposures to the public and environment to levels that are as low as reasonably achievable (ALARA) below the appropriate dose limits.

DOE 5820.2A, Radioactive Waste Management, specifies the requirements for the treatment, storage and disposal of HLW, TRU, and LLW.

40 CFR 264 and 265 specify the requirements for permitted and interim status hazardous waste treatment facilities, including technical standards and inspections.

40 CFR 266 provides standards for the management of specific hazardous wastes (e.g., used oil, lead ccid batteries) and specific types of hazardous waste management facilities.

40 CFR 268 specifies the requirements for the treatment of land disposal restricted hazardous waste.

\section{CRITERIA}

A. All storage, treatment, and/or disposal areas are identified in site waste management plans, and it is understood by DOE and the operating contractor which regulatory requirements apply to each area.

B. All wastes received for treatment or recycling are accepted in accordance with waste acceptance criteria or waste analysis plans. These plans are current, and are routinely evaluated to determine if they are adequate. Inspections, testing, and $\mathrm{QA} / \mathrm{OC}$ are done in accordance with and at the frequency specified in these plans. All wastes subject to the RCRA land disposal restrictions (LDRs) have been identified, and the appropriate treatment standards met prior to disposal (see POC WM.6).

C. Procedures are in place to ensure that the unit-specific and general facility technical standards are met during the design and operation of storage, treatment, and/or disposal units. These technical standards, depending on the units regulated, could 
include compliance with emissions limits, monitoring requirements, maintenance of secondary containment, and management of residuals.

D. Procedures are in place to identify and, if necessary, collect and further manage all treatment residuals that are subject to regulation. These residuals management procedures are routinely evaluated, modified, and subjected to quality assurance and quality control measures to ensure that their management is in compliance with appropriate requirements (see POC QA.3).

E. A quality assurance and quality control program is established for the operation of each treatment, storage, or disposal unit that can monitor the effectiveness of all operating procedures, including analytical methods, that are associated with the treatment process (see POC QA.1).

F. Regular inspections of treatment, storage, and disposal areas are conducted in accordance with formal procedures and comprehensive records are maintained. There is a system in place to investigate nonconformances, develop and implement corrective actions, and track both nonconformances and actions.

G. Personnel operating or overseeing treatment, storage, and disposal units have appropriate training which is documented for the particular job functions associated with the treatment processes, including waste handling, unit operation, monitoring, $\mathrm{QA} / \mathrm{OC}$, and waste residual management.

H. All wastes subject to the RCRA land disposal restrictions (LDRs) are managed in compliance with the LDRs, and certified to be in compliance with the LDR treatment standards (or alternate treatment levels specified under a Treatability Variance) prior to being sent to a disposal facility.

1. At the conclusion of its operation, closure of a unit occurs in compliance with the specified closure plan.

J. When regulations or DOE Orders are enacted that require eventual closure of units, the regulations or DOE Orders are evaluated and documented in a central location. The appropriate regulatory authorities are identified under whose plan final closure (or remediation) will occur. DOE, operating contractor, and Federal and state regulatory personnel have evaluated and agreed upon the appropriate regulatory authorities for each of these units.

K. The handling of all radioactive and mixed wastes is conducted in accordance with a formal ALARA program.

L. The disposal of radioactive and mixed wastes is conducted in accordance with a formal procedure, and records are maintained.

M. A contingency plan has been prepared that describes actions to be taken by facility personnel in response to any fire, explosion, or unplanned sudden or non-sudden release of hazardous waste or hazardous waste constituent to air, soil, or surface water (see POC WM. 10). 


\section{PERFORMANCE OBJECTIVE}

A program: should be in place to ensure that appropriate records are maintained to demonstrate that wastes are managed in an environmentally sound manner, and that recordkeeping-related activities are performed in accordance with all applicable DOE, Federal, state, and local requirements.

DOE 5400.3, Hazardous and Radioactive Mixed Waste Program, requires that mixed wastes be managed in accordance with the requirements of Subtitle C of RCRA and of the Atomic Energy Act (AEA). RCRA applies to the extent that it is not inconsistent with the AEA.

DOE 5820.2A, Radioactive Waste Management, specifies the recordkeeping requirements associated with the management of HLW, TRU, and LLW.

40 CFR 262.40 specifies the recordkeeping requirements for generators of hazardous waste.

40 CFR 263.20 - 263.22 specify the recordkeeping requirements for transporters of hazardous waste.

40 CFR 264 and 265 specify the recordkeeping requirements for hazardous waste treatment, storage, and disposal facilities.

40 CFR 268.7 specifies the recordkeeping requirements associated with the management of land disposal restricted hazardous waste.

\section{CRITERIA}

A. The facility has prepared a Radioactive Waste Management Plan and/or other strategic waste planning documents to ensure that future waste generation can be managed in accordance with regulatory requirements.

B. The facility waste management plan addresses the recordkeeping and tracking needs and identifies clear roles and responsibilities for the completion, maintenance, and verification of the records.

C. The site has met regulatory requirements for establishing and maintaining, where appropriate, internal waste characterization records, including waste analysis and sampling results; offsite waste manifests, LDR notifications, and LDR certifications; daily and weekly inspection reports; personnel training records; an Operating Record; release incident and followup ieports; Biennial and other Summary Reports; and Standard Operating Procedures (SOPs).

D. Recordkeeping and tracking systems are current, flexible, and are implemented site wide among all waste generators or managers. 
E. Record and tracking discrepancies are noted, and are evaluated to determine their causes and the need for any corrective actions. When discrepancies are noted, recordkeeping and tracking systems are evaluated to determine their adequacy and corrective actions required.

F. The site actively tracks the amount of hazardous waste generated and stored/accumulated on a monthly basis to determine RCRA generator status. The site also evaluates the effectiveness of its waste minimization program in reducing the quantity and toxicity of waste requiring storage, treatment and disposal.

G. The facility has documented locations and instances where hazardous and mixed wastes may be stored but are not being managed in compliance with the RCRA LDR storage prohibitions. There are also plans or other efforts underway to adequately characterize these wastes, to determine appropriate treatment for these wastes, and to take steps to ensure that treatment will occur in the future.

H. The facility has evaluated Federal and state requirements for waste management under the Federal Facility Compliance Act (FFCA). It has developed compliance agreements with the appropriate authorities for any existing violations and has otherwise documented compliance with the requirements.

1. The facility is developing plans for compliance by October 1995 with the 90-day storage limitation on mixed waste under the FFCA.

J. The facility has a system to provide data for reports required under the FFCA and any Federal Facilities Compliance Agreements (e.g., mixed waste LDR), consent orders, or Memoranda of Understanding. 


\section{WM.6 MINIMIZATION AND RECYCLING}

\section{PERFORMANCE OBJECTIVE}

A program should be in place to ensure that wastes are minimized to the greatest practical extent, radwaste volume reduction and radioactivity reduction is practiced, and that waste minimization related activities are performed in accordance with all applicable DOE, Federal, state, and local requirements.

DOE 5400.1, General Environmental Protection Program, specifies the requirements for the development and implementation of waste minimization programs and plans.

Implementation Guidance for DOE Order 5400.1, Waste Minimization Plan, and Waste Reduction Reporting of DOE Hazardous, Radioactive, and Radioactive Mixed Wastes, provides guidance on the development of waste minimization plans.

DOE 5400.3, Hazardous and Radioactive Mixed Waste Program, requires facilities to implement programs for the minimization of hazardous and mixed wasies.

DOE 5480.19, Conduct of Operations Requirements for DOE Facilities, requires that operations at DOE facilities be managed with a consistent and auditable set of requirements, standards, and responsibilities.

DOE 5700.6C, Quality Assurance, establishes quality assurance requirements for DOE.

DOE 5820.2A, Radioactive Waste Management, specifies the requirements for the minimization, volume reduction, and radioactivity reduction of HLW, TRU, and LLW.

Federal Register Notice, 52 FR 25056, June 12, 1989 provides EPA guidance to hazardous waste generators on the elements needed for an effective waste minimization program.

40 CFR 246 contains requirements for source separation and recovery of specified materials, including high-grade paper.

40 CFR 261 defines regulated and nonregulated recycling activities.

40 CFR 262 requires generators of hazardous wastes to certify that they have waste minimization programs in place to reduce the volume and toxicity of the wastes generated to the greatest degree that is economically practical.

40 CFR 266 provides special requirements for recycling certain wastes (e.g., used oil, lead acid batteries).

Many state and local governments also regulate waste minimization and recycling activities. Requirements are specific to each state or local authority, and they should be consulted by the specialist. 


\section{CRITERIA}

A. Requirements for waste minimization are recognized in the waste management plan, and all generators and waste managers are taking actions to implement the requirements and elements of the plan. Roles and responsibilities for these activities are delineated clearly both within DOE and among each contractor that generates waste.

B. The facility has developed and implemented a formalized waste minimization program which includes the elements identified in the DOE and EPA guidance documents. This includes the requirements of the Pollution Prevention Awareness Plan (see POC TCM.7).

C. Volume reduction and radioactivity reduction are integral parts of the management of radioactive wastes.

D. The effectiveness of the programs is routinely evaluated, the results of the evaluation documented, and modifications made as appropriate.

E. There are mechanisms to transfer successful waste minimization programs from one site or area to other parts of the facility or to other DOE facilities.

F. All wastes that are potentially amenable to treatment are evaluated for treatment as required. Wastes potentially amenable to recycling are evaluated as part of overall facility waste management plans (including waste minimization).

G. The operations of units that treat or recycle wastes in accordance with specific exemptions (e.g., wastewater treatment tanks, discharge to publicly owned treatment works, discharge under another program permit) are routinely evaluated to ensure that they and the wastes sent to the units are in compliance with the requirements specified under the exemption. 


\section{WM.7 OFFSITE FACILITY EVALUATIONS}

\section{PERFORMANCE OBJECTIVE}

\section{A program should be in place to evaluate offsite commercial facilities used for waste storage, treatment, or disposal to ensure that wastes are properly handled.}

CERCLA Section 107 establishes that generators of hazardous substances may be considered to be strictly liable for any releases of those hazardous substances from a treatment, storage, or disposal facility.

DOE 5700.6C, Quality Assurance, requires DOE to ensure that procured items and services meet established requirements and perform as specified, and that prospective suppliers be evaluated and selected on the basis of specific criteria.

40 CFR 262.20 requires generators to designate a facility "which is permitted to handle the waste described on the manifest."

This POC should be coordinated with the quality assurance specialist to avoid duplication of effort and ensure adequate coverage.

\section{CRITERIA}

A. A formal plan, including evaluation criteria, for conducting offsite facility investigations of TSD facilities to which wastes are sent has been prepared.

B. Appropriate personnel are assigned to implement the offsite facility evaluations. These personnel are adequately trained in conducting audits, and their training is documented.

C. Formal recordkeeping and reporting requirements are prepared for each assessment or audit conducted, and the findings of the assessment or audit are used to determine the suitability of a facility for receiving DOE wastes. When decisions about the suitability of a TSD facility are based on audits conducted by other DOE organizations, complete documentation of assessments, audits, and other evaluations is maintained.

D. Coordination of offsite evaluations occurs with Federal and state regulatory agencies, where appropriate, prior to the conduct of such an audit.

E. Formal determinations of site compliance with waste analysis plans of offsite TSDFs have been made. 


\section{WM.8 MONITORING}

\section{PERFORMANCE OBJECTIVE}

A program should be in place to ensure that waste management facilities are monitored in accordance with all applicable DOE, Federal, state, and local requirements.

DOE 5400.3, Hazardous and Radioactive Mixed Waste Program, requires that mixed wastes be managed in accordance with the requirements of Subtitle C of RCRA and of the Atomic Energy Act (AEA). RCRA applies to the extent that it is not inconsistent with the AEA.

DOE 5820.2A, Radioactive Waste Management, specifies the requirements for environmental monitoring and surveillance of LLW, HLW, and TRU management facilities.

40 CFR 264 (Subpart F) and 265 (Subpart F) specify the requirements for groundwater monitoring at hazardous waste management facilities.

40 CFR 264 and 265 specify unit-based monitoring requirements during operation, closure, and post-closure.

This POC should be coordinated with the groundwater, air, and radiation specialists to avoid duplication of effort and ensure adequate coverage of the POC.

\section{CRITERIA}

A. The facility has a system in place to accurately monitor all environmental media that are potentially affected by waste facilities. This program of monitoring is implemented in conformance with a formal plan (such as the Facility Effluent Monitoring Plan).

B. Environmental monitoring samples are taken from all monitoring stations at the intervals established in the plan, and appropriate analytical procedures are established to evaluate the camples.

C. Appropriate documentation associated with the results of the monitoring is maintained.

D. An evaluation of the results of the monitoring program is routinely prepared and used to make the necessary determinations about the protection of workers, protection of the public, and protection of environmental resources.

E. Periodic evaluations of the effectiveness and accuracy of the monitoring plan occur, as well as updates of the plans when necessary.

F. All monitoring equipment is regularly calibrated, effectively maintained, and operated by personnel trained in its use. 


\section{WM.9 PERMIT APPLICATIONS AND NOTIFICATIONS}

\section{PERFORMANCE OBJECTIVE}

\section{A program should be in place to ensure that permit applications, reports, and notifications to regulatory agencies are prepared and submitted in accordance with all applicable Federal, state, and local requirements.}

DOE 5400.3, Hazardous and Radioactive Mixed Waste Program, requires that mixed wastes be managed in accordance with the requirements of Subtitle C of RCRA and of the Atomic Energy Act (AEA). RCRA applies to the extent that it is not inconsistent with the AEA.

DOE 5480.19, Conduct of Operations Requirements for DOE Facilities, requires that operations at DOE facilities be managed with a consistent and auditable set of requirements, standards, and responsibilities.

DOE 5700.6C, Quality Assurance, establishes quality assurance requirements for DOE.

40 CFR 262 specifies the requirements for hazardous waste generators for preparation and submittal of biennial reports.

40 CFR 264 and 265 specify the requirements for hazardous waste management facilities for the preparation and submission of permit-related notifications for certain units.

40 CFR 270 specifies the requirements for the preparation and submission of hazardous waste management facility permit applications.

\section{CRITERIA}

A. Permit applications, notifications of new interim status, changes to existing interim status, and new Section 3010 notifications are prepared in a timely manner and submitted by the statutory or other deadlines established in agreements, plans, or orders in effect at the facility.

B. The facility has a set of procedures in place that allows for the timely preparation of the required paperwork to maintain compliance, including appropriate levels of contractor and DOE review.

C. Roles and responsibilities for preparing all reports, notifications, and permit applications are clear, and are well defined among all parties. Formal procedures for revising and updating permit applications are in place.

D. The site has regular contact with Federal and state regulators and with DOE Headquarters about ongoing and upcoming issues related to permitting and reporting.

E. Where necessary, the facility has coordinated its permit applications and other action-related documents with NEPA procedures. 


\section{WM.10 CONTINGENCY PLANNING}

\section{PERFORMANCE OBJECTIVE}

A program should be in place to ensure that effective emergency preparedness plans and contingency plans are prepared and implemented in accordance with all applicable DOE, Federal, state, and local requirements.

DOE 5400.3, Hazardous and Radioactive Mixed Waste Program, requires that mixed waste be managed in accordance with the requirements of Subtitle C of RCRA and of the Atomic Energy Act. RCRA applies to the extent that it is not inconsistent with the AEA.

DOE 5820.2A, Radioactive Waste Management, specifies the contingency action and plan requirements for HLW, TRU, and LLW management facilities.

40 CFR 264 (Subparts C and D) and 265 (Subparts C and D) specify the requirements for emergency preparedness plans and contingency plans at hazardous waste management facilities.

\section{CRITERIA}

A. Hazardous waste facilities are designed, constructed, maintained, and operated to minimize the possibility of fire, explosion, seismic events, or any unplanned sudden or non-sudden release of hazardous waste or hazardous waste constituents to air, soil, or surface water which could threaten human health or the environment.

B. Hazardous waste facilities are equipped with appropriate and readily accessible communications/alarm devices and emergency fire-control systems. Testing and maintenance programs and procedures are in effect to ensure proper operation.

C. Adequate aisle space is provided to permit emergency response.

D. Arrangements have been made with police, fire departments, hospitals, and emergency response teams who might be involved in the event of an emergency.

E. A contingency plan has been prepared that describes actions to be taken by facility personnel in response to any fire, explosion, or unplanned sudden or non-sudden release of hazardous waste or hazardous waste constituent to air, soil, or surface water.

F. An emergency coordinator has been designated, who is thoroughly familiar with all aspects of the contingency plan and who has been given the authority to commit the resources needed to carry out the plan.

G. Formal procedures have been developed to guide the actions of the emergency coordinator. 


\section{WM.11 UNDERGROUND STORAGE TANK MANAGEMENT}

\section{PERFORMANCE OBJECTIVE}

A program should be in place to manage underground storage tanks (UST) to minimize the potential for releases to the environment and to ensure compliance with all applicable DOE. Federal, state, and local requirements.

DOE 5480.19, Conduct of Operations Requirements for DOE Facilities, requires that operations at DOE facilities be managed with a consistent and auditable set of requirements, standards, and responsibilities.

DOE 5700.6C, Quality Assurance, establishes quality assurance requirements for DOE.

40 CFR 280 specifies the requirements for the design, construction, installation, notification, operation, release detection and response, and closure of underground storage tanks containing regulated substances, including petroleum products and substances defined as hazardous under CERCLA or RCRA.

State or local UST programs may include more stringent requirements.

\section{CRITERIA}

A. The appropriate agency has been notified of existing and new USTs that store regulated substances and prompt notification of any closure actions are made.

B. There are standard operating procedures in place that detail procedures and equipment in place to prevent spills or overfills.

C. General operating requirements delineated in standard operating procedures ensure that only substances compatible with the UST system are stored; that corrosion protection equipment is inspected and maintained, and records are kept; and that any repairs to the UST system are made in accordance with manufacturer's specifications and EPA, state, or local requirements.

D. Release detection requirements have been met for all new USTs (1988 to present) and all older existing USTs (before 1975). A compliance schedule has been developed for all USTs installed prior to December 1988 to meet release detection requirements by the required dates. In addition, records of leak detection testing and installation are maintained.

E. All suspected releases of petroleum or of a hazardous substance are reported as required, and immediate response activities initiated in accordance with formal plans and procedures.

F. USTs taken out of service permanently or USTs that cannot meet release detection requirements are assessed to determine if releases have occurred. Such USTs are closed by emptying the tank and refilling with an inert substance or by removing the UST from the ground. 
G. Inspections, maintenance, releases, corrective actions, repairs, closures, and other required activities are conducted by trained personnel in accordance with formal procedures, and adequate records are maintained. 


\section{WM.12 MANAGEMENT OF NONHAZARDOUS WASTE}

\section{PERFORMANCE OBJECTIVE}

A program should be in place to manage nonhazardous waste to minimize the potential for releases to the environment and to ensure compliance with all applicable DOE, Federal, state, and local requirements.

DOE 5480.19, Conduct of Operations Requirements for DOE Facilities, requires that operations at DOE facilities be managed with a consistent and auditable set of requirements, standards, and responsibilities.

DOE 5700.6C, Quality Assurance, establishes quality assurance requirements for DOE.

40 CFR 243 specifies the requirements for storage and collection of solid waste materials.

40 CFR 246 contains requirements for source separation and recovery of specified materials, including high-grade paper.

40 CFR 257 specifies the requirements for siting nonhazardous waste disposal facilities.

40 CFR 258 contains criteria for municipal solid waste landfills. State or local solid waste regulations may include more stringent requirements.

State and local governments commonly regulate the management of nonhazardous waste. Requirements are specific to each state or local authority, and should be consulted by the specialist.

\section{CRITERIA}

A. The facility's waste minimization program identifies opportunities to minimize (at the source, whenever practical) and to recycle nonhazardous waste (see POC WM.6).

B. The facility participates in any state or local recycling programs. Facilities with more than 100 office workers recover high-grade paper.

C. Solid wastes and materials separated for recycling are stored in a manner that is protective of workers, the public and the environment. Storage receptacles meet applicable design and maintenance standards.

D. Storage receptacles are inspected regularly to verify that hazardous, radioactive and/or mixed wastes are not being deposited.

E. Facility personnel are periodically informed about materials that are prohibited from disposal in solid waste receptacles. 
F. Solid wastes and materials separated for recycling are collected according to regular schedules. All solid wastes are collected with sufficient frequency to inhibit the development of nuisances.

G. Collection operations are conducted in a manner that is protective of workers, the public and the environment. Collection equipment meets applicable design and maintenance standards.

H. Fedoral and state requirements for solid waste management are included in the facility's program to identify and document compliance with the Federal Facility Compliance Act (see POC WM.5).

I. The facility determines the suitability of offsite commercial TSD facilities for its nonhazardous waste, as part of its offsite facility evaluation effort (see WM.7).

J. There are procedures in place to ensure that only allowable wastes are accepted at treatment and disposal facilities.

K. Personnel operating or overseeing treatment, storage, and disposal units have appropriate training for the particular job functions associated with the treatment processes, including waste handling, unit operation, monitoring, $\mathrm{QA} / \mathrm{QC}$, and waste residual management.

L. Procedures are in place to ensure that the unit-specific and general facility technical standards are met during the design and operation of treatment and/or disposal facilities, including recordkeeping.

M. Procedures are in place to ident treatment residuals. These resic i necessary, collect and further manage all treatment procedures are routinely evaluated, modified, and subjectcd to quality assurance and quality control measures to ensure that their management is in compliance with appropriate requirements (see POC QA.3).

N. A quality assurance and quality control program is established for the operation of each treatment, or disposal facility that can monitor the effectiveness of all operating procedures, including analytical methods, that are associated with the treatment process (see POC QA.1).

O. Regular inspections of treatment, storage, and disposal areas are conducted in accordance with formal procedures and comprehensive records are maintained. There is a system in place to investigate nonconformances, develop and implement corrective actions, and track both nonconformances and actions.

P. At the conciusion of its operation, closure of a unit occurs in compliance with the specified closure plan. 
This page intentionally left blank. 


\section{PERFORMANCE OBJECTIVES AND CRITERIA FOR TOXIC AND CHEMICAL MATERIALS}

\section{Overview}

The toxic and chemical materials (TCM) specialist is responsible for determining whether site operations and activities are conducted in a manner that will ensure compliance with applicable Federal, state, and local statutes, regulations, ordinances, or other legally enforceable requirements that are designed to prevent harm to public health or the environment from releases or misuse of TCM.

Applicable Federal environmental protection laws and regulations, as well as Executive Orders, are listed in DOE 5400.1 (Ger:eral Environmental Protection Program), which specifically defines environmental protection requirements at the programmatic level. Specific DOE Orders and segments of the Code of Federal Regulations (CFR) that are pertinent to the TCM assessment are shown in Table TCM-1. The TCM specialist should note that this assessment incorporates a segment of the regulations implemented to enforce the Occupational Safety and Health Act (29 CFR 1910), since the regulations supporting the Toxic Substances Control Act do not include detailed specifications for the storage of all types of chemical and toxic materials used at DOE sites. Both DOE 5480.4 and DOE 5483.1A require compliance with 29 CFR 1910, and some sites may manage compliance through organizations in charge of industrial hygiene or health and safety. Internal DOE policies, state and local laws, regulations, and ordinances also apply, except where DOE is specifically exempted. TCM specialists are advised to inquire about the existence of any Memorandum of Understanding or Federal Facilities Compliance Agreements that may supersede regulatory requirements. Site operations and procedures also should be reviewed to determine whether activities adhere to best management practices (BMPs). BMPs are typically evaluated when statutes or regulations do not describe specific actions that may be required to achieve the statutory or regulatory goals, or do not go far enough to achieve protection of human health and the environment. BMPs also are used when regulations do not exist for, or do not apply to, a particular activity.

The general approach to compiling a representative sampling of information for use in assessing the compliance status of the site consists of: (1) a review of site-specific documentation, including policy statements, program plans, standard operating procedures, and previous audits and assessments; (2) an examination of facilities and other sources that have the potential to introduce TCM into the environment, and an examination of any techniques or practices in use to prevent or minimize such releases; and (3) interviews with DOE, site, and contractor personnel. While the scope and depth of the information collection process is not intended to identify every compliance problem at a site, it is intended to compile a representative sampling of information for use in developing a broad understanding and awareness of the compliance status of the site on the programmatic level in order to define the range of compliance issues and problems that may exist.

The reviewer should interact and work closely with other technical specialists to ensure adequate coverage of the TCM Performance Objectives and Criteria (POC) and to avoid duplication of effort. For example, the TCM specialist should coordinate with the surface 
water specialist on oil storage issues. Input from the both the surface water and groundwater specialists should be obtained on the facility's program for handling and storing TCMs. The specialist for inactive waste sites should be consulted regarding the requirements of CERCLA/SARA Title III, the Emergency Planning and Community Right-toKnow Act.

A series of POC documents has been developed to provide general guidance to the TCM specialist for conducting the assessment or audit and to ensure that relevant aspects of environmental regulations and DOE Orders are considered. A list of the POC is shown in Table TCM-2. Each of the POC includes a stated objective; citations of applicable DOE Orders, regulations, and requirements that provide the basis for the POC; and criteria that should be used in evaluating the site's performance against the programmatic objective. 


\begin{tabular}{|c|c|c|}
\hline & $\begin{array}{l}\text { TABLE TCM-1 } \\
\text { LIST OF TOXIC AND CHEMICAL MATERIALS } \\
\text { REGULATIONS/REQUIREMENTS/GUIDELINES }\end{array}$ & \\
\hline mequationis?: & 8081001811198. & Alutroniry \\
\hline $\begin{array}{l}\text { CERCLA/SARA } \\
\text { Section } 103\end{array}$ & Notices, Penalties & EPA \\
\hline $\begin{array}{l}\text { CERCLA/SARA } \\
\text { Section } 301-330\end{array}$ & $\begin{array}{l}\text { Emergency Planning and Community Right-to- } \\
\text { Know }\end{array}$ & EPA \\
\hline DOE 5000.3A & $\begin{array}{l}\text { Occurrence Reporting and Processing of } \\
\text { Operations Information }\end{array}$ & DOE \\
\hline DOE 5400.1 & General Environmental Protection Program & DOE \\
\hline DOE 5480.3 & $\begin{array}{l}\text { Safety Requirements for the Packaging and } \\
\text { Transportation of Hazardous Materials, Hazardous } \\
\text { Substances, and Hazardous Waste }\end{array}$ & DOE \\
\hline $\begin{array}{l}29 \text { CFR } 1910 \\
\text { Subpart H }\end{array}$ & Hazardous Materials Storage & OSHA \\
\hline 40 CFR 61 & $\begin{array}{l}\text { (NESHAP) National Emission Standards for } \\
\text { Hazardous Air Pollutants - Asbestos }\end{array}$ & EPA \\
\hline 40 CFR 112 & Oil Pollution Prevention (CWA) & EPA \\
\hline 40 CFR 125 & $\begin{array}{l}\text { Criteria and Standards for the National Pollutant } \\
\text { Discharge Elimination System }\end{array}$ & EPA \\
\hline 40 CFR 165 & (FIFRA) Pesticide Storage/Disposal Regulations & EPA \\
\hline 40 CFR 171 & Certification of Pesticide Applicators & EPA \\
\hline $\begin{array}{l}49 \text { CFR } 171,173, \\
177,178, \text { and } 397\end{array}$ & $\begin{array}{l}\text { Transportation of Hazardous Materials, } \\
\text { Packaging, Marking, Spill Reporting, etc. }\end{array}$ & DOT \\
\hline 40 CFR 300 & $\begin{array}{l}\text { National Oil and Hazardous Substances } \\
\text { Contingency Plan }\end{array}$ & EPA \\
\hline 40 CFR 302 & $\begin{array}{l}\text { Designation, Reportable Quantities, and } \\
\text { Notification }\end{array}$ & EPA \\
\hline 40 CFR 355 & Emergency Planning and Notification & EPA \\
\hline
\end{tabular}




\begin{tabular}{|c|c|c|}
\hline & $\begin{array}{l}\text { TABLE TCM-1 } \\
\text { LIST OF TOXIC AND CHEMICAL MATERIALS } \\
\text { REGULATIONS/REQUIREMENTS/GUIDELINES }\end{array}$ & \\
\hline 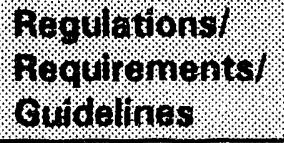 & Soctionsmitios & $40161011 \%$ \\
\hline 40 CFR 370 & $\begin{array}{l}\text { Hazardous Chemical Reporting: Community Right- } \\
\text { to-Know Act }\end{array}$ & EPA \\
\hline 40 CFR 372 & Toxic Chemical Release Reporting & EPA \\
\hline 40 CFR 761 & $\begin{array}{l}\text { (TSCA) Polychlorinated Biphenyls (PCBs) } \\
\text { Manufacturing, Processing, Distribution in } \\
\text { Commerce, Use Prohibitions }\end{array}$ & EPA \\
\hline
\end{tabular}


TABLE TCM-2

\section{PERFORMANCE OBJECTIVES AND CRITERIA FOR TOXIC AND CHEMICAL MATERIALS}

TCM.1 Management Program for Procurement, Handling, and Storage of Toxic and Chemical Materials

TCM.2 Polychlorinated Biphenyls Management and Control

TCM.3 Management and Control of Pesticides

TCM.4 Management and Control of Chemicals in Aboveground Storage Tanks

TCM.5 Management and Control of Toxic and Chemical Materials in Bulk Quantities

TCM.6 Management and Control of Asbestos

TCM.7 Pollution Prevention Awareness Program

TCM.8 Explosives Management and Control

TCM.9 Release Reporting 


\section{TCM.1 MANAGEMENT PROGRAM FOR \\ PROCUREMENT, HANDLING, AND STORAGE OF \\ TOXIC AND CHEMICAL MATERIALS}

\section{PERFORMANCE OBJECTIVE}

An effective toxic and chemical materials (TCM) management program should be in place for the procurement, use, handling, storage and shipping of toxic and chemical materials.

DOE 5400.1, General Environmental Protection Program, establishes the DOE policy to conduct operations in an environmentally safe and sound manner. This Order calls for an effective TCM management program for environmental protection and to ensure compliance with relevant legal requirements.

DOE 5480.10 requires that contractors maintain an inventory of potential chemical hazards.

DOE 5480.19, Conduct of Operations, requires procedures that provide for proper storage of toxic and chemical materials. 29 CFR 1910.101, 1910.106 and 1920.106 also establish requirements for secondary containment, segregation of incompatible chemicals and gases, and protection of compressed gas cylinders from several possible hazards. Although 29 CFR 1910, Subpart H, requirements address the handling and storage of compressed gases primarily to ensure safety, compliance with those standards would also minimize the potential for releases to the environment.

DOE/EV/06194, the DOE Explosives Safety Manual, states requirements for the safe management of explosive materials, most of which also are toxic.

40 CFR 129, Toxic Pollutant Effluent Standards; 40 CFR 122, National Pollutant Discharge Elimination System; 40 CFR 125, Criteria and Standards for the National Pollutant Discharge Elimination System; and, 40 CFR 131, Water Quality Standards, limit the degradation of surface water quality. To meet these requirements, positive controls must be in place to prevent any leaks or spills from reaching a pathway to a surface water source.

This POC should be coordinated with the surface water and groundwater specialists to avoid duplication of effort and ensure adequate coverage.

\section{CRITERIA}

A. Formal procedures are in place to track and manage all aspects of the TCM program, including controlled acquisition, documentation, distribution, storage, handling, and use of TCM by staff and contractors.

B. A formal program for the management of TCM that provides for appropriate reviews, audits, appraisals, and corrective actions has been in:plemented. 
C. Responsibilities and authorities for the TCM program have been defined and communicated effectively. Procedures include coordination with DOE management, and appropriate emergency response organizations and regulatory agencies.

D. Procedures are in place for the identification and disposal of TCM that are potentially reactive, including explosives.

E. A training program on environmental requirements is in place for handlers, users, and managers of TCM. This program includes source reduction, recognition of potentially reactive chemicals, waste minimization and pollution prevention. All training is documented.

F. Mechanisms have been established for identifying TCM and recording the information in comprehensive inventories.

G. Controls are in place to designate, maintain and inspect TCM storage facilities.

H. Procedures are in place for monitoring and limiting the type and quantity of chemicals purchased. 


\section{TCM.2 POLYCHLORINATED BIPHENYLS MANAGEMENT AND CONTROL}

\section{PERFORMANCE OBJECTIVE}

A program should be in effect to provide for compliance with applicable Federal, state and local ragulations governing polychlorinated biphenyls (PCBs).

DOE 5400.1 requires compliance with the letter and spirit of Title 15, U.S.C., Toxic Substances Control Act (TSCA), as amended.

DOE 6430.1A, General Design Criteria, 1630-2.3.5, states that existing PCB or PCBcontaminated equipment shall not be relocated or reused in other existing or new facilities, and requires that existing PCE or PCB-contaminated electrical equipment be labeled with a warning sign.

40 CFR Part 761 governs the manufacture, use, handling, storage and disposal of PCBs. Included are requirements that specific procedures be in place for the cleanup of PCB spills, any oil-filled transformer whose PCB concentration is not known be assumed to be PCB-contaminated, and PCBs and PCB items be stored in facilities that meet specific criteria.

\section{CRITERIA}

A. An appropriate PCB management plan and procedures for the identification, inspection, storage, tracking and disposal of PCBs has been implemented. Procedures are in place for a comprehensive survey of all oil-filled equipment that may contain PCBs.

B. Responsibilities and authorities for the PCB program are clearly defined and communicated, and a training program has been established for appropriate personnel.

C. Comprehensive and accurate inventories of all PCBs and PCB-containing equipment, including historic spills, are well documented.

D. Documentation (including correspondence with the Environmental Protection Agency) for the storage, inspection, cleanup and disposal of all PCBs has been established.

E. Storage facilities meet the specified structural requirements and are appropriately inspected.

F. Appropriate plans and procedures have been established for storing and/or disposing of PCBs that are radioactively contaminated, or contain RCRA land disposal restricted wastes.

G. Formal written procedures for a Spill Prevention, Control and Countermeasure (SPCC) Plan have been developed and implemented, and formal procedures have 
been established for appropriate notification and interaction with regulatory and emergency response organizations (see POC SW.6). 


\section{PERFORMANCE OBJECTIVE}

An effective program should be in place to ensure that pesticide use, storage, and disposal are properly managed.

The Federal Insecticide, Fungicide, and Rodenticide Act (FIFRA), 40 CFR 165 and 40 CFR 171 , specify the requirements for the licensing of pesticide applicators and the storage, labeling, and disposal of pesticides.

DOE 4330.4A, Maintenance Management Program, specifies requirements for the conduct of maintenance activities, including planning, scheduling and coordination. The use of this Order to supplement the requirements of 40 CFR 165, 171 will depend on local needs for pest control, and organizational assignment of responsibility.

DOE 5400.1, General Environmental Protection Program, states "It is DOE policy to conduct its operations in an environmentally safe and sound manner. . . Accordingly, it is DOE policy to conduct the Department's Operations in compliance with the letter and spirit of applicable environmental statutes, regulations, and standards."

DOE $\mathbf{5 4 8 0 . 1 0}$ requires that contractors maintain an inventory of potential chemical hazards.

DOE 5480.19, Conduct of Operationss, requires that operations at DOE facilities be managed with an auditable set of requirements, standards, and responsibilities.

ANSI/ASME NQA-1 is the proposed standard for quality assurance (per DOE 5700.6B), which requires the inspection of services furnished by a supplier (in this case, if applicable, a contract pesticide applicator).

\section{CRITERIA}

A. A pesticides management plan and procedures for the acquisition, labeling, application, inspection, storage, tracking and disposal of pesticides have been implemented.

B. Responsibilities and authorities for the site's pesticide management program have been clearly defined and communicated.

C. Appropriate personnel have been trained and licensed as required.

D. Contracts and records for contractor applicators have been well documented and managed.

E. Procedures for the oversight of pesticide applications made by contractors have been well established. 
F. Inventories of all pesticides used and stored on site are comprehensive and accurate.

G. Secure storage facilities exist that meet specified structural requirements.

H. Appropriate signs and labels for storage facilities and application equipment are properly placed.

I. Policy and procedures the notification and interaction with regulatory and emergency response o. yanizations are well established. 


\section{TCM.4 MANAGEMENT AND CONTROL OF CHEMICALS IN}

ABOVEGROUND STORAGE TANKS

\section{PERFORMANCE OBJECTIVE}

There should be an effective program in place for the management and control of chemicals in aboveground storage tanks (ASTs) to ensure that the potential for release of these materials to the environment is minimized.

DOE 4330.4A, Maintenance Management Program, designates line management assigned programmatic responsibility for the periodic examination of structures (including tanks) to determine their performance characteristics and to identify signs of decreasing performance.

DOE 5400.1, General Environmental Protection Program, requires compliance with the letter and spirit of Title 33, U.S.C. 1251, et seq., the Clean Water Act, as amended.

DOE 5480.4 and DOE 5483.1A require compliance with 29 CFR 1910. 29 CFR 1910, Occupational Safety and Health Standards, establishes requirements for the handling and storage of TCM, including environmental protection such as secondary containment.

DOE 5480.10 requires that contractors maintain an inventory of potential chemical hazards.

DOE 5480.19, Conduct of Operations, requires procedures that provide for the types of controls necessary to implement policies, such as complete and accurate inventories of storage vessels, labeling programs and inspections for TCM.

40 CFR 129, Toxic Pollutant Effluent Standards; 40 CFR 122, National Pollutant Discharge Elimination System; 40 CFR 125, Criteria and Standards for the National Pollutant Discharge Elimination System; and, 40 CFR 131, Water Quality Standards, limit the degradation of surface water quality. To meet these requirements, positive controls must be in place to prevent any leaks or spills from reaching a pathway to a surface water source.

40 CFR 302, Designation, Reportable Quantities and Notification, contains a listing of hazardous substances, reportable quantities, and notification procedures in the event of a spill. 


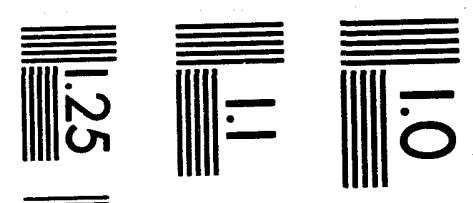

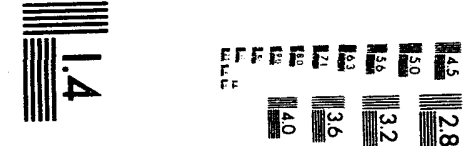

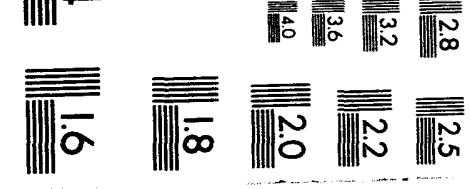




$$
\begin{aligned}
& \stackrel{N}{o} \\
& \stackrel{D}{\omega}
\end{aligned}
$$




\section{CRITERIA}

A. Written plans and procedures have been established for the acquisition, labeling, inspection, storage, tracking and disposal of chemicals in ASTs.

B. Responsibilities and authorities for the AST program are clearly defined and communicated.

C. A training program is in place for appropriate personnel, especially operators and those involved with the transfer of TCMs to and/or from ASTs, and all training is documented.

D. The location and contents of all ASTs, and a corresponding file of MSDSs are accurately documented in a comprehensive inventory.

E. ASTs have been properly sited, segregated, designed and protected.

F. Adequate secondary containment is provided and maintained.

G. The destinations of all drains and subsurface sewer line connections running from ASTs or AST secondary containment are adequately identified and controlled.

H. Written policies and procedures for appropriate notification and interaction with regulatory and emergency response organizations have been developed and implemented. 


\section{TCM.5 MANAGEMENT AND CONTROL OF TOXIC AND CHEMICAL MATERIALS IN BULK QUANTITIES}

\section{PERFORMANCE OBJECTIVE}

Provisions should be in effect to ensure that bulk quantities of toxic and chemical materials are stored in a manner to prevent or minimize the potential for release of these substances to the environment.

DOE 5480.4 and DOE 5483.1A require compliance with 29 CFR 1910 which establishes requirements for the handling and storage of TCM, including environmental protection such as secondary containment.

DOE 5480.10 requires that contractors maintain an inventory of potential chemical hazards.

DOE 5480.19, Conduct of Operations, requires procedures that provide for the types of controls necessary to implement policies, such as complete and accurate inventories of storage vessels for TCM, labeling programs and inspections.

40 CFR 129, Toxic Pollutant Effluent Standards; 40 CFR 122, National Pollutant Discharge Elimination System; 40 CFR 125, Criteria and Standards for the National Pollutant Discharge Elimination System; and, 40 CFR 131, Water Quality Standards, limit the degradation of surface water quality. To meet these requirements, positive controls must be in place to prevent any leaks or spills from reaching a pathway to a surface water source.

40 CFR 302, Designation, Reportable Quantities and Notification, contains a listing of hazardous substances, reportable quantities in the event of a spill, and notification procedures.

\section{CRITERIA}

A. Written plans and procedures are in place for the acquisition, labeling, inspection, storage, tracking and disposal of chemicals in bulk quantities.

B. Responsibilities and authorities for a bulk quantities program have been clearly defined and communicated.

C. A training program has been established for appropriate personnel, especially operators and those involved with the transfer of TCMs, and all training is documented.

D. An accurate, comprehensive inventory exists of the location and contents of all bulk TCM storage, with a corresponding file of Material Safety Data Sheets (MSDSs).

E. TCM bulk storage areas are properly sited, segregated, labeled, designed and protected. 
F. Adequate secondary containment is provided and maintained with appropriate spill containment and clean-up materials, especially for potentially reactive chemicals.

G. Drains and subsurface sewar line connections running from bulk TCM storage areas or their secondary containment have been identified and capped, as appropriate.

H. Written policies and procedures for appropriate notification and interaction with regulatory and emergency response organizations have been developed and implemented. 


\section{TCM.6 MANAGEMENT AND CONTROL OF ASBESTOS}

\section{PERFORMANCE OBJECTIVE}

\section{A program should be in effect to manage and control the identification, maintenance, abatement, and disposal of asbestos and asbestos-containing material (ACM).}

DOE 5400.1, General Environmental Protection Program, requires management and operating contractors to conduct their operations in an environmentally safe and sound manner that limits risks to the environment and protects the public health.

DOE 6430.1A, General Design Criteria, states that maintenance, repair, and demolition of DOE facilities shall comply with $40 \mathrm{CFR}$ as it pertains to asbestos-containing materials (ACM).

Best management practice suggests that facilities implement comprehensive written policies and procedures for asbestos identification, maintenance, abatement, and disposal to ensure compliance with 40 CFR 61, the National Emission Standards for Hazardous Air Pollutants (NESHAP) for asbestos and to avoid the potential for adverse environmental impact.

NESHAP training requirements require that an onsite representative trained in asbestos demolition and renovation provisions, and the means of complying with them, be present when a regulated (ACM) is stripped, removed, or disturbed. Evidence that the required training has been completed shall be posted at the demolition or renovation site.

\section{CRITERIA}

A. Comprehensive policies, administrative controis, and raining have been established to ensure compliance with NESHAP.

B. Written policies and procedures have been established and implemented for the identification, documentation, cross-reference and tracking of asbestos or ACM records.

C. An inventory and quantity of asbestos and ACM throughout the site has been maintained and updated.

D. A training program has been established for appropriate personnel, and all training is documented.

E. Administrative controls are in place to ensure that projects are not conducted prior to proper notification of appropriate staff and that staff have been adequately trained in asbestos management and handling. 
TCM. 7 POLLUTION PREVENTION AWARENESS PROGRAM

\section{PERFORMANCE OBJECTIVE}

An effective Pollution Prevention Awareness Program should be in place to increase knowledge about and visibility of pollution prevention.

Executive Order 12856, Federal Compliance with Right-To-Know Laws and Pollution Prevention Requirements, Section 3-302(d), requires each facility that meets the threshold requirements established in the Emergency Planning and Community Right-to-Know Act (EPCRA) to develop a written Pollution Prevention Plan by December 31, 1995. The plan must indicate the facility's contribution to the Agency-wide goal of 50 percent reduction in toxic pollutant releases.

DOE 5400.1, Chapter III, Section 4, requires the development and implementation of a periodically reviewed and updated Pollution Prevention Awareness Program (PPAP) by November 1989. This documented program must include specific employee awarenes 3 training, awareness campaigns, and incentives and awards programs.

The Pollution Prevention Act of 1990 established pollution prevention as a national objective and the most important component of the environmental management hierarchy. In this hierarchy, pollution prevention is the preferred approach, followed by recycling, treatment, and disposal.

\section{CRITERIA}

A. The facility, if required, is in the process of preparing its Pollution Prevention Plan.

B. A formal Pollution Prevention Awareness Program has been developed and implemented.

C. Senior management clearly demonstrates its commitment to pollution prevention.

D. A formal pollution prevention awareness training program has been developed and implemented for all employees and contractors.

E. There is a common understanding among all employees of the pollution prevention hierarchy: source reduction, recycling, treatment, and disposal.

F. There is a system to recognize and provide incentives or awards for employee contributions to pollution prevention.

G. The facility has a system to publicize pollution prevention success stories internally.

H. The facility is aware of and follows the development of pollution prevention regulations, DOE policy, emerging technologies, trends, and issues. 


\section{TCM.8 EXPLOSIVES MANAGEMENT AND CONTROL}

\section{PERFORMANCE OBJECTIVE}

An effective program should be in place to ensure that explosive materials do not represent an unrecognized toxic hazard to the environment through spillage, reaction or other means.

DOE 5400.1, General Environmental Protection Program, establishes policies to conduct operations in an environmentally safe and sound manner.

DOE/EV/06194, the DOE Explosives Safety Manual, establishes requirements for the facilities and management of explosive materials. This Order establishes provisions for obtaining exemptions from certain requirements.

State governments frequently regulate waste minimization. Requirements are specific to each state authority, and should be consulted by the specialist.

\section{CRITERIA}

A. A storage review program has been established with a committee to approve storage review intervals for all explosives stored at the facility.

B. Mechanisms are in place to ensure that degraded explosives are not inadvertently stored or handled on site.

C. Written policies and procedures have been developed for the acquisition, inventory, storage, handling, use, transport, and disposal of explosive materials, including notifications of appropriate oversight organizations.

D. Appropriate documentation and designation of potential hazards and hazard conditions, including stability data have been developed.

E. The quantity of explosives at each operating location is the minimum necessary for the work being performed.

F. Placards and signs are located and posted at appropriate locations.

G. Facilities comply with structural requirements, and are regularly inspected and maintained by appropriate personnel.

H. Firing ranges are properly managed in regard to potential environmental contamination.

I. Burning/detonation facilities are managed in accordance with all permits and other applicable requirements.

J. A formal explosive materials management program has been developed and all training is documented. 


\section{TCM.9 RELEASE REPORTING}

\section{PERFORMANCE OBJECTIVE}

A program should be in place to discover, characterize, and report, within the required timeframes of the law and regulations, releases of hazardous substances that are reportable to the Federal or state government.

CERCLA Section 103(a) requires "[a]ny person in charge of a vessel or an offshore or an onshore facility shall, as soon as he has knowledge of any release (other than a Federally permitted release) of a hazardous substance from such vessel or facility in quantities equal to or greater than those determined pursuant to Section 102 of this title, immediately notify the National Response Center established under the Clean Water Act of such release." The regulatory requirements for reporting are found in 40 CFR 302.

CERCLA Section 103(c) requires that any owner or operator of a facility that discovers a site that treated, stored, or disposed of hazardous substances and that is not under RCRA Subtitle $\mathrm{C}$ authority (i.e., inactive waste sites) must notify the Administrator of EPA.

SARA Section 302 requires that facilities notify the state emergency response commission if an extremely hazardous substance present at the facility is in an amount equal to or in excess of the threshold planning quantity established for that substance. The regulatory requirements for this notification are found in 40 CFR 355.

SARA Section 304 requires that facilities notify State and Local Emergency Planning Committees (SEPCs and LEPCs) of releases of extremely hazardous substances when such release requires notification under CERCLA Section 103(a). The regulatory requirements for this notification are found in 40 CFR 355.

SARA Sections 311 and 312 require that facilities who are required to prepare or have available a Material Safety Data Sheet (MSDS) for a hazardous chemical under OSHA, and if such chemical exceeds an established threshold quantity level, shall submit a MSDS for each chemical, or a list of such chemicals to the SEPCs, LEPCs, and fire departments. Furthermore, facilities are required to submit annual hazardous chemical inventory Tier I or II forms to the same agencies when the minimum threshold level for reporting has been exceeded. This information shall be made available to the public when requested. The regulatory requirements for this submission are found in 40 CFR 370 .

SARA Section 313 requires that covered facilities submit annual Form $R$ reports on toxic chemical releases to the EPA and state. In addition, facilities are required to retain all supporting materials and documentation used to make any compliance determination with respect to Section 313 and to support the calculations of the quantity of each toxic chemical released and whether a threshold quantity applies for each toxic chemical. The regulatory requirements for these submissions are found in 40 CFR 372 .

DOE 5000.3A, Occurrence Reporting and Processing of Operations Information, establishes specific requirements for the categorization, reporting, and processing of occurrences related to the operation of DOE facilities. These occurrences include releases of radionuclides, hazardous substances, and oil to the environment. The Order also 
requires that a system be developed and implemented for determining the appropriate corrective action and review schedule, and ensuring that such action is effectively taken. Furthermore, facilities are required to establish training programs for both DOE and contract personnel in the requirements of this Order.

DOE 5500.2A, Emergency Notification, Reporting, and Response Levels, requires immediate notification to DOE Headquarters Emergency Operations Center and the National Response Center as soon as possible (always within 24 hours) after discovery of a hazardous material spill or release to the environment (in excess of reportable quantities) as a result of DOE operations. State requirements for reporting of releases also must be met to the extent they are applicable.

40 CFR 300.405 outlines the discovery and notification requirements for a hazardous substance release.

\section{CRITERIA}

A. DOE and the operating contractor have plans that outline specific responsibilities for and procedures to assess all releases potentially subject to CERCLA requirements and specific responsibilities for reporting, if necessary, to appropriate Federal, state, and DOE authorities within the required timeframes.

B. The plans are approved by appropriate persons and implemented consistently throughout the facility by all parties, including DOE personnel and all contractor personnel who handle substances that, if released, will be subject to the releasereporting requirements.

C. All release notification and reporting requirements established in facility permits (e.g., RCRA Part B) are followed.

D. There is a regular training program about release-reporting requirements. It is offered for all parties that are responsible for handling hazardous substances that, if released, will be subject to the release-reporting requirements, and for personnel that are responsible for preparing periodic reports. All training is documented.

E. There are regular audits by appropriate DOE and contractor staff to ensure that all personnel are trained in release reporting procedures. Any deficiencies found during the audits are documented, and corrective action measures are immediately implemented.

F. Information about releases of hazardous substances is reported according to the plans outlined, and reports are correctly and accurately made to all Federal, state, and DOE parties.

G. Follow-up occurrence documentation is completed correctly, in a timely manner, and is sent to the appropriate Federal, state, or DOE parties within the required timeframes.

H. Appropriate follow-up measures to respond to the release occur immediately, and steps are taken to correct any causes of the release. 
I. Annual release and inventory reports (Form $\mathbf{R}$ and Tier I or II) are prepared correctly, on time, and are sent to appropriate Federal, state, local, or DOE personnel. Oversight of the reporting process is provided by senior DOE or contractor management to ensure timely and accurate report preparation. Copies of all submissions are made available to the public, as requested, and copies are kept on site. Information used in determining the facility's reporting requirements is retained on site.

J. A complete set of MSDSs or a hazardous chemical list has been provided to the SEPC, LEPC and fire departments. A system is in place to ensure that an updated chemical list or MSDS is provided to the above mentioned agencies when new chemicals that exceed the threshold planning quantity are used, processed or manufactured on site.

K. There is a program to comply with the notification procedures for continuous releases of hazardous substances, including procedures to identify such potential releases; evaluate the nature and magnitude of such releases with appropriate statistical certainty; and submit required annual reports. 
This page intentionally left blank. 


\section{PERFORMANCE OBJECTIVES AND CRITERIA \\ FOR INACTIVE WASTE SITES AND RELEASES}

\section{Overview}

The responsibility of the inactive waste sites specialist is to determine whether site activities comply with applicable Federal and state statutes, regulations, DOE Orders, agreements, and other relevant policy guidance for planning, carrying out, and evaluating a facility's program for inactive waste sites.

The primary statutes, regulations and DOE Orders that address the management of an inactive waste sites program are the Comprehensive Environmental Response,

Compensation, and Liability Act (CERCLA) as amended by the Superfund Amendments and Reauthorization Act (SARA), the Resource Conservation and Recovery Act (RCRA) corrective action requirements, and DOE 5400.3 and 5400.4. Specific Federal laws, DOE Orders and segments of the Code of Federal Regulations (CFR) that are pertinent to the inactive waste site assessment are shown in Table IWS-1. In many cases, there also will be important State statutes and regulations that address inactive site cleanup. In addition, the inactive waste sites specialist must identify and understand the impacts of any Federal Facility Agreements or consent orders that are in effect for the facility. Finally, the inactive waste sites specialist also will review all activities for adherence to best management practices (BMPs). BMPs are typically evaluated when statutes or regulations, which often specify only a minimum standard that must be achieved or a broad goal or requirement such as "protection of human health or the environment," do not exist, do not apply directly at the site, or do not describe specific actions that may be required to achieve the broad statutory goal. For inactive waste sites, BMPs are particularly important because the statutes and regulations often are very general or specify only a performance standard. Therefore, inactive waste site reviews often must evaluate site-specific activities against accepted procedures or guidance manuals.

The general approach of the inactive waste sites specialist conducting an environmental assessment or audit includes the following information collection activities: (1) review of available documentation, including agreements, court orders or decrees, program plans, specific site action plans, EPA and state documents related to specific site activities, the results of previous site audits, assessments, or inspections, and inventories of site areas requiring cleanup; (2) examination of the activities underway at the site, including field visits to sites where investigations or response work is occurring and to sites where work will occur in the future; and (3) interviews with DOE, site contractor, and regulatory personnel. Although the scope of the review is not designed to evaluate every aspect of the inactive site activities, it is designed to review in detail enough of the program to gain a broad understanding and awareness of the compliance status of the site. This review, therefore, is designed to gain a programmatic understanding of the site to define both the range of compliance activities that may exist and to assess the facility's overall systems for conducting response activities.

The scope of the inactive waste site specialist's work generally is defined as investigating all site areas where activities are no longer occurring. This specialist's work can, however, overlap with the efforts of the radiation and waste management specialists. This is because of the similarity of the waste materials found at inactive and active sites and 
because many inactive waste sites actually could be addressed under "active" waste management programs (e.g., RCRA closure or corrective action, which may also address inactive waste sites). As a result, the inactive waste site specialist should coordinate work with the specialists for environmental radiation protection and waste management. The inactive waste site specialist should also consult with the toxic and chemical materials specialist regarding the requirements of CERCLA/SARA Title III, the Emergency Planning and Community Right-to-Know Act.

Significant issues that each inactive waste site audit will need to address require: (1) identifying and understanding the specific regulatory authorities under which the site response program is occurring; (2) understanding the unique factors imposed on each inactive waste site program as a result of any agreements or court orders or decrees that are in effect for the facility; and (3) evaluating how the site has moved from complying only with the broad requirements of the statutes and regulations to establishing detailed program plans and site-iesponse plans that are consistent with the broad requirements, but that also reflect appropriate site-specific decision-making.

Because of the potentially broad scope and complexity of inactive waste site programs across DOE sites, the different regulatory authorities under which inactive waste site responses may uccur, and the variety of state programs and agreements that may be in effect, a series of Performance Objectives and Criteria (POC) documents has been developed to assist the inactive waste site specialist in conducting a programmatically oriented assessment or audit. A list of the POC developed for the inactive waste sites assessment is shown in Table IWS-2. Each of the POC includes a stated objective; citations of applicable DOE Orders, statutes, and regulations; and criteria that should be used in evaluating the site's performance against the programmatic objective.

NOTE: Sites may be subject to either Superfund (40 CFR 300) or RCRA corrective action (RCRA 7003, proposed Subpart 5 regulations, Administrative Orders, or consent decrees) for inactive waste site activities. These POC apply broadly to both types of actions and address programmatic aspects. Specific requirements may differ from site to site. In addition, the requirements of proposed Subpart 5 may not yet be adopted by state agencies. Auditors should review and understand the site-specific implementing orders and agreements to determine what requirements apply. 


\begin{tabular}{|c|c|c|}
\hline & $\begin{array}{c}\text { TABLE IWS-1 } \\
\text { LIST OF INACTIVE WASTE SITES } \\
\text { REGULATIONS/REQUIREMENTS/GUIDELINES }\end{array}$ & \\
\hline gieguiationst: & sectionstitilo. & Alithorits? \\
\hline $\begin{array}{l}\text { CERCLA/SARA } \\
\text { Section } 103\end{array}$ & Notices, Penalties & EPA \\
\hline $\begin{array}{l}\text { CERCLA/SARA } \\
\text { Section } 104\end{array}$ & Response Authorities & EPA \\
\hline $\begin{array}{l}\text { CERCLA/SARA } \\
\text { Section } 105\end{array}$ & $\begin{array}{l}\text { National Contingency Plan, Preparation, } \\
\text { Contents, etc. }\end{array}$ & EPA \\
\hline $\begin{array}{l}\text { CERCLA/SARA } \\
\text { Section } 107\end{array}$ & Liability & EPA \\
\hline $\begin{array}{l}\text { CERCLA/SARA } \\
\text { Section } 120\end{array}$ & Federal Facilities & EPA \\
\hline DOE 4300.1A & Real Estate (Real Property) Management & DOE \\
\hline DOE 4300.1B & $\begin{array}{l}\text { Real Property and Site Development } \\
\text { Planning }\end{array}$ & DOE \\
\hline DOE 4320.1B & Site Development Planning & DOE \\
\hline DOE 5400.1 & General Environmental Protection Program & DOE \\
\hline DOE 5400.3 & Hazardous and Mixed Waste Program & DOE \\
\hline DOE 5400.4 & CERCLA Requirements & DOE \\
\hline DOE 5400.5 & $\begin{array}{l}\text { Radiation Protection of the Public and the } \\
\text { Environment }\end{array}$ & DOE \\
\hline DOE 5480.19 & Conduct of Operations & DOE \\
\hline 40 CFR 124 & Procedures for Decisionmaking & EPA \\
\hline 40 CFR 300 & $\begin{array}{l}\text { National Oil and Hazardous Substances } \\
\text { Contingency Plan }\end{array}$ & EPA \\
\hline 40 CFR 373 & $\begin{array}{l}\text { Reporting Hazardous Substance Activity } \\
\text { when Selling or Transferring Federal Real } \\
\text { Property }\end{array}$ & EPA \\
\hline
\end{tabular}


TABLE IWS-2

\section{PERFORMANCE OBJECTIVES AND CRITERIA FOR INACTIVE WASTE SITES AND RELEASES}

IWS. $1 \quad$ Inactive Site Program Planning

IWS.2 Site Discovery and Evaluation

IWS.3 Response Investigations

IWS.4 Risk Assessment

IWS.5 Alternative Identification and Remedy Selection

IWS.6 Removal Actions and Interim Removal Actions

IWS.7 Remedial Action Design and Construction

IWS.8 Natural Resource Damage Assessments

IWS.9 Administrative Record/Community Relations

IWS.10 Property Transfer 
IWS.1 INACTIVE SITE PROGRAM PLANNING

\title{
PERFORMANCE OBJECTIVE
}

\begin{abstract}
A program should be in place to plan and effectively implement all actions required to manage responses to past releases of hazardous substances and hazardous wastes to the environment.
\end{abstract}

RCRA 7003 allows state and Federal agencies to compel corrective action where an imminent and substantial danger exists.

DOE 4320.1B, Site Development Planning, requires that all DOE sites develop a Technical Site Information document and a Site Development Plan to document the site planning process. These documents are to be updated annually. Chapter I and II of the Order outline the specific plan requirements, such as maps identifying contaminated areas, types of contamination, areas suspected of contamination for which no data exist, and general plan requirements.

DOE 5400.1, General Environmental Protection Program, describes DOE's policy of correcting existing environmental problems, minimizing risks to the environment or public health, and anticipating and addressing potential environmental problems before they pose a threat to the environment or public health. The Order further states that efforts to meet environmental obligations must be carried out consistently across all operations.

DOE 5400.3, Hazardous and Mixed Waste Program, requires that actions taken under RCRA authorities comply with RCRA to the extent it is not inconsistent with AEA, including developing and implementing a program to ensure compliance, requesting sufficient funds to implement the program and actions, and identifying any inconsistencies with the AEA.

DOE 5400.4, Comprehensive Environmental Response, Compensation, and Liability Act (CERCLA) Requirements, outlines the responsibilities of all parties in implementing the requirements for DOE facilities to respond to releases and potentially imminent releases of hazardous substances in accordance with CERCLA, the National Oil and Hazardous Substances Pollution Contingency Plan (NCP), and Executive Order 12580. The DOE Order requires, among other things, that sufficient funds should be requested to ensure that an adequate resource planning level is available to satisfy the Order; that appropriate DOE personnel oversee all responses for compliance with applicable requirements of CERCLA and maintain a field organization-wide record of all actions taken; and that they take such actions as necessary to ensure that organization personnel have maintained contact as necessary with appropriate EPA, state, and local officials, and have received training designed to ensure DOE compliance with applicable CERCLA requirements.

DOE 5400.4 also states that, in some instances, corrective actions carried out under other authorities, such as Sections 3004(u) or 3008(h) of the Resource Conservation and Recovery Act (RCRA) or state laws, may satisfy CERCLA requirements for response actions to a release of a hazardous substance. In these instances, DOE needs to ensure that these corrective actions are not inconsistent with the NCP for them to satisfy CERCLA requirements. An efficient means of accomplishing this is through the use of 
interagency agreements (IAGs) or Federal Facility Agreements (FFAs) to establish which response authority will be used. DOE 5400.4 also requires that DOE facilities make all required notifications, prepare and submit all required documents, and integrate the procedural requirements of CERCLA and National Environmental Policy Act (NEPA), wherever practical, in a timely manner.

DOE 5480.19, Conduct of Operations, states that it is DOE policy to conduct its operations with a consistent and auditable set of requirements, standards, and responsibilities. Chapter 1 of the Order states "effective implementation and control of operating activities are primarily achieved by established written standards in operations, periodically monitoring and assessing their performance and holding personnel personally responsible for their performance."

The IWS specialist should coordinate with the radiation specialist regarding decontamination and decommissioning of radioactively contaminated facilities (see POC RAD.6).

\section{CRITERIA}

A. DOE and the operating contractor have developed appropriate site-specific response action plans or other equivalent documents that outline the nature and scope of the response action program and establish priorities and time schedules for initiating required responses in a manner consistent with signed facility agreements, Orders, or regulatory requirements. These plans are consistent with the approach and guidelines of the regulatory authority (i.e., RCRA or CERCLA) selected for the site, and with any site-specific conditions agreed to in an FFA, court order, or consent decree. These formal plans, documents and/or procedures are reviewed and updated on a regular basis, and are also the basis on which personnel, budgeting, and other planning decisions associated with the response action program are made.

B. Environmental restoration activities carried out under RCRA authority are consistent with CERCLA requirements.

C. Adequate funding requests are made during each budget period to conduct all phases of the response process in a manner consistent with the time schedule established in site-specific planning documents, IAGs, or FFAs.

D. Allocation of funding to different elements of the response program (e.g., site discovery, site investigation, implementation of remedies) is regularly reviewed and allocations are consistent with the priorities established for each funding period.

E. Appropriate and sufficient personnel are hired by DOE and contractors responsible for operating the site to plan, conduct, and oversee all aspects of the response action program. These personnel have proper experience and knowledge in performing response activities. A program is in place to ensure that all workers involved in response field activities are appropriately trained in and follow health and safety requirements in conformance with 29 CFR 1910.120. All trainıng is documented. 
F. Federal and state regulations and DOE Orders that are directly applicable to the site's response activities are tracked, identified and responded to appropriately.

G. Issues associated with the response program are regularly discussed by senior DOE and contractor managers at the site, there are clear lines of authority and responsibility for all phases of site actions, and decisions made during the program have the appropriate levels of concurrence before actions are taken (see POC EM.1).

H. Appropriate contact is maintained with regulatory or oversight agencies, including DOE Headquarters, EPA Regional personnel, state, and local personnel who may have jurisdiction over or a legitimate interest in response to activities being planned or taken at the site. There also is formalized documentation of the occurrence of these meetings and resultant action items.

I. Appropriate procurement regulations are followed when advertising for, evaluating, selecting, and working with contractors or subcontractors who may be hired as part of the response action process. Included in all plans and procurements are clear and specific procedures for accountability and oversight, both within DOE and contractor urganizations (see POC EM.1).

J. The phases of the response process are adequately documented in a timely and formalized manner, copies of documents are regularly sent to all appropriate DOE, contractor, and regulatory agency parties, and copies are kept for onsite and offsite (when required) review.

K. Formalized, documented concurrence is obtained by all appropriate parties on what authorities will be used to take actions for inactive waste sites, what parties will have specific review and approval responsibilities, and how work will be initiated and performed.

L. Adequate DOE and contractor oversight mechanisms are developed and documented. When response activities are planned or conducted, appropriate parties are able to provide timely, thorough, and accurate review, and to take any actions required to make corrections before plans are approved.

M. Environmental restoration activities are well integrated and coordinated with all applicable site operations (e.g., environmental surveillance, decontamination and decommissioning (D\&D), construction and maintenance) to ensure effective implementation and compliance with Federal and state regulations, and DOE Orders (see POC RAD.6).

O. A mechanism is in place, through audits and oversight, to ensure that all plans are being followed, funds are being properly expended, regulations are being adhered to, appropriate contacts are being maintained, and response actions are being adequately performed and are meeting stated objectives. 


\section{IWS.2 SITE DISCOVERY AND EVALUATICIN}

\section{PERFORMANCE OBJECTIVE}

An effective program should be in place to identify inactive waste sites, assess whether response actions are required, and if they are, determine what type of response is necessary and within what timeframe the response should be implemented.

CERCLA Section 103(c) requires that any owner or operator of a facility that discovers a site that treated, stored, or disposed of hazardous substances and that is not under RCRA Subtitle $C$ authority (i.e., inactive waste sites) notify the Administrator of EPA.

CERCLA Section 120 requires that EPA establish a Federal Agency Hazardous Waste Compliance Docket for all Federal facilities at which releases of hazardous substances may have occurred. Within 18 months of the enactment of SARA, a preliminary assessment of each facility on the docket must be conducted in accordance with the procedures of Section 105, which invokes the National Contingency Plan, for determining priorities among releases.

RCRA Section 3004(u) requires that EPA or a State shall require corrective action for all releases from any solid waste management unit (SWMU) at a treatment, storage, or disposal facility seeking a permit under Subtitle C. Permits issued under Section 3005 shall contain a schedule of compliance for such corrective action (where such corrective action cannot be completed prior to issuance of the permit).

RCRA Section 3004(v) allows EPA to require corrective action where releases have migrated off site.

DOE 5400.1, General Environmental Protection Program, describes DOE's policy of correcting existing environmental problems, minimizing risks to the environment or public health, and anticipating and addressing potential environmental problems before they pose a threat to the environment or public health. The Order further states that efforts to meet environmental obligations be carried out consistently across all operations.

DOE 5400.3, Hazardous and Mixed Waste Program, requires compliance with all RCRA laws and regulations, to the extent that compliance is not inconsistent with the AEA. This includes the conduct of RCRA Facility Assessments.

DOE 5400.4, CERCLA Requirements, requires that DOE respond to hazardous substance releases regardless of whether the facility is listed on the National Priorities List, in accordance with CERCLA and the NCP, and that DOE facilities shall "gather information with respect to releases and potentially imminent releases of hazardous substances and maintain a field organization-wide record of all actions taken under this Order, CERCLA, and applicable DOE policies, requirements, and procedures."

40 CFR 300.410 and 415 outline the requirements in performing a removal site evaluation and removal action. 
40 CFR 300.420 specifies the procedures required in conducting a preliminary assessment (PA) and site investigation (SI) for response activities managed according to CERCLA.

\section{CRITERIA}

A. Adequate procedures are in place and adequate efforts have been made to identify all areas where hazardous substances may have been stored or released and, therefore, require reporting to EPA or other implementing agencies (e.g., states).

B. Once identified, an accurate inventory of all potential inactive waste sites at the facility is maintained in a central location. The inventory shall at least provide information that includes the accurate location of the site, history of the site (including types of waste or hazardous materials that may have been released), and history of any facility responses to environmental problems.

C. The inventory is regularly reviewed and updated, and progress reports about the status of and actions taken at each site in the inventory are available for review.

D. For each site in the inventory, a determination is made whether an immediate action is required to ensure protection of human health and the environment.

E. Where appropriate, and at the direction of the lead agency (e.g., EPA), the Hazard Ranking System (HRS), based on the results of a preliminary assessment/site inspection (PA/SI), has been used to score each site on the inventory within 18 months of listing on the docket.

F. Where appropriate, preliminary assessments (PAs) and/or RCRA Facility Assessments (RFAs) are conducted to determine whether further investigation and corrective action are required. Where both PAs and RFAs are required, they are coordinated to ensure that both objectives can be met through one organized effort.

G. Accurate reports are made regularly to the Field Office and DOE Headquarters about the number, nature, and actions taken on all sites in the inventory.

H. Programmatic reviews are made to ensure that procedures for site discovery and evaluation are being followed and that follow-up response actions are being pursued.

1. Prior to conducting field sampling as part of a site evaluation, the facility shall develop sampling and analysis plans that provide a process for obtaining data of sufficient quality and quantity to satisfy data needs. 


\section{IWS.3 RESPONSE INVESTIGATIONS}

\section{PERFORMANCE OBJECTIVE}

A program should be in place to plan for and carry out investigations and characterizations of the site including identifying, within acceptable statistical parameters, the horizontal and vertical extent of suspected releases in all media.

RCRA Section 3004(u) requires that EPA or a State shall require corrective action for all releases from any solid waste management unit (SWMU) at a treatment, storage, or disposal facility seeking a permit under Subtitle C. Permits issued under Section 3005 shall contain a schedule of compliance for such corrective action (where such corrective action cannot be completed prior to issuance of the permit). The regulatory requirements for this investigation are found in 40 CFR 264 and 265.

RCRA Section 3004(v) allows EPA to require corrective action where releases have migrated off site.

DOE 5400.3, Hazardous and Mixed Waste Program, requires compliance with all RCRA laws and regulations to the degree they are not inconsistent with the AEA. Where appropriate, a RCRA Facility Investigation (RFI) is conducted to determine whether there have been releases from SWMUs, the nature and extent of such releases, and the risks that such releases pose to human health and the environment.

DOE 5400.4, CERCLA Requirements, requires that DOE respond to hazardous substance releases in accordance with CERCLA and the NCP, regardless of whether the facility is listed on the National Priorities List, and that DOE Facilities shall "gather information with respect to releases and potentially imminent releases of hazardous substances and maintain a field organization-wide record of all actions taken under this Order, CERCLA, and applicable DOE policies, requirements, and procedures."

40 CFR 300.430 (b) of the NCP requires that the scope and timing of remedial investigations and feasibility studies for CERCLA sites be tailored to the nature and complexity of the problem and the response alternatives being considered. Scoping (planning) of remedial investigations must include preparation of certain plans, identification and evaluation of existing data, initial development of response alternatives, and development of remedial action objectives.

40 CFR 300.430(d)(2) requires the lead agency for CERCLA sites to characterize the nature of and threat posed by hazardous substances and hazardous materials and gather data by conducting field investigations as necessary to assess the extent to which the releases pose a threat to human health or the environment or to support the analysis and design of potential response actions.

The facility may also be subject to enforcement actions through administrative orders, consent decrees, or interagency agreements pursuant to CERCLA, RCRA or other state/local laws and regulations. These documents may specify the scope and schedule of site characterization activities. 


\section{CRITERIA}

A. The activities required under scoping and work plan preparation are conducted and necessary reports are submitted to regulatory agencies in a timely manner, with appropriate levels of review and approval by both DOE and appropriate contractors. The investigation and analytical studies are tailored to site circumstances so that the scope and detail of the analysis is appropriate to the complexity of site problems being addressed.

B. A conceptual site model is developed that reflects all known or potential sources of waste, migration pathways, and potential receptors; is updated as new data become available; and is used as the basis for planning and conducting all subsequent site investigations.

C. Field investigations systematically and consistently characterize the nature of, and threat posed by, a hazardous substance release. The investigation has collected data in a thorough and consistent manner to assess the extent to which the release poses a threat to human health or the environment. If response actions are performed, field investigations are performed to support the analysis and design of the proposed/completed action.

D. All field activities are described in the appropriate work plans. These plans are completed in a timely manner and approved by all appropriate DOE offices and regulatory agencies and contractors prior to the initiation of any field sampling activities.

E. Appropriate quality assurance project plans have been prepared and approved.

F. The sampling and analysis plans provide for an appropriate sampling strategy, are based on appropriate data quality objectives (DOOs) developed for the site, describe appropriate field procedures, identify acceptable laboratory and QA/OC protocols, include appropriate recordkeeping procedures, and outline required data reduction and validation procedures.

G. Regular oversight of field and laboratory procedures occurs by contractor and DOE personnel to ensure all $\mathrm{QA} / \mathrm{QC}$ and documentation procedures are being followed.

H. There is a consistent and clear coordination and integration of work plans, data collection, and characterization studies at facilities with multiple, concurrent response activities.

I. Environmental restoration activities carried out under RCRA authority are consistent with RFI procedures/policies and CERCLA RI/FS requirements.

J. Procedures are established to identify the need for field testing of potential treatment or response technologies, including innovative technologies, at appropriate times in the scoping, field investigation, and remedy design stages.

K. Reports presenting the results of and conclusions drawn from data collection and analysis activities are prepared accurately, receive appropriate DOE and contractor 
review, and are submitted in a timely manner in accordance with the work plans and any operating agreements.

L. The appropriateness of treatability studies is specifically evaluated during project scoping and site investigations. If appropriate, a specific schedule for conducting treatability studies is developed and implemented as part of the investigation process. If conducted, the tests include appropriate sampling protocols and documentation.

M. Investigation/cleanup agreements entered into under CERCLA and/or RCRA are evaluated to determine any impact on the aforementioned criteria. 


\section{IWS.4 RISK ASSESSMENT}

\section{PERFORMANCE OBJECTIVE}

Procedures should be in place to conduct an accurate assessment of human health and environmental risks that are posed by the site.

DOE 5400.1, General Environmental Protection Program, describes DOE's policy of correcting existing environmental problems, minimizing risks to the environment or public health, and anticipating and addressing potential environmental problems before they pose a threat to the environment or public health.

DOE 5400.3, Hazardous and Mixed Waste Program, requires compliance with all RCRA laws and regulations to the degree they are not inconsistent with the AEA. This includes conducting a human health and/or environmental risk assessment, if this is required as part of the site-specific corrective action process.

DOE 5400.4, CERCLA Requirements, requires that DOE respond to hazardous substance releases in accordance with, CERCLA and the NCP, regardless of whether the facility is listed on the National Priorities List, and that DOE facilities shall "gather information with respect to releases and potentially imminent releases of hazardous substances and maintain a field organization-wide record of all actions taken under this Order, CERCLA, and applicable DOE policies, requirements, and procedures."

40 CFR 300.430 (d)(4) of the NCP requires that the lead agency for CERCLA sites, using the data developed during the RI, "shall conduct a site-specific baseline risk assessment to characterize the current and potential threats to human health and the environment that may be posed by contaminants migrating to ground water or surface water, releasing to air, leaching through soil, remaining in the soil, and bioaccumulating in the food chain. The results of the baseline risk assessment will help establish acceptable exposure levels for use in developing remedial alternatives in the Feasibility Study (FS)."

\section{CRITERIA}

A. Personnel qualified and experienced in conducting and overseeing risk assessments are on the facility's staff or available through subcontracting arrangements.

B. Data needs for the human health and environmental risk assessments are evaluated early in the scoping process, and the data elements required are specifically addressed in sampling and analysis plans.

C. Data for the risk assessments are collected with appropriate techniques to provide the required detection limits for conducting risk assessments.

D. Selection of contaminants of concern is fully justified and documented. 
E. For human health risk assessments, exposure assessments are carried out on all relevant exposure pathways and receptors identified in the conceptual evaluation model. Elimination of any exposure pathways or receptors from the quantitative analysis is fully documented and reviewed and approved by all appropriate parties.

F. For human health risk assessments, toxicity assessments use the latest valid toxicity information that is available, and the values used are based on the hierarchy of acceptable EPA sources or have been approved by other appropriate parties.

G. For human health risk assessments, risk characterization clearly presents baseline risk assessment results and the discussion includes a list of the significant assumptions and uncertainties associated with the risk results.

H. For environmental risk assessments, techniques are identified to study and assess all potential impacts of site releases on biological receptors.

I. For environmental risk assessments, study results address current observed effects and summarize potential risks and threats to affected populations.

J. Formal documentation is maintained to support the facility's risk management strategy at hazardous substance release sites or to support the facility's decision on risk acceptability. To support the facility's overall risk management program, routine sitewide surveillances and/or monitoring of release sites are conducted. 


\section{IWS.5 ALTERNATIVE IDENTIFICATION AND REMEDY SELECTION}

\section{PERFORMANCE OBJECTIVE}

A program should be in place to develop response action alternatives at appropriate times in the process, to screen the alternatives, to identify appropriate alternatives for detailed analysis, and to select and implement the remedy.

CERCLA Section 121(d) requires that a remedial action for CERCLA sites must comply with any Federal or state environmental laws or requirements that are applicable or relevant and appropriate requirements (ARARs) at the time the remedial action is complete.

DOE 5400.4, CERCLA Requirements, requires that DOE respond to hazardous substance releases in accordance with CERCLA and the NCP, regardless of whether the facility is listed on the National Priorities List, and that DOE facilities shall "gather information with respect to releases and potentially imminent releases of hazardous substances and maintain a field organization-wide record of all actions taken under this Order, CERCLA, and applicable DOE policies, requirements, and procedures."

40 CFR 300.415 (i) requires that removal actions comply with ARARs to the extent practicable considering the exigencies of the situation (e.g., urgency of the situation and scope of the removal action).

40 CFR $300.430(e)(1)$ through (6) of the NCP specify the requirements for developing response action alternatives for CERCLA sites. A range of alternatives should be developed, including one alternative to reduce the toxicity, mobility, or volume of the hazardous substances and one or more alternatives that involve little or no treatment, but provide protection of human health and the environment primarily by preventing or controlling exposure to hazardous substances through engineering controls and, as necessary, institutional controls. For groundwater response actions, a limited number of remedial alternatives that attain site-specific remediation levels within different restoration time periods using one or more different technologies should be developed. One or more innovative treatment technologies should be developed if those technologies offer the potential for comparable or superior performance or implementability; fewer or lesser adverse impacts than other available approaches; or lower costs for similar levels of performance than demonstrated technologies.

40 CFR $300.430(e)(7)$ requires the lead agencv for CERCLA sites to screen alternatives based on effectiveness, implementability, and cost to reduce the number of alternatives, and to notify the support agency of the alternatives selected to undergo a detailed analysis.

40 CFR $300.430(e)(9)$ requires the lead agency to evaluate a limited number of alternatives against the nine NCP criteria to determine which offers the best relative tradeoffs and the best approach to attain the threshold criteria. In addition, each alternative must be cost effective and must reduce the toxicity, mobility, or volume of wastes to the maximum extent practicable. 
40 CFR $300.430(f)$ discusses the necessary steps and criteria that must be achieved in selecting a final remedy. Prior to selecting a final remedy, the proposed plan must be presented to the general public for review and comment. The public comment shall be reviewed and a determination made as to whether the proposed remedy continues to satisfy the nine NCP criteria. At such time, a final remedy selection shall be documented in the Record of Decision (ROD).

40 CFR 300.435 outlines the requirements of remedial design, remedial action, and operation and maintenance activities for CERCLA sites.

For RCRA investigations, a Corrective Measures Study (CMS) will be requested by Federal and state authorities as part of Corrective Action Orders (Section $3008(\mathrm{~h})$ ) and corrective action requirements in permit applications and permits (Section 3004(u)\&(v)). The RCRA proposed rule, Corrective Action for Solid Waste Management Units at Hazardous Waste Management Facilities (40 CFR 264.500-.599) outlines the proposed requirements in performing a CMS and selecting a final remedy (Section 264.520-.525). RCRA generally will require a corrective measures study (CMS) to be undertaken. Therefore, it is appropriate to use available guidance, the proposed regulations, site-specific orders, and other available material to assess compliance.

\section{CRITERIA}

A. Alternatives that meet remedial action objectives for all exposure pathways have been developed. The elements of alternatives have been adequately documented, and reviewed by appropriate DOE and contractor personnel.

B. When appropriate, alternatives have been screened to reduce them to a workable number for final consideration. For CERCLA sites, this screening occurs against the factors of effectiveness, implementability, and cost. Where done, this screening has been adequately documented and reviewed by appropriate DOE and operating contractor personnel.

C. Earh alternative retained after screening has been evaluated against appropriate remedy selection criteria. For CERCLA sites, evaluation occurs in detail against the nine NCP criteria, a comparative analysis of alternatives has been conducted for each criterion, and a preferred remedy has been identified that meets the NCP requirements. The evaluation has been adequately documented and reviewed by appropriate DOE and contractor personnel.

D. For CERCLA sites, the Proposed Plan has been prepared in accordance with the NCP and EPA guidance, the plan has been distributed to all parties, and a public comment period of at least 30 days has been allowed. For RCRA sites, appropriate permit modification or other documentation is prepared to solicit the required public comment.

E. DOE has identified and analyzed other environmental laws and regulations that must be met during the action, and the selected alternative meets these requirements. 


\section{IWS.6 REMOVAL ACTIONS AND INTERIM REMEDIAL ACTIONS}

\section{PERFORMANCE OBJECTIVE}

A program should be in place to implement removal actions or interim remedial actions where warranted to mitigate a threat to public health or welfare or the environment.

DOE 5400.1, General Environmental Protection Program, Section 5a, states that it is DOE policy to correct environmental problems, minimize risks to the environment and public health, and to anticipate and address potential environmental problems before they become a threat to the quality of the environment or the public welfare.

DOE 5400.4, CERCLA Requirements, requires that DOE respond to hazardous substance releases in accordance with CERCLA and the NCP, regardless of whether the facility is listed on the National Priorities List (NPL). DOE responses shall include removal and/or remedial actions, as appropriate.

40 CFR 300.410 and 415 outline the requirements in performing a removal site evaluation and removal action.

40 CFR 300.6 defines removal actions and provides the criteria and methods to be used in performing a removal action.

40 CFR 300.65 specifies that a removal action may be determined necessary at any release, regardless of whether the site is included on the NPL, where the lead agency determines that there is a threat to public health or welfare or the environment. $40 \mathrm{CFR}$ 300.65 also defines the factors to be considered in determining the appropriateness of a removal action.

\section{CRITERIA}

A. Inactive waste sites are reviewed to determine whether there exist actual or potential threats to public health, public welfare or the environment, and whether a removal action is appropriate.

B. A program is in place to implement removal actions where they are determined to be appropriate.

C. The facility has developed adequate programs and procedures for performing removal action, such as interim remedial actions, to minimize potential or existing threats to public welfare and the environment.

D. Removal actions and/or interim remedial actions, which can occur at any time in the preliminary assessment/site investigation (PA/SI) and remedial investigation/ feasibility study (RI/FS) process, consist of limited actions to protect human health and the environment from actual or potential threats while fincl solutions are being developed. 
E. Removal actions and interim remedial actions conform with all reporting, notification, and administrative record requirements under CERCLA and the NCP, operating permits, interagency agreements, and state and local regulations. 


\title{
IWS.7 REMEDIAL ACTION DESIGN AND CONSTRUCTION
}

\section{PERFORMANCE OBJECTIVE}

\begin{abstract}
A program should be in place to complete design, construction, operation and maintenance, and post-closure monitoring associated with implementation of remedial actions.
\end{abstract}

CERCLA Section 121 (d) requires that a remedial action for CERCLA sites must comply with any Federal or state environmental laws or requirements that are applicable or relevant and appropriate requirements (ARARs) at the time the remedial action is complete.

DOE 5400.4, CERCLA Requirements, requires that DOE respond to hazardous substance releases in accordance with CERCLA and the NCP, regardless of whether the facility is listed on the National Priorities List.

DOE 6430.1A, General Design Criteria Manual, contains the controlling criteria for the design of DOE facilities and should be addressed in remedial design and construction at DOE facilities.

40 CFR 264.500 -.599 outlines the proposed requirements for performing Corrective Actions at Solid Waste Management Units at RCRA Hazardous Waste Management Facilities.

40 CFR 300.435 outlines the requirements of remedial design, remedial action, and operation and maintenance activities for CERCLA sites.

\section{CRITERIA}

A. All remedial design and implementation activities for inactive waste sites, such as those taken under CERCLA remedial design (RD) and remedial action (RA) or RCRA corrective measures implementation (CMI), conform with specifications in formal decision documents and design documents. For CERCLA actions, activities conform with the record of decision (ROD), the conditions of an explanation of significant differences (ESD), or the ROD Amendment. For RCRA sites, activities conform to the signed remedy selection document. Any changes to these documents are prepared in accordance with appropriate regulatory review, public notice, and public comment periods.

B. Work Plans are prepared to reflect activities that will occur during remedial actions and are reviewed and approved in accordance with any negotiated agreements.

C. Design and construction documents and schedules for the completion of these documents are specified and met. Remedial construction conforms with these approved documents. These documents typically include technical specifications, drawings, design reports including conceptual, preliminary, pre-final, and final designs, construction quality assurance/quality control plan, health and safety plans, contract bid documents, demonstration of compliance plans, and postclosure site control plans. 
D. Procedures are established for the documentation and approval of field modifications to designs and specifications.

E. Plans are developed (or included as part of appropriate documents) that address operation and maintenance (O\&M) activities, including long-term monitoring, that must occur after remedial construction is complete. The plans include specific responsibilities for $O \& M$ activities and monitoring procedures. All $O \& M$ activities are incorporated into regular site operations, or special procedures are in place to ensure they are implemented.

F. Performance criteria are established against which evaluations can be made to measure long-term effectiveness of the completed remedial action. Additionally, procedures are in place for the implementation of corrective actions.

G. Remedial designs address the criteria provided by DOE $6430.1 \mathrm{~A}$, General Design Criteria Manual. 
IWS.8 NATURAL RESOURCE DAMAGE ASSESSMENTS

\section{PERFORMANCE OBJECTIVE}

Procedures should be in place to assess natural resource damage claims, and to involve natural resource trustees in the planning and implementation of all response actions.

CERCLA Section 104(b)(2), 40 CFR 300.135(j)\&(k), and 40 CFR 300.430(b)(7) require that DOE, as a lead agency, notify and coordinate with other state and Federal Natural Resource Trustees when DOE discovers a discharge or release that may injure natural resources.

DOE 5400.4, CERCLA Requirements, requires that where DOE determines that natural resources (i.e., surface water, groundwater, air, geologic, biologic) for which DOE has been granted trusteeship are or may have been potentially injured by a release, DOE will implement the Natural Resource Damage Assessment (NRDA) process consistent with the requirements set forth in 43 CFR Part II.

DOE 5400.4 further outlines the department's policy of responding to releases of hazardous substances in accordance with the provisions of CERCLA, as well as those of the NCP.

DOE guidance document, "Natural Resource Trusteeship and Ecological Evaluation for Environmental Restoration at DOE Facilities," provides objectives and guidance for DOE in responding to the NCP (40 CFR 300).

40 CFR $300.135(j)$ states that DOE shall "promptly notify the trustees" and "shall seek to coordinate all response activities" with the trustees. 40 CFR $300.430(\mathrm{~b})(7)$ further states that DOE shall seek to coordinate necessary assessments, evaluations, investigations, and planning with state and Federal trustees.

40 CFR 300.600, Subpart G of the NCP, designates trustees for natural resources and describes their responsibilities pursuant to CERCLA Section 107(f), "when there is injury to, destruction of, loss of, or threat to natural resources as a result of a hazardous substance release."

40 CFR $300.410(\mathrm{~g})$ outlines the necessary actions that the lead agency must complete during a removal site evaluation to ensure that state and Federal trustees of affected resources are promptly notified in order that the trustees may initiate appropriate actions, including those identified in 40 CFR 300.600.

\section{CRITERIA}

A. Plans for evaluating natural resource damages that occurred as a result of releases of hazardous substances are incorporated into appropriate scoping, remedial investigation, feasibility study, and remedial design/remedial action (RD/RA) activities. 
B. Compliance with appropriate laws is maintained during natural resource damage assessments. These laws include the Endangered Species Act, the Migratory Bird Treaty Act, the MPRSA, and the Marine Mammal Protection Act.

C. Trustees for natural resources that are not under the jurisdiction of DOE, but that are affected by the site (e.g., other Federal agencies, state trustees), are promptly notified and involved in all aspects of the investigation and response process, as required by the regulations.

D. Comprehensive natural resource surveys of the facility and surrounding property have been performed by the DOE to determine non-DOE natural resource trusteeships.

E. Collection and use of data and information in NRDA, NEPA assessments, and environmental risk assessments are coordinated. Furthermore, baseline environmental studies performed by the facility are reviewed to determine whether natural resources under DOE and non-DOE jurisdiction have been impacted by the facility's operation.

F. Appropriate procedures are developed for NRDA notification, interagency coordination, and assessment of the nature and extent of natural resource damages.

G. Appropriate mitigation, reclamation or other allowable measures are identified, evaluated, and implemented as part of the RI/FS or RFI/CMS, or through other means that are specified in the IAG or FFA. 


\title{
IWS.9 ADMINISTRATIVE RECORD/COMMUNITY RELATIONS
}

\section{PERFORMANCE OBJECTIVE}

\begin{abstract}
An Administrative Record should be established and maintained and community relations activities should be initiated and carried out in accordance with appropriate EPA guidance and CERCLA/NCP requirements.
\end{abstract}

CERCLA Section $113(k)(1)$ and 40 CFR 300.800 , Subpart I of the NCP, describes the requirements for establishing and maintaining the Administrative Record during the RI/FS and RD/RA, including special requirements for such records for Federal facilities, the location of the administrative record, the contents of the records, and its use after the Record of Decision (ROD) is signed.

DOE 5400.4, CERCLA Requirements, requires that DOE respond to hazardous substance releases regardless of whether the facility is listed on the National Priorities List in accordance with CERCLA and the NCP, and that DOE facilities shall "gather information with respect to releases and potentially imminent releases of hazardous substances and maintain a field organization-wide record of all actions taken under this Order, CERCLA, and applicable DOE policies, requirements, and procedures."

40 CFR 124 specifies the public involvement requirements for RCRA permit actions. In addition, orders, agreements, and other signed documents may contain specific public involvement and Administrative Record requirements.

40 CFR 300.155 outlines for CERCLA sites the general functions and responsibilities in developing a community relations program; $.415(\mathrm{~m})$ describes community relations requirements during removal actions; .425 (d) describes the public notice requirements for listing a site on the National Priority List; and .430(c) states the requirements when performing a RI/FS and remedy selection study. 40 CFR 300.435 (c) describes the community relations requirements that must be met during remedial design, remedial action, and operation and maintenance activities.

40 CFR 300.430 (c), requires that the lead agency for CERCLA sites shall, prior to commencing field work for the remedial investigation, prepare a formal community relations plan, establish at least one information repository at or near the location of the response action, and inform the local community of the availability of technical assistance grants.

40 CFR 300.430 (f)(2) and (3) of the NCP describe for CERCLA sites the community relations activities that must occur in conjunction with the preparation and issuance of the proposed remedy and ROD. 40 CFR $300.430(f)(6)$ outlines the requirements after the ROD is signed.

40 CFR 300.820 (a) requires that the lead agency must make the administrative record file available for public inspection when a removal action is appropriate and the planning period before onsite removal activities commence will exceed six months. 
Office of Solid Waste and Environmental Response (OSWER) 9355.3-01 provides guidance in developing and implementing an administrative record.

EPA Handbeok on Community Relations in Superfund - Interim Version, provides a detailed overview of the goals, objectives and requirements necessary to fulfill the community relations program requirements of CERCLA.

\section{CRITERIA}

A. DOE and appropriate contractors have developed a plan for assembling and maintaining an Administrative Record. The plan has been approved by all appropriate parties, and includes the necessary components to allow for the accurate maintenance of all documents, as well as their timely access and retrieval.

B. There are procedures to identify and verify all documents meeting the requirements to ensure that the Administrative Record is complete. Formal procedures and defined responsibilities are established for identifying documents to be contained or submitted to the record.

C. Procedures are in place to evaluate which documents are appropriately considered privileged documents, and the required actions associated with such documents are followed during the assembly and maintenance of the record.

D. The administrative record is located where the general public has access and a formal notification has been made to the public concerning its location.

E. Community relations plans are prepared in a timely manner, and reviewed by all appropriate parties.

F. The need for modifications to the community relations plan is considered at appropriate points in the response process, and any changes that are determined to be required to meet the letter and spirit of the statute and regulations are made in a timely manner. Facility documentation has been developed outlining the duties and responsibilities of each organization and the designation of individuals or offices to whom the community should address concerns.

G. Community relations activities are carried out in a manner that is consistent with the community relations plans, all agreements that are in effect for the response action, and all statutory and regulatory requirements.

H. DOE and contractor management exhibit willingness to be open and forthright with the public regarding all aspects of a remedial or removal program. Community groups are fully informed in a timely manner of actions proposed by the facility, and ample opportunity is provided for commenting on the proposed actions. 
IWS.10 PROPERTY TRANSFER

\section{PERFORMANCE OBJECTIVE}

Property transfer requirements should be followed for property that has had storage or releases of hazardous substances (including radioactive substances) when the property is sold or transferred.

CERCLA Section $120(\mathrm{~h})$ requires that whenever a Federal agency enters into a contract for the sale or other transfer of real property owned by the Federal government and on which any hazardous substance was stored for one year or more or known to have been released or disposed of, the contract must include notice of the type and quantity of such hazardous substance and the time at which such activities took place. Section $120(\mathrm{~h})$ also requires that a certification has been completed before the date of the transfer that states all remedial actions necessary to protect human health and the environment with respect to any such substances remaining on the property. The certification shall also indicate that any additional remedial actions found to be necessary after the date of the property transfer shall be conducted by the Federal facility.

DOE 4300.1A, Real Estate (Real Property) Management, requires that for real property disposed of prior to July 1987, certification be obtained documenting that the property is sufficiently free of radioactivity to permit unrestricted public use.

DOE 4300.1B, Real Property and Site Development Planning, states "field elements" shall keep records up-to-date and that reliability of records is essential to assure that all potential users can obtain current and accurate real property data as needed.

DOE 5400.5, Radiation Protection of the Public and the Environment, Chapter IV, provides radiological protection requirements and guidelines for cleanup of residual radioactive material. . . and release of property.

40 CFR 373 defines the form and manner of the contract notice that must be provided. This notice shall be initiated after the last day of the six month period beginning on April 16,1990 , and the notice only applies when hazardous substances are or may have been stored in quantities greater than or equal to 1,000 kilograms, or the CERCLA reportable quantity found at 40 CFR 302, whichever is greater. Hazardous substances that are also listed under 40 CFR 261.30 as acutely hazardous wastes, and that are stored for one year or more, are subject to the notice requirements when stored in quantities greater than or equal to one kilogram.

The notice required for the known release of hazardous substances applies only when hazardous substances are or have been released in quantities greater than or equal to the substance's CERCLA reportable quantity found at 40 CFR 302. 


\section{CRITERIA}

A. Procedures are in place to evaluate whether property that is transferred to any entity has been evaluated to determine whether hazardous substances were ever stored for more than one year or whether there was any evidence that hazardous substances were released.

B. Appropriate and timely notification is provided to all parties receiving property in accordance with the requirements.

C. Remedial actions have been completed for all property prior to transfer of title. Maps and/or appropriate documentation that outline specific areas of contamination, such as buildings and lands, and the types of contamination present, have been provided to all interested parties.

D. All contracts for the transfer of such property include required notifications and statements. A documentation/record keeping system is developed and maintained for real property as it relates to CERCLA and DOE requirements.

E. Plans and protocols have been developed prior to implementation of cleanup of residual radioactive materials at real properties that are prepared for transfer. 


\section{PERFORMANCE OBJECTIVES AND CRITERIA FOR ENVIRONMENTAL RADIATION PROTECTION}

\section{Overview}

The radiation specialist is responsible for assessing current facility operations with respect to applicable radiological environmental regulations and roE Orders. The overall goal of the assessment is to evaluate the impact of radiological eleases from facility operations to the environment and their contribution to public radiaticn exposure.

Control and management of radioactive materials are governed by the Atomic Energy Act (AEA) of 1954, as amended, the Energy Reorganization Act of 1974, and the Department of Energy Organization Act. Under the authority of these acts, the DOE is responsible for control and management of its activities and facilities using radioactive materials except for certain facilities that are licensed by the Nuclear Regulatory Commission. DOE implements the requirements of these acts through a series of DOE Orders. In addition, DOE is subject to EPA, DOT and other regulations that relate to the radiological protection of the environment. Specific DOE orders and segments of the Code of Federal Regulations (CFR) that are pertinent to the radiation assessment are shown in Table RAD-1. Further, because DOE Orders incorporate by reference ANSI, ASTM, INPO and other standards, such standards should be used in evaluating facilities. Accepted industry practices (NRC Regulatory Guides and NUREGS, as applicable) should also be included in the assessment. Conditions addressed in environmental permits, Federal Facility Compliance Agreements (FFCAs), and Consent Decrees may also be of assistance in identifying potential problems. In addition to specific requirements, the facility's operations must be evaluated on the basis of best management practices (BMPs). BMPs are typically evaluated when statutes or regulations, which often specify only a minimum standard that must be achieved or a broad goal or requirement such as "protection of human health or the environment," do not exist, do not apply directly at the site, or do not describe specific actions that may be required to achieve the broad statutory goal.

The assessment should be conducted using a combination of methodologies, including field observations, interviews, and reviews of site-specific documents. Documents to be reviewed should include such items as maintenance and calibration logbooks, internal and external environmental inspections and audits, facility procedures related to environmental activities, laboratory data, monitoring reports, communications with regulators, internal memoranda pertaining to environmental issues, and reports of facility-specific environmental studies. These resources should be used to assess the facility's current environmental status, identify specific problem areas, and evaluate the adequacy of the DOE and contractor organizations and resources.

The radiation specialist must coordinate extensively with the other technical specialists in order to evaluate the impacts of radiological releases, and with the quality assurance specialist in order to ascertain the quality of radiological data. Coordination also reduces the likelihood of duplication of effort.

Performance Objectives and Criteria (POC) documents, derived from applicable regulations, DOE Orders and industry standards and practices, were prepared for use in evaluating the site's performance against programmatic objectives. A list of the POC developed for the 
environmental radiation protection assessment is shown in Table RAD-2. Each of the POC includes a stated objective; citations of applicable DOE Orders, regulations, and requirements that provide the basis for the POC; and criteria that should be used in evaluating the site's performance against the programmatic objective. 


\begin{tabular}{|c|c|c|}
\hline & $\begin{array}{c}\text { TABLE RAD-1 } \\
\text { LIST OF RADIATION } \\
\text { REGULATIONS/REQUIREMENTS/GUIDELINES }\end{array}$ & \\
\hline $\begin{array}{l}\text { Regulationsil } \\
\text { Requirements! } \\
\text { Guidelines }\end{array}$ & Sections/Title & Authority \\
\hline DOE 5400.1 & General Environmental Protection Program & DOE \\
\hline DOE 5400.3 & $\begin{array}{l}\text { Hazardous and Radioactive Mixed Waste } \\
\text { Program }\end{array}$ & DOE \\
\hline DOE 5400.5 & $\begin{array}{l}\text { Radiation Protection of the Public and the } \\
\text { Environment }\end{array}$ & DOE \\
\hline DOE N5400.9 & Sealed Radioactive Source Accountability & DOE \\
\hline DOE 5480.1B & $\begin{array}{l}\text { Environment, Safety, and Health Programs } \\
\text { and Department of Energy Operations }\end{array}$ & DOE \\
\hline DOE 5480.4 & $\begin{array}{l}\text { Environmental Protection, Safety and Health } \\
\text { Protection Standards }\end{array}$ & DOE \\
\hline DOE 5480.11 & $\begin{array}{l}\text { Radiation Protection for Occupational } \\
\text { Workers }\end{array}$ & DOE \\
\hline DOE 5480.19 & $\begin{array}{l}\text { Conduct of Operations Requirements for } \\
\text { DOE Facilities }\end{array}$ & DOE \\
\hline DOE $5481.1 \mathrm{~B}$ & Safety Analysis and Review System & DOE \\
\hline DOE 5484.1 & $\begin{array}{l}\text { Environmental Protection, Safety, and } \\
\text { Health Protection Information Reporting } \\
\text { Requirements }\end{array}$ & DOE \\
\hline DOE 5500.1A & Emergency Management System & DOE \\
\hline DOE 5500.3 & $\begin{array}{l}\text { Reactor and Non-Reactor Facility Emergency } \\
\text { Planning, Preparedness and Response for } \\
\text { DOE Operations }\end{array}$ & DOE \\
\hline $\begin{array}{l}\text { DRAFT DOE } \\
5500.3 \mathrm{~A}\end{array}$ & $\begin{array}{l}\text { Emergency Planning and Preparedness for } \\
\text { Operational Emergencies }\end{array}$ & DOE \\
\hline DOE $5700.6 C$ & Quality Assurance & DOE \\
\hline DOE $5820.2 A$ & Radioactive Waste Management & DOE \\
\hline DOE $6430.1 \mathrm{~A}$ & General Design Criteria & DOE \\
\hline
\end{tabular}




\begin{tabular}{|c|c|c|}
\hline \multicolumn{3}{|c|}{$\begin{array}{c}\text { TABLE RAD-1 } \\
\text { LIST OF RADIATION } \\
\text { REGULATIONS/REQUIREMENTS/GUIDELINES }\end{array}$} \\
\hline $\begin{array}{l}\text { Regulationst } \\
\text { Requblinements/ } \\
\text { Guidelines }\end{array}$ & Sections Ifitle & Authority \\
\hline DOE/EH-0173T & $\begin{array}{l}\text { Environmental Regulatory Guide for } \\
\text { Radiological Effluent Monitoring and } \\
\text { Environmental Surveillance }\end{array}$ & DOE \\
\hline $\begin{array}{l}\text { DOE Guidance } \\
\text { Document }\end{array}$ & $\begin{array}{l}\text { Procedures in Applying the ALARA Process } \\
\text { for Compliance with DOE } 5400.5 \text { (March } 8 \text {, } \\
1991 \text { ) }\end{array}$ & DOE \\
\hline 10 CFR 20 & Standards for Protection Against Radiation & NRC \\
\hline 10 CFR 34 & $\begin{array}{l}\text { Licenses for Radiography and Radiation } \\
\text { Safety Requirements for Radiographic } \\
\text { Operations }\end{array}$ & NRC \\
\hline 10 CFR 39 & $\begin{array}{l}\text { Licenses and Radiation Safety Requirements } \\
\text { for Well Logging }\end{array}$ & NRC \\
\hline 40 CFR 192 & $\begin{array}{l}\text { Health and Environmental Protection } \\
\text { Standards for Uranium and Thorium Mill } \\
\text { Tailings }\end{array}$ & EPA \\
\hline
\end{tabular}


TABLE RAD-2

\section{PERFORMANCE OBJECTIVES AND CRITERIA FOR} ENVIRONMENTAL RADIATION PROTECTION

RAD.1 Radiation Dose Evaluations

RAD.2 Environmental Radiological Protection and Facility Design

RAD.3 Radiological Environmental Monitoring Program

RAD.4 Evaluation of Unplanned Releases of Radioactive Material

RAD.5 Radioactively Contaminated Liquid Soil-Column Discharges

RAD.6 Decontamination and Decommissioning Program

RAD.7 ALARA Program 


\section{RAD. 1 RADIATION DOSE EVALUATIONS}

\section{PERFORMANCE OBJECTIVE}

A program should be in place to demonstrate compliance with limits for radiation exposure to the public by documentation of an appropriate combination of measurements and calculations.

DOE 5400.5, Radiation Protection of the Public and the Environment, establishes the radiation dose limits included in the following regulations as mandatory environmental protection standards:

10 CFR 712, "Grand Junction Remedial Action Criteria."

40 CFR 61, "National Emission Standards for Hazardous Air Pollutants."

40 CFR 141, "National (Interim) Primary Drinking Water Regulations."

40 CFR 190, "Environmental Radiation Protection Standards for Nuclear Power Operations."

40 CFR 191, "Environmental Radiation Protection Standards for Management and Disposal of Spent Nuclear Fuel, High-Level, and Transuranic Radioactive Waste."

40 CFR 192, "Health and Environmental Protection Standard for Uranium and Thorium Mill Tailings."

DOE 5400.5, Radiation Protection of the Public and the Environment, also sets a limit for exposure of members of the public to radiation sources as a consequence of all routine DOE operations to an effective dose equivalent of $100 \mathrm{mrem} / \mathrm{yr}$. Temporary increases of the dose limit, not to exceed $500 \mathrm{mrem} / \mathrm{yr}$, may be approved by $\mathrm{EH}-1$ where the lower limit is shown to be impractical. This Order also requires that DOE comply with legally applicable regulations (e.g., 40 CFR 61, 141, 191, and 192 and 10 CFR 60, 72, and 71.2) and implementation of the "as low as reasonably achievable" (ALARA) process. Specific requirements are provided for demonstrating compliance with the dose limits.

The Order further states reasonable efforts shall be made to limit dose to members of the public, from multiple sources of radiation to 100 mrem effective dose equivalent, or less, in a year.

DOE 5820.2A, Radioactive Waste Management, establishes an effective dose equivalent to any member of the public from the release of low-level waste.

\section{CRITERIA}

A. Measured and calculated doses to the public have not exceeded the limits of DOE 5400.5 and other applicable regulations. 
B. Public dose limits include all factors considered germane to dose determination. Doses from certain non-DOE sources to members of the public are considered when, in combination with DOE sources, the potential exists for exceeding 10 mrem effective dose equivalent in a year.

C. The highest dose to any member of the public in the vicinity of the site, and collective doses to the public within $80 \mathrm{~km}$ of the site are evaluated and documented at least annually.

D. The responsibility for evaluating potential doses is clearly defined and assigned to an appropriate individual or organizational unit.

E. The program for evaluating dose is formalized through a set of controlled procedures and related documents, and is conducted under a quality assurance program conforming to the requirements of DOE $5700.6 \mathrm{C}$ (see POC QA.1).

F. Dose evaluations consider all potential pathways and are supported with adequate documentation including the recording of all parametric values and the use of proper dose conversion factors.

G. Dose evaluations are as realistic as possible and apply to real individuals but when accurate data are unavailable, estimates are sufficiently conservative such that it is unlikely that the actual dose would exceed the calculated dose.

H. Models used for dose evaluations are appropriate for emission characteristics, environmental conditions, and exposure pathways, and are validated as necessary. Complete documentation of models, input data, default values, and computer programs is provided in a manner that supports the annual site environmental report or other application.

I. Information on demography, land use, and food supplies shall be documented, updated as needed, and used in the calculations.

J. Procedures for evaluating dose address the specific requirements of DOE 5400.5.

K. The reporting requirements of DOE 5400.1, DOE 5484.1, and DOE 5400.5 have been met. DOE-related effective dose equivalent contributions of $10 \mathrm{mrem}$ or more in a year are reported by DOE operators, as required.

L. Except where mandated otherwise (e.g., compliance with 40 CFR Part 61), the assessment models selected for all environmental dose assessments appropriately characterize the physical and environmental situation encountered. The information used in dose assessments is as accurate and realistic as possible.

M. When performing human food chain assessments, a complete set of human exposure pathways is considered, consistent with current methods, and is documented to support the site Environmental Monitoring Plan. 


\section{RAD.2 ENVIRONMENTAL RADIOLOGICAL PROTECTION AND FACILITY DESIGN}

\section{PERFORMANCE OBJECTIVE}

A system should be in place to ensure that environmental radiological protection is considered in the design, construction, use, and modification of facilities in which radioactive materials are handled.

DOE 6430.1A, General Design Criteria, provides specific guidance for incorporating radiological controls, effluent control and monitoring, decontamination and decommissioning, and ALARA principles into facility designs. This guidance applies to new facilities, and to existing facilities that are modified. Most criteria apply to all facilities and there are additional criteria for Special facilities. Special facilities include those facilities that handle radioactive material.

DOE 5481.1B, Safety Analysis and Review System, requires a safety analysis for all operations that involve hazards that are not routinely encountered and accepted in the course of everyday living by the vast majority of the general public. The analysis is required to demonstrate that there is reasonable assurance that the operation can be conducted in a manner that will limit risks to the health and safety of the public and employees, and adequately protect the environment. The Order requires that construction, operation, and subsequent significant modification, including decommissioning be authorized based on a safety analysis. Physical and administrative changes must be evaluated to determine if they increase the risk beyond that previously analyzed and reviewed, and thereby constitute a significant modification.

The Order also contains a backfit provision which requires that ongoing DOE operations be evaluated to determine if a safety analysis is required. Detailed requirements for the review and authorization process for safety analyses of nuclear facilities and reactors are addressed in DOE 5480.5 and DOE 5480.6.

\section{CRITERIA}

A. A formal program is in place which ensures that the applicable environmental protection related general design criteria are incorporated into new facilities or facility modifications during the earliest phases of the project life cycle.

B. A formal program is in place which ensures that all new activities and facilities are evaluated for potential environmental impact during the earliest phases of the life cycle to determine if a safety analysis is required.

C. A formal system is in place to evaluate all changes to facilities or activities that have a safety analysis to ensure that such changes do not constitute a significant modification related to potential environmental impacts.

D. A program is in place to evaluate potential environmental impacts of all existing facilities or activities to determine if a backfit safety analysis is required. 
E. Features and procedures that simplify and facilitate decommissioning are identified during the planning and design phase based upon a proposed decommissioning method as conversion to other use.

F. The responsibility for implementing programs is clearly defined and assigned to an appropriate organizational unit.

G. All programs are conducted under a quality assurance program conforming to the requirements of DOE 5700.6C (see POC QA.1).

H. Safety analyses are prepared by individuals with appropriate environmental protection expertise and consider the full range of operating conditions and credible accidents.

1. Facility designs, operational activities, and safety analyses undergo an independent review and approval by individuals with expertise in applicable areas of environmental protection.

J. Procedures or other formal documents exist which ensure that all administrative controls and preventive or mitigative design features established by the safety analysis are maintained on a day-to-day basis.

K. The environmental aspects of safety analyses are reviewed periodically and updated as necessary.

L. The level of effort is commensurate with the type and magnitude of the environmental hazards involved. 


\section{RAD.3 RADIOLOGICAL ENVIRONMENTAL MONITORING PROGRAM}

\section{PERFORMANCE OBJECTIVE}

A radiological environmental monitoring program should be in place to provide accurate and complete surveillance of the radiological effects of facility operations on the environment.

DOE 5400.1, General Environmental Protection Program, Chapter IV, establishes the requirements and guidance for environmental monitoring programs.

DOE 5400.1, Chapter IV, Section 4, requires that a written environmental monitoring plan shall be prepared by November 11, 1991, for each site, facility, or process that uses, generates, releases or manages significant pollutants, as applicable. The plan shall be reviewed annually and updated every 3 years.

DOE 5400.5, Radiation Protection of the Public and Environment, requires that compliance be based upon information obtained from monitoring and surveillance programs.

DOE 5484.1, Environmental Protection, Safety and Health Protection Information Reporting Requirements, Chapter III, establishes effluent and environmental monitoring program requirements that are similar to those in DOE 5400.1.

DOE/EH-0173T, Regulatory Guide for Radiological Effluent Monitoring and Environmental Surveillance, contains detailed guidance for the development and implementation of effluent monitoring and environmental surveillance programs.

Portions of this $\mathrm{POC}$ require coordination with the specialists for air, surface water, groundwater, waste management, ecological and cultural resources, and quality assurance to avoid duplication of effort and ensure adequate coverage of the POC.

\section{CRITERIA}

A. An evaluation is conducted and used as the basis for establishing an environmental surveillance program for all DOE-controlled sites. For all new or modified facilities coming on-line, a preoperational assessment is made to determine the types and quantities of effluents to be expected.

B. Responsibility for program development, maintenance, and implementation is clearly defined.

C. The program reflects facility characteristics, hazard potential, and quantities and concentrations of materials released. It is conducted in accordance with DOE Orders and other requirements.

D. The program is formalized through a set of controlled procedures and related documents. 
E. The program includes surveillance of onsite media resources such as air, stormwater, groundwater, soil, sediment, flora, and fauna as applicable.

F. The need for environmental sampling and analysis is evaluated, by exposure pathway analysis, for each site radionuclide effluent or emission (liquid or airborne). A critical pathway analysis (radionuclide/media) is performed.

G. Further provisions are made, as appropriate, for the detection and quantification of unplanned releases.

H. The extent and use of affected air, land, and water, and specific local or public interests or concerns are identified, documented, used as a part of the program basis, and periodically reevaluated.

1. All analytical data undergo documented review in an expeditious manner which includes comparison with pre-established lower limits of detection and action levels.

J. The overall accuracy and precision results are estimated, and the approximate Environmental Detection Limit, at a specified confidence level, is determined and documented.

K. All environmental surveillance techniques are designed to take a representative sample or measurement of the important radiation exposure pathway media. Sampling or measurement frequencies take into account the half-life of the radionuclides to be measured.

L. "Background" or "control" location measurements are made for every significant radionuclide and pathway combination that is considered in the dose calculations.

M. Environmental conditions are considered when locating effluent monitoring systems to avoid conditions that will influence the operation of the system.

N. Sampling and monitoring systems are recalibrated with appropriate frequency, and are routinely checked with known sources to determine that they are functioning properly.

O. Continuous monitoring systems, if required, have alarms set to provide timely warnings. The systems are designed to signal the need for corrective actions to prevent public or environmental exposures from exceeding recommended limits.

P. An annual review of the radionuclide composition of effluents or emissions is made and compared with those used to establish the site Environmental Monitoring Plan. A mechanism is established to ensure that the plan is reviewed annually and updated every 3 years.

Q. All operational changes, new facilities, and facility modification are evaluated to determine their impact on the program. The program is modified as needed. 
R. The results of the program are used to demonstrate compliance with DOE Orders and regulatory requirements, confirm adherence to DOE environmental protection policies, and support environmental management decisions.

S. Each program element is conducted under a quality assurance program conforming to the requirements of DOE $5700.6 \mathrm{C}$ (see POC QA.1). As they apply to environmental surveillance activities, the general quality assurance program provisions of DOE/EH-0173T, Chapter 10, are followed.

T. Analytical laboratories participate in the DOE interlaboratory quality assurance program. Contractor laboratories are evaluated to ensure they implement a quality assurance program conforming with DOE $5700.6 \mathrm{C}$ before being allowed to analyze samples (see POC QA.1).

U. When completed, the environmental monitoring plan will be the primary document that defines the program, its basis, and its implementation. 


\section{RAD.4 EVALUATION OF UNPLANNED RELEASES OF RADIOACTIVE MATERIAL}

\section{PERFORMANCE OBJECTIVE}

\section{A program should be in place to evaluate unplanned releases of radioactive materials and to assess the impact of such releases on members of the public and the environment.}

DOE 5500.1A, Emergency Management System, requires the preparation and maintenance of emergency plans, procedures, and capabilities for accidents that involve environmental contamination or the accidental release of radioactive or toxic material.

DOE 5500.3, Reactor and Non-reactor Facility Emergency Planning, Preparedness, and Response for DOE Operations, requires that DOE reactors and nonreactor nuclear facilities develop site-specific emergency plans and procedures for radiological emergencies. It further requires that emergency actions be planned, coordinated, and implemented to respond to the offsite consequences of a radiological emergency to assure the protection of public health and safety, and the environment.

The Order also delineates planning and preparedness requirements in the following areas: organization and assignment of responsibilities; emergency response support and resources; emergency communications; emergency facilities and equipment; accident assessment; protective response; exercises; and training.

Draft DOE 5500.3A, Emergency Planning and Preparedness for Operational Emergencies, provides detailed guidance on development and implementation of emergency management programs including concept of operations, hazards assessment, planning and preparedness, facilities and equipment, and consequence assessment.

DOE 5400.1, General Environmental Protection Program; DOE 5000.3, Unusual Occurrence Reporting System; and Draft DOE 5000.3A, Occurrence Reporting, and Utilization of Operations Information; establish reporting requirements for unplanned releases.

DOE 5820.2A, Radioactive Waste Management, requires contingency plans for the unplanned release of high level, low level, and transuranic waste. These include steps to prevent the further migration of the release to soil or surface water, and remove or stabilize the contaminated soil.

\section{CRITERIA}

A. Formal emergency plans and procedures exist which provide for the assessment of offsite consequences from the unplanned release of radioactive material.

B. Plans and procedures describe the mobilization of field teams, environmental sampling for applicable media, and direct measurements of radioactivity in the environment. 
C. A mechanism is provided to transport field samples to a radiochemistry laboratory for analysis and to transmit the results to the consequence analysis team.

D. Plans and procedures provide for facilities and personnel to dispatch and direct field teams; receive, evaluate, and manage the data from these teams; and assess the consequences to the public and the environment.

E. The roles of each member of the field and consequence analysis teams are formally defined and individuals receive initial classroom training, periodic retraining, and participate in exercises specific to their assigned responsibilities. All training is documented.

F. Facilities, equipment, and supplies are identified, listed in procedures, and are maintained with documented inventory, calibration, and maintenance as applicable.

G. Equipment and supplies are dedicated to emergency use, or a formal mechanism is in place to ensure that the amount and types identified in the procedures are always available.

H. Field and consequence analysis teams have primary and backup communication links identified in the procedures.

1. The consequence analysis team has ready access to real-time and historical effluent monitoring and meteorological information.

J. The consequence analysis team has ready access to safety analyses, hazards information, radioactive inventory, and other similar information for each building.

K. The consequence analysis team has a computer model or documented calculation methods to perform offsite dose projections, initial assessments, extended assessments, post-accident assessments, and back calculation of source terms from field data.

L. The consequence analysis team has formal procedures and methods to evaluate and recommend protective action requirements for the public and the environment.

M. Unplanned releases are reported in accordance with the provisions of DOE 5400.1 , and DOE 5000.3.

N. The emergency management program and procedures are maintained under a quality assurance program conforming to the requirements of DOE $5700.6 \mathrm{C}$ (see POC QA.11. 


\section{RAD.5 RADIOACTIVELY CONTAMINATED LIQUID \\ SOIL-COLUMN DISCHARGES}

\section{PERFORMANCE OBJECTIVE}

\section{Controls should be in place to prevent or phase out the discharge of radioactively contaminated liquids to soil columns.}

DOE 5400.5, Radiation Protection of the Public and Environment, requires that the use of soil columns to retain, by sorption or ion exchange, suspended or dissolved radionuclides from liquid waste streams shall be discontinued at the earliest practicable time in favor of an acceptable alternative disposal means. This requirement is intended to protect the environment from the spread of contamination.

Except as permitted by the provisions in DOE 5400.5, Paragraph II.3e(1), new or increased discharges of radionuclides in liquid waste to active soil columns and virgin soil columns is prohibited after May 8, 1990.

Liquid discharges, even though uncontaminated, are prohibited in inactive release areas to prevent the further spread of radionuclides.

The ALARA process is applicable to all radioactively contaminated liquid releases. The best available technology (BAT) process must be applied to soil-column releases that will continue for indefinite periods.

Soil column release activities shall be documented in a plan that is approved by the Field Office Manager and updated annually in the Waste Management Plan, consistent with the provisions of DOE 5820.2A, Radioactive Waste Management.

\section{CRITERIA}

A. A program is conducted to identify and evaluate all past and ongoing releases of radioactively contaminated liquid to soil columns.

B. The program is formalized through a set of controlled procedures and related documents.

C. Responsibility for program development, maintenance, and implementation is clearly defined.

D. The program includes a mechanism to review all operational changes, new facilities, and facility modifications to determine if they will increase an ongoing soil column release, create a new one, or discharge uncontaminated liquid to an inactive soilcolumn release area.

E. The program includes a plan to discontinue all ongoing soil-column releases at the earliest practicable time. 
F. A plan and schedule for implementing alternate acceptable disposal for all ongoing soil column releases that are not first treated by BAT was submitted to the DOE by August 8, 1990.

G. The plan is approved by the Field Office Manager and the program contains provisions to update it annually in the Waste Management Plan in accordance with DOE 5820.2A.

H. Documentation exists which demonstrates that the BAT and ALARA processes are applied to soil-column releases that contain process-derived radionuclides and will continue for an indefinite period of time.

1. The program contains a mechanism which ensures that new or increased discharges of radionuclides in liquid waste to active or virgin soil columns are prohibited after May 8, 1990.

J. All contaminated soil columns, drainage systems, and groundwater to which contaminated liquid discharges have been discontinued have been identified and are being managed or decontaminated pursuant to the requirements of DOE Orders.

K. The program implements a mechanism which ensures that liquid discharges, even though uncontaminated, are prohibited in inactive release areas.

L. The program is conducted under a quality assurance program conforming to the requirements of DOE $5700.6 \mathrm{C}$ (see POC OA.1). 


\section{RAD.6 DECONTAMINATION AND DECOMMISSIONING PROGRAM}

\section{PERFORMANCE OBJECTIVE}

A program should be in place to manage the decontamination and decommissioning of all facilities.

DOE 5400.1, General Environmental Protection Program, Section 5a, establishes DOE policy to conduct operations in compliance with the letter and spirit of applicable environmental statutes, regulations, and standards. The Order also states that environmental obligations will be carried out consistently across all operations and programs.

DOE 5400.4, CERCLA Requirements, requires that DOE respond to hazardous substance releases in accordance with CERCLA and the NCP, regardless of whether the facility is listed on the National Priorities List.

DOE 5400.5, Radiation Protection of the Public and the Environment, Chapter II, Sections 5.b and 5.c, set forth requirements for the release for reuse of personal property and materials and equipment that could potentially be radioactively contaminated.

DOE 5480.19, Conduct of Oparations, states that it is DOE policy to conduct its operations with a consistent and auditable set of requirements, standards, and responsibilities.

DOE 5820.2A, Radioactive Waste Management, Chapter V, establishes policies and guidelines for the management, decontamination, and decommissioning of radioactively contaminated facilities under DOE ownership or control. Radioactive'y contaminated facilities shall be managed in a safe, cost-effective manner to assure that release of, and exposure to, radioactivity and other hazardous materials comply with Federal and state standards.

DOE organizations shall develop and document their programs to provide for the surveillance, maintenance, and decommissioning of contaminated facilities. Facilities, equipment, and valuable materials shall be recovered and reused when practicable.

40 CFR 192, Health and Environmental Protection Standards for Uranium and Thorium Mill Tailings, establishes standards for control and cleanup of inactive uranium processing sites.

\section{CRITERIA}

A. An effective decontamination and decommissioning (D\&D) program is being conducted.

B. The D\&D program is formalized through a set of controlled procedures and related documents. 
C. The responsibility for implementing the program is clearly defined and assigned to an appropriate organizational unit.

D. The program addresses D\&D requirements for new, operational, and excess facilities.

E. A complete list of contaminated facilities both operational and excess has been prepared and maintained.

F. Operational records (e.g., facility design drawings and modifications, contamination characterization data, prior D\&D activicies, and incident reports) are maintained for all contaminated facilities.

G. The responsible DOE program office is identified and documented for each facility.

H. Excess facilities are placed in a safe storage condition, and adequate surveillance and maintenance are provided.

1. Excess contaminated facilities are identified, the potential for reuse and recovery of materials and equipment is documented, and schedules for decommissioning are developed.

J. All high-level waste and stored hazardous materials are removed by the operator as part of the last operational activities.

K. Prior to initiation of D\&D activities, a Decommissioning Pro;ect Plan is developed and approved consistent with the requirements of DOE O ders and regulatory requirements.

L. D\&D activities are well integrated with environmental restoration activities, including investigations, removal actions and remedial actions at inactive waste sites, to ensure effective implementation and compliance with applicable regulatory requirements. Long-term schedules and priorities are established to ensure that environmental restoration and D\&D programs are completed in an integrated and effective manner and that regulatory requirements are met (see POC IWS.1).

M. D\&D activities are reviewed for environmental compliance requirements, including requirements under CERCLA, RCRA Part B Permits, Interagency Agreements or Federal Facilities Agreements, and state and local regulations and guidelines. $D \& D$ activities are evaluated to determine if they may be considered removal actions or remedial actions under CERCLA.

N. D\&D act vities involving materials which may be contaminated with both radiountive and hazardous waste are integrated with remedial actions under the inactive waste site programs to ensure compliance with CERCLA and other applicable requirements. Additionally, D\&D activities at inactive waste sites which are undergoing environmental restoration activities are reviewed to determine if they may be impacting or may be impacted by environmental restoration activities. 
O. D\&D final project reports are issued and other required post-decommissioning activities are conducted.

P. The D\&D program and all associated activities are conducted under a quality assurance program conforming to the requirements of DOE $5700.6 \mathrm{C}$ (see POC QA.11.

Q. Procedures exist that require potentially contaminated personal property to be surveyed with appropriate instrumentation prior to release for unrestricted use.

R. The D\&D program is conducted in a manner that recognizes ALARA requirements. 


\section{RAD.7 ALARA PROGRAM}

\section{PERFORMANCE OBJECTIVE}

An effective program should be in place to maintain radiation exposures of the public and environment to levels that are as low as reasonably achievable (ALARA) below the appropriate dose limits.

DOE 5400.1, General Environmental Protection Program, states that it is DOE policy to conduct its operations in an environmentally safe and sound manner. It further states that it is DOE policy to conduct operations in compliance with both the letter and the spirit of applicable environmental statutes, regulations, and standards. In addition, it is stated that DOE is committed to good environmental management, and to minimize environmental risks.

DOE 5400.5, Radiation Protection of the Public and Environment, requires all DOE operations to maintain radiation exposures of the public and environment to levels that are ALARA below the applicable limits. The ALARA process is to be applied to all DOE activities that may cause public doses.

DOE Guidance on the Procedures in Applying the ALARA Process for Compliance with DOE 5400.5, dated March 8, 1991, provides interim guidance for the implementation of the ALARA process to protect the public and environment. It is intended to supplement the radiation protection requirements of the DOE 5400 series Orders.

\section{CRITERIA}

A. Responsibilities and authorities associated with developing and implementing the ALARA process are clearly defined and communicated in formal documents.

B. The ALARA program is defined in the Environmental Protection Implementation Plan, or, where additional detail is needed in a separate approved ALARA plan.

C. The ALARA process is implemented through a set of controlled documents such as implementing procedures and work instructions.

D. Goals to reduce, minimize, and/or eliminate releases of radiological effluents are established annually, and results of effluent monitoring are tracked to evaluate progress.

E. The ALARA program addresses the factors and issues defined in the DOE ALARA guidance document.

F. The ALARA process is applied to all activities that might result in radiation doses to the public or the environment.

G. The level of effort directed toward gathering information to support the ALARA process is commensurate with the magnitude of potential doses and costs. 
H. Information gained through routine radiological monitoring or surveillance programs is used to support the ALARA process and evaluate its effectiveness.

1. ALARA decisions ar'a based ur: quantitative and qualitative methods as appropriate and judgmentai sriteria are explicitly defined.

J. ALARA decision processes consider appropriate options and their potential performance.

K. The ALARA der.ision processes are well documented and the documentation creates an effective audit trail.

L. There is a formal system in place to monitor the program effectiveness and implement corrective actions.

M. The ALARA program is subjected to a formal, documented review at least every three years, and revisions made as appropriate.

N. The ALARA process is subject to a quality assurance program that meets the requirements of DOE $5700.6 \mathrm{C}$. 
This page intentionally left blank. 


\section{PERFORMANCE OBJECTIVES AND CRITERIA FOR \\ PRESERVATION AND PROTECTION OF \\ ECOLOGICAL AND CULTURAL RESOURCES}

\section{Overview}

The responsibility of the ecological and cultural resources specialist is to determine whether site activities comply with applicable Federal, state, and local statutes and regulations, DOE Orders, permits, agreements and other legally enforceable requirements that relate to the preservation and protection of ecological and cultural resources.

The primary statutes, regulations and DOE Orders that address the preservation and protection of ecological and cultural resources are the Endangered Species Act, the Coastal Zone Management Act, Executive Order 11988 - Floodplain Management, Executive Order 11990 - Protection of Wetlands, Section 404 of the Clean Water Act, the Migratory Bird Treaty Act, Executive Order 11593 - Protection and Enhancement of the Cultural Environment, the National Historic Preservation Act, the Archaeological Resources Protection Act, and DOE Orders 5400.1 and 5400.5. The National Environmental Policy Act (NEPA) is the primary enforcement tool for protecting ecological and cultural resources, since compliance with each of the many statutes protecting specific types of ecological and cultural resources must be documented during project-specific NEPA reviews. Specific Federal laws, DOE Orders and segments of the Code of Federal Regulations (CFR) that are pertinent to the ecological and cultural resources assessment are shown in Table ECOL-1. In many cases, there also will be important state statutes and regulations that address resource preservation and protection. Finally, the ecological and cultural resources specialist also will review all activities for adherence to best management practices (BMPs). BMPs are typically evaluated when statutes or regulations do not describe specific actions that may be required to achieve their goals, or do not go far enough to preserve and protect ecological and/or cultural resources.

The general approach of the ecological and cultural resources specialist conducting an environmental assessment or audit includes the following information collection activities: (1) review of available documentation, including policy statements, program plans, standard operating procedures, specific site action plans, EPA and state documents related to specific site activities, the results of previous site audits, assessments, or inspections, and inventories of ecological and cultural resources; $(2)$ examination of the activities underway at the site, habitats of protected biota, historic properties, and any measures to preserve and protect these resources; and (3) interviews with DOE, site contractor, and regulatory personnel. Although the scope of the review is not designed to evaluate every aspect of the resource preservation and protection activities, it is designed to review in detail enough of the programs to gain a broad understanding and awareness of the compliance status of the site. This review, therefore, is designed to gain a programmatic understanding of the site to define both the range of compliance activities that may exist and to assess the facility's overall systems for conducting response activities.

Because many Federal laws protect ecological resources indirectly by protecting the physical environmental media upon which the health of biota and ecosystems depends, the ecological and cultural resources specialist will need to work with nearly every one of the other specialists during the course of the assessment or audit. The air, surface water, and 
radiation specialists can provide information on contaminant releases and environmental monitoring plans as they pertain to affected biota and ecosystems. The waste management specialist can be consulted about land farming, soil injection, and other waste disposal methods used by the facility. The toxic and chemical materials specialist can offer information about the facility's programs to manage pesticide use and hazardous substance releases. The inactive waste sites specialist will be a valuable resource regarding the facility's environmental risk and natural resource damage assessments. The quality assurance specialist can offer insights into the QA elements of the facility's sampling programs for physical and biological media of affected ecosystems. Finally, the ecological and cultural resources specialist should coordinate with the NEPA specialist in reviewing NEPA documentation, which will contain baseline inventories of ecological and cultural resources, assessments of project impacts to these resources, and facility-specific plans to mitigate these impacts.

Because of the potentially broad scope and complexity of ecological and cultural resources issues across DOE sites and the myriad environmental regulations and requirements, a series of Performance Objectives and Criteria (POC) documents has been developed to assist the ecological and cultural resources specialist in conducting a programmatically oriented assessment or audit. A list of the POC developed for the ecological and cultural resources assessment is shown in Table ECOL-2. Each of the POC includes a stated objective; citations of applicable DOE Orders, statutes, and regulations; and criteria that should be used in evaluating the site's performance against the programmatic objective. 


\begin{tabular}{|c|c|c|}
\hline \multicolumn{3}{|c|}{$\begin{array}{l}\text { TABLE ECOL-1 } \\
\text { LIST OF ECOLOGICAL AND CULTURAL RESOURCES } \\
\text { REGULATIONS/REQUIREMENTS/GUIDELINES }\end{array}$} \\
\hline $\begin{array}{l}\text { Requilationsl } \\
\text { Requirements/ } \\
\text { Quidelines }\end{array}$ & Sections Titlo & Authority \\
\hline $\begin{array}{l}\text { Executive Order } \\
11593\end{array}$ & $\begin{array}{l}\text { Protection and Enhancement of the } \\
\text { Cultural Environment }\end{array}$ & $\begin{array}{l}\text { National Park } \\
\text { Service (NPS) }\end{array}$ \\
\hline $\begin{array}{l}\text { Executive Order } \\
11988\end{array}$ & Floodplain Management & EPA \\
\hline $\begin{array}{l}\text { Executive Order } \\
11990\end{array}$ & Protection of Wetlands & EPA \\
\hline 16 USC $469-469 c$ & $\begin{array}{l}\text { Historical and Archaeological Data } \\
\text { Preservation Act }\end{array}$ & NPS \\
\hline $\begin{array}{l}16 \text { USC } 470-470 w- \\
6\end{array}$ & National Historic Preservation Act & NPS \\
\hline 16 USC $1451-1464$ & Coastal Zone Management Act & $\begin{array}{c}\text { National } \\
\text { Oceanographic and } \\
\text { Atmospheric } \\
\text { Administration } \\
\end{array}$ \\
\hline 16 USC 1531 & Endangered Species Act & $\begin{array}{l}\text { National Marine } \\
\text { Fisheries Service } \\
\text { (NMFS) and US } \\
\text { Fish and Wildlife } \\
\text { Service (USFWS) }\end{array}$ \\
\hline $\begin{array}{l}42 \text { USC } 4321 \text { et } \\
\text { seq }\end{array}$ & National Environmental Policy Act & $\begin{array}{l}\text { Council on } \\
\text { Environmental } \\
\text { Quality }\end{array}$ \\
\hline DOE 5400.1 & $\begin{array}{l}\text { General Environmental Protection } \\
\text { Program }\end{array}$ & DOE \\
\hline DOE 5400.5 & $\begin{array}{l}\text { Radiation Protection of the Public and } \\
\text { the Environment }\end{array}$ & DOE \\
\hline DOE/EH-0173T & $\begin{array}{l}\text { Environmental Regulatory Guide for } \\
\text { Radiological Effluent and Environmental } \\
\text { Surveillance }\end{array}$ & DOE \\
\hline $\begin{array}{l}\text { DOE Memorandum, } \\
\text { May } 1,1990 \\
\text { Revision } 5\end{array}$ & $\begin{array}{l}\text { Management of Cultural Resources at } \\
\text { Department of Energy Facilities }\end{array}$ & DOE \\
\hline 10 CFR 1022 & $\begin{array}{l}\text { Compliance with Floodplain/Wetlands } \\
\text { Environmental Review }\end{array}$ & DOE \\
\hline
\end{tabular}




\begin{tabular}{|c|c|c|}
\hline \multicolumn{3}{|c|}{$\begin{array}{l}\text { TABLE ECOL-1 } \\
\text { LIST OF ECOLOGICAL AND CULTURAL RESOURCES } \\
\text { REGULATIONS/REQUIREMENTS/GUIDELINES }\end{array}$} \\
\hline $\begin{array}{l}\text { Regulations/ } \\
\text { Requirements/ } \\
\text { Guidelines }\end{array}$ & Sections/Title & Authority \\
\hline $\begin{array}{l}18 \text { CFR } 1312,32 \\
\text { CFR } 229,36 \text { CFR } \\
296, \text { and } 43 \text { CFR } 7\end{array}$ & $\begin{array}{l}\text { Implementing Regulations for the } \\
\text { Archeological Resources Protection Act }\end{array}$ & NPS \\
\hline 25 USC $3001-3013$ & $\begin{array}{l}\text { Native American Graves Protection and } \\
\text { Repatriation Act }\end{array}$ & $\begin{array}{c}\text { Bureau of Indian } \\
\text { Affairs }\end{array}$ \\
\hline 30 CFR 297 & Wild and Scenic Rivers Act Regulations & NPS \\
\hline 33 CFR 230.25 & $\begin{array}{l}\text { Fish and Wildlife Coordination Act } \\
\text { Regulations }\end{array}$ & USFWS \\
\hline 33 CFR $320-324$ & $\begin{array}{l}\text { Section } 404 \text { of the Clean Water Act .. } \\
\text { U.S. Army Corps of Engineers } \\
\text { Regulations }\end{array}$ & $\begin{array}{l}\text { US Army Corps of } \\
\text { Engineers }\end{array}$ \\
\hline 50 CFR 20 & Migratory Bird Treaty Act & USFWS \\
\hline
\end{tabular}


TABLE ECOL-2

\section{PERFORMANCE OBJECTIVES AND CRITERIA FOR \\ PRESERVATION AND PROTECTION OF ECOLOGICAL AND CULTURAL RESOURCES}

ECOL.1 Preservation of Endangered Species and Ecological Resources

ECOL.2 Floodplain Management and Wetlands Protection Program

ECOL.3 Protection and Assessment of Soil and Sediment Resources

ECOL.4 Preservation of Historic and Cultural Resources 


\section{ECOL. 1 PRESERVATION OF ENDANGERED SPECIES AND ECOLOGICAL RESOURCES}

\section{PERFORMANCE OBJECTIVE}

\section{Each DOE facility shall exercise leadership and take action to ensure the inventory, monitoring, preservation, and management of endangered species and ecological resources.}

The National Environmental Policy Act of 1970 (NEPA; 42 USC 4321 et seq.) and DOE's NEPA implementing regulations (10 CFR 1021), require DOE to fully assess and mitigate adverse impacts of its actions/projects on ecological resources, including endangered species, fish, wildlife, wetlands, and other valuable habitat.

DOE 5400.1, General Environmental Protection Program, requires DOE facilities to monitor the effects, if any, of DOE activities on onsite and offsite environmental and natural resources. A priority of the biological surveillance element of the monitoring program is to monitor facility impacts on Federally-protected biota and ecosystems, such as anadromous fish, endangered species, migratory birds, wetlands, floodplains, and other protected habitats.

DOE 5400.5, Radiation Protection of the Public and the Environment, requires that environmental monitoring and surveillance programs demonstrate compliance with dose limits for native animal aquatic organisms, and for foods consumed by humans. This Order also requires that the use of soil columns to attenuate radioactive contamination in liquid effluents be phased out, and imposes related controls on the release of radioactive liquids to protect resources such as land, surface water, ground water, and the related ecosystems from undue contamination.

DOE Guidance Document, DOE/EH-0173T, Environmental Regulatory Guide for Radiological Effluent Monitoring and Environmental Surveillance, contains specific guidance on environmental surveillance requirements, which include monitoring of facility effects on soil, groundwater, surface water, sediments, biota, endangered species, and terrestrial/aquatic foodstuffs, which include agricultural products, game animals, fish and waterfowl.

10 CFR Part 834, Radiation Protection of the Public and the Environment; Proposed Rule, dated March 25, 1993, contains proposed regulations which if approved will codify the general guidance elements and environmental surveillance requirements of DOE facilities for physical media and biota, including endangered species and terrestrial/aquatic foodstuffs, that are contained in DOE Orders 5400.1 and 5400.5, and Guidance Document DOE/EH-0173T.

40 CFR 257, Criteria for Classification of Solid Waste Disposal Facilities and Practices, prohibits solid waste disposal facilities or practices from adversely affecting floodplains and endangered species.

The Endangered Species Act of 1973, as amended, requires DOE to conduct programs to protect and conserve Federally listed endangered and threatened flora and fauna. Any 
DOE action that may affect Federally listed species or their critical habitats requires consultation with the National Marine Fisheries Service (NMFS) and/or the U.S. Fish and Wildlife Service (USFWS), as the two services share responsibility for administering the Act.

The Fish and Wildlife Coordination Act requires DOE to consult with the NMFS and/or the USFWS (trustees), regarding DOE facility impacts to Federally protected fish and wildlife resources.

The Sikes Act requires DOE facilities to execute cooperative plans with the USFWS and the state to manage and conserve fish and wildlife resources. It allows facilities to charge fees for hunting and fishing permits, and requires that they be used for fish and wildlife conservation programs on site.

The Fish and Wildlife Conservation Act of 1980 promotes state programs for the purpose of conserving, restoring, or otherwise benefiting nongame fish and wildlife, their habitats, and their uses.

The Wild and Scenic Rivers Act of 1968 prohibits the use of Federal funds for activities that would have an adverse affect on those characteristics that caused a river to be classified as wild, scenic, or recreational.

The Coastal Zone Management Act of 1972 establishes national policy pertaining to the coordinated Federal, state, and local management of natural resources of the coastal zones of the United States, including wetlands, floodplains, fish and wildlife, and their habitats. DOE development activities in the coastal zone must be consistent with state Coastal Zone Management Plans established pursuant to CZMA.

The Marine Protection, Research, and Sanctuaries Act of 1972 implements the provisions of international conventions on ocean dumping and marine pollution, to which the United States is a signatory. Title I of the MPRSA prohibits ocean dumping of solid, hazardous, medical, and radioactive wastes without a permit. Title III provides for the establishment of national marine sanctuaries that are afforded special protection and management programs.

The Marine Mammal Protection Act prohibits the illegal taking of marine mammals, irrespective of whether or not they are protected under the Endangered Species Act. The environmental monitoring plans of coastal DOE facilities should ensure that facility effects on marine mammals are monitored and mitigated to the fullest extent practicable.

The Migratory Bird Treaty Act protects migratory birds, their nests, and eggs. Construction, repairs, inadvertent poisoning, and other such actions that can harm nests, eggs, or individuals are covered under the act. A depredation permit is required before any person may take, possess, or transport migratory birds, or disturb their nests, eggs, or young.

The Draft United Nations Convention on Biodiversity, presented in June 1992 at the United Nations Conference on the Environment and Development, in Rio de Janeiro, Brazil, promotes the conservation of biological diversity, restoration of damaged ecosystems, recovery of threatened and endangered species, and the sustainable use of biological resources. The United States is a signatory to the Convention. 
Executive Order 11987, Exotic Organisms, requires executive agencies to restrict the introduction of exotic species into natural ecosystems which they own or lease and encourages the states to prevent such introductions.

Executive Order 11989, Use of Off-Road Vehicles on The Public Lands, specifies that ORVs may not be used except in specifically-designated areas within public lands.

Portions of this POC require coordination with the SW, TCM, IWS, Rad, QA, and NEPA specialists to avoid duplication of effort and ensure adequate coverage of the POC.

\section{CRITERIA}

A. The facility maintains a current file of applicable Federal, state, and local regulations pertaining to the protection and management of ecological resources.

B. Facility NEPA reviews/documents have adequately documented the presence, locations, and diversity of aquatic, wetland, and terrestrial flora, fauna, and ecosystems, and have assessed adverse facility impacts on these ecological resources, to the maximum extent practicable (see POC NEPA.1).

C. The facility has performed a Baseline Assessment of Threatened and Endangered Species (BATES) and/or NEPA review for any activities potentially affecting any Federally-listed endangered or threatened species occurring onsite, in consultation with appropriate Federal (USFWS or NMFS) and/or state agencies (e.g. Natural Heritage Program), and conducts approved programs for the protection and management of the species and its critical habitat.

D. The facility consults state and Federal agencies annually, both to obtain updated reports of new listings and/or local sightings of Federally- and state-listed endangered and threatened species of flora and fauna, and to select appropriate protected species for inclusion in biological surveillance programs.

E. The facility has a program for the management and protection of fish and wildlife, and where appropriate, has installed protective, exclusionary devices and migration corridors.

F. The facility uses baseline ecological resource inventories, included in facility-specific NEPA documents and/or environmental risk assessments (see POC IWS.4), to design customized, facility-specific programs for the monitoring, preservation, and management of biological diversity and natural ecosystems.

G. Biological surveillance plans and programs are adequate to demonstrate compliance with laws and regulations protecting biota, ecosystems, and related ecological resources.

H. Biological surveillance plans and programs include the sampling and analysis of biota for facility-derived pollutants where appropriate, and adequately monitor facility impacts to protected biota and their habitats (see POC RAD.3). 
I. Surface water sampling locations/methods, parameters, and analytical detection limits are adequate to assess the ecological risks of adverse toxicological effects of facility-derived contaminants (effluents) on aquatic biota and food chains (see POC SW.3, IWS.4, RAD.3, and QA.4).

J. Facility environmental surveillance programs include the sampling and analysis of agricultural products of plant and animal origin, collected within a $16 \mathrm{~km}$ radius of the facility, to monitor the presence and concentrations of facility-derived radionuclides (see POC RAD.3).

K. Data on the extent of facility-derived chemical and radionuclide contamination in physical and biological media are incorporated into baseline assessments of environmental risks to human and ecological receptors (see POC IWS.4 and RAD.3).

L. Land, water resource, vegetation, and pest management plans and operations are consistent with modern conservation and land use principles, provide measures for the conservation of biological diversity, and minimize adverse effects of pesticides on biota and ecosystems (see POC TCM.3).

M. Facility activities have not adversely affected or altered those ecological features of Wild and Scenic Rivers upon which their national registration was based.

N. The facility carefully monitors and restricts onsite recreation, hunting, trapping, and fishing in natural habitats, in accordance with Federal and state regulations. 
This page intentionally left blank. 


\section{ECOL. 2 FLOODPLAIN MANAGEMENT AND WETLANDS PROTECTION PROGRAM}

\section{PERFORMANCE OBJECTIVE}

Each DOE facility shall exercise leadership and develop effective management plans and programs to prevent damages from DOE operations to the ecological functions of floodplains and waters of the United States, including wetlands.

Executive Order 11988, Floodplain Management, requires rigorous evaluation of any proposed action taking place within floodplains. Such actions must be taken in compliance with flosdplain management guidance proposed by the U. S. Water Resources Council (40 FR 6030, February 10, 1978).

Executive Order 11990, Protection of Wetlands, requires all Federal agencies to issue procedures for ensuring that wetlands protection issues are considered in all decisionmaking activities. Existing procedures such as those established to implement NEPA shall be modified to include wetlands protection and management.

The Migratory Bird Treaty Act of 1918 (Public Law 65-186; as amended) provides protection for migratory birds that migrate between the United States and Canada, Mexico, Japan, or the (former) USSR. Although focused mostly on the deliberate taking of birds by hunters (50 CFR 20), penalties also exist for killing migratory birds by any means, including their accidental death by inadvertent poisoning.

The Convention on Wetlands of International Importance especially as Waterfowl Habitat, more commonly known as The Ramsar Convention of 1971 requires the United States to identify, register, and protect wetlands of international importance to waterfowl.

The Coastal Zone Management Act of 1972 (CZMA) establishes national policy for the coordinated Federal, state, and local management of natural resources in the coastal zones of the United States, including wetlands, floodplains, fish and wildlife, and their habitats. DOE development activities in wetlands and floodplains of the coastal zone must be consistent with the Coastal Zone Management Plans established by the states pursuant to CZMA.

DOE 5400.1, General Environmental Protection Program, requires that biological surveillance be incorporated into a comprehensive environmental surveillance program that addresses both radiological and non-radiological contaminants released from DOE facilities, in order to monitor the effects of DOE activities on the local environment and natural resources.

10 CFR 1022, Compliance with Floodplain/Wetlands Environmental Review Requirements, mandates that DOE sites avoid long- and shori-term adverse impacts associated with the destruction of wetlands and the modification or occupancy of wetlands and floodplains. Wetland and floodplain development are to be avoided whenever and wherever there is a practicable project alternative. 
33 CFR 320-324, U.S. Army Corps of Engineers (COE) Regulations under Section 404 of the Clean Water Act, outlines the permit requirements and regulations for dredging and/or filling of "waters of the United States," which include vegetated wetlands. The Section 404 public interest review also must consider DOE project impacts to aesthetics, economics, land use, recreation, shore erosion, water quality, and wetland, fish, and wildlife resources.

33 CFR 320, U. S. Army Corps of Engineers Permit Program Regulations, emphasizes the requirement that floodplain development be considered as a last resort, to be avoided where other appropriate alternatives exist.

40 CFR 230, Guidelines for Specification of Disposal Sites for Dredge and Fill Material [Section 404(b)(1)], describes requirements for managing wastes from dredging and filling operations. Subpart B establishes restrictions on disposal at special aquatic sites, and these sites (further described in Subpart E) include wetlands, mud flats, vegetated shallows, and riffle and pool complexes.

A "no net loss policy" for the nation's wetlands, effective as of January 31, 1990, was jointly established in a November, 1989 Memorandum of Agreement by the U.S. Environmental Protection Agency and the COE. This policy requires that destruction of wetlands be avoided whenever possible, especially in cases where less damaging alternatives to destructive projects are available.

Many states have wetland protection laws and regulations that are administered independently of the Section 404 provisions of the Clean Water Act cited above.

\section{CRITERIA}

A. Required programs for floodplain management and wetlands protection have been developed in formal documents following guidelines established in the applicable regulations or Executive or DOE Orders.

B. The floodplain management program shall incorporate as its goals:

- no net loss of natural flood storage capacity on- or offsite;

- identification, evaluation, preservation, enhancement, and/or restoration of the natural ecological and beneficial societal functions provided by floodplains;

- $\quad$ avoidance, whenever possible, of building construction and other projects within floodplains, so as to reduce human health and safety hazards from flooding;

- consultation with the COE regarding projects in floodplains;

- implementation, whenever possible, of project siting or design alternatives which will avoid, minimize, or mitigate adverse impacts to the floodplain; 
- minimization of actual impacts from floods on human health, safety, and welfare; and

- $\quad$ construction of any necessary structures to be in accordance with criteria set forth in regulations promulgated by the Federal Insurance Administration pursuant to the National Flood Insurance Act of 1968, as amended.

C. The wetlands protection program shall:

- identify, preserve, manage, and enhance the natural habitat features and beneficial functions of wetlands as specified in the 404(b)(1) guidelines;

- avoid impacts to onsite and site-affected wetlands whenever possible;

- (for unavoidable project impacts) minimize the destruction, loss, or degradation of wetlands and provide functionally-effective mitigation;

- $\quad$ identify and ensure facility compliance with wetland impact mitigation and monitoring requirements of Federal, state, and local wetland permits; and

- ensure that routine monitoring of wetland biota is integrated as part of the facility's biological surveillance program.

D. Responsibilities, authorities, and accountabilities for these programs are clearly defined, and each individual responsible for action is positively identified.

E. Floodplain and wetland management plans and program elements have been reviewed and concurred with by the facility's senior environmental managers.

F. Appropriate permits from the COE have been obtained for dredging activities and work in waters of the U.S., including wetlands.

G. Biological monitoring requirements of DOE 5400.1 and/cr the facility's permits have been satisfied.

H. Suitable erosion and sediment control practices are used on land undergoing clearing, grading, or other development activities, to ensure that these activities will not adversely affect adjacent floodplains, wetlands, or surface waters.

I. The required assessments and evaluations are performed in a logical, practical manner, and all options or alternatives have been included for consideration.

J. All steps in floodplain and wetland related decision-making are documented so that public review of plans and proposals for action may proceed effectively.

K. Adequate measures are taken to protect migratory birds and their habitats from poisoning and/or hunting on DOE property. 
L. The facility has obtained a Certificate of Consistency with the state's Coastal Zone Management Plan, for projects located in wetlands, floodplains, or other coastal land areas.

M. Environmental risk assessments (see POC IWS.4) and natural resource damage assessments (see POC IWS.8) conducted by the facility have adequately addressed risks and/or damages to wetland and floodplain ecosystems and their biota.

N. Baseline ecological data contained in facility-specific NEPA documents are used to develop site-specific floodplain and wetland management programs, in order to ensure implementation of the long-term impact mitigation measures originally proposed in these same NEPA documents (see POC NEPA.1). 


\title{
ECOL.3 PROTECTION AND ASSESSMENT \\ OF SOIL. AND SEDIMENT RESOURCES
}

\section{PERFORMANCE OBJECTIVE}

\begin{abstract}
A comprehensive program should be conducted to inventory, ecologically characterize, conserve, and monitor facility effects on the quality of soil and sediment resources.
\end{abstract}

The Federal Insecticide, Fungicide, and Rodenticide Act (FIFRA), as amended by the Federal Environmental Pesticide Control Act of 1972 (P.L. 92-516), recommends proper disposal methods for pesticides (40 CFR 165.8), including disposal in landfills and by injection into soil.

Section 108 of the Uranium Mill Tailings Radiation Control Act of 1978 (40 CFR Part 192) establishes health and environmental protection standards for uranium and thorium mill tailings, including standards for control and cleanup of residual radioactive material in buildings and soil.

DOE 5400.1, General Environmental Protection Program, requires a written environmental monitoring plan and program, designed to: (1) monitor the effects, if any, of DOE activities on onsite and offsite environmental and natural resources; (2) characterize and define trends in the physical, chemical, and biological condition of the environmental media; (3) establish baselines of environmental quality; and (4) identify and quantify new or existing environmental quality problems. The Order states further that ambient water quality monitoring should be conducted through a network of fixed stations from which data will establish well defined histories of the physical, biological, and chemic ' conditions of local bodies of water and sediments.

DOE 5400.5, Radiation Protection of the Public and the Environment, requires facility environmental monitoring and surveillance programs to demonstrate compliance with radioactive effluent treatment and discharge standards that are designed to protect ground water and prevent radionuclide buildup in soils and sediments. This Order also requires phase out of the use of soil columns to attenuate radioactive contamination in liquid effluents, and requires that soil columns contaminated with radioactive material be managed or decontaminated pursuant to the procedures and requirements of DOE 5480.14 .

DOE Guidance Document, DOE/EH-0173T, Environmental Regulatory Guide for Radiological Effluent Monitoring and Environmental Surveillance, contains specific guidance on environmental surveillance requirements, which include monitoring of facility effects on soil, groundwater, surface water, sediments, biota, endangered species, and terrestrial/aquatic foodstuffs. This is a cumpanion document to the regulations proposed under 10 CFR Part 834, discussed below, which outline DOE facility environınental surveillance requirements.

7 CFR 658, the Farmland Protection Policy Act of 1981, minimizes the extent to which Federal programs contribute to the unnecessary conversion of farmland to non-agricultural use. 
10 CFR Part 834, Radiation Protection of the Public and the Environment; Proposed Rule, dated March 25, 1993, contains proposed regulations which if approved will codify the general guidance elements and environmental surveillance requirements of DOE facilities for physical media and biota, including endangered species and terrestrial/aquatic foodstuffs, that are contained in DOE 5400.1 and 5400.5, and Guidance Document DOE/EH-0173T.

40 CFR 257, Criteria for Classification of Solid Waste Disposal Facilities and Practices, regulates the disposal of sludge by application to land used for the production of foodchain crops, on the basis of waste constituents and soil chemistry of the receiving area.

40 CFR 761.120-761.125 outlines EPA policy regarding the reporting, disposal, and precleanup sampling requirements for the release of materials containing polychlorinated biphenyls (PCBs) at concentrations of $50 \mathrm{ppm}$ or greater, as well as establishing criteria that EPA will use to evaluate the adequacy of PCB cleanup efforts.

Portions of this POC require coordination with nearly every one of the other specialists to avoid duplication of effort and ensure adequate coverage of the POC.

\section{CRITERIA}

A. Facility-specific NEPA documents adequately characterize and map soil and sediment resources of all terrestrial, wetland, and aquatic ecosystems onsite and in offsite areas potentially affected by facility-derived contaminants.

B. The use of soil columns to retain and attenuate radioactive contaminants contained in facility effluent has been and/or is being discontinued, in accordance with DOE 5400.5, regulations proposed under 10 CFR Part 834, and DOE Guidance Document DOE/EH-0173T.

C. The facility has a written environmental monitoring plan and program, pursuant to DOE 5400.1, that incorporates all elements needed to monitor facility effects on soil and sediment quality, as outlined in DOE Guidance Document DOE/EH-0173T.

D. The facility's environmental monitoring program includes soil and sediment sampling locations in all areas potentially affected by atmospheric deposition, discharges of contaminated groundwater (seeps), and/or facility effluent to surface water resources.

E. Agricultural soils and sediments associated with marine and freshwater fisheries (aquatic foodstuffs), located within $16 \mathrm{~km}$ of the facility, are monitored for sitederived radionuclides as part of the environmental surveillance program.

F. Written soil and sediment sampling protocols and analytical methods include appropriate quality assurance elements and are strictly adhered to as part of the facility's environmental surveillance program.

G. The facility's environmental surveillance program monitors the impacts of sitederived contaminants, and annual environmental reports document these impacts, 
on both the physicochemical and biological characteristics of soil and sediment resources.

H. Land-farming and/or soil injection methods used for disposal of sludges, pesticides, radionuclides, and other wastes are conducted in compliance with applicable Federal and state regulations, and DOE Orders.

I. Cleanup criteria established for chemical and radiological contaminants in soils and sediments are based on applicable Federal and state regulations, DOE Orders, and assessments of human health and ecological risks, such that any residual soil or sediment contamination following cleanup will pose no significant human health or ecological risk.

J. A protective vegetative cover or other measure is used to conserve soils, minimize dust-induced damages to air quality, prevent erosion-mediated contaminant migration off site, and/or preclude siltation damages to aquatic ecological receptors. 


\section{ECOL.4 PRESERVATION OF HISTORIC AND CULTURAL RESOURCES}

\section{PERFORMANCE OBJECTIVE}

\section{Each DOE facility shall exercise leadership and take actions to ensure the preservation of historic and cultural resources.}

Executive Order 11593 of May 13, 1971, Protection and Enhancement of the Cultural Environment directs Federal agencies to provide leadership in preserving, restoring, and maintaining the historic and cultural environment of the nation; to locate, inventory, and nominate all eligible properties under their control to the National Register; and to ensure the preservation of these cultural resources pending their inventory and evaluation for listing in the National Register.

The American Indian Religious Freedom Act of 1978 states the policy of the United States to protect and preserve for American Indians their inherent rights of freedom to believe, express, and exercise the traditional religions of the American Indian, Eskimo, Aleut, and native Hawaiians.

The Antiquities Acl of 1906 protects and regulates scientific study of historic and prehistoric ruins, objects of antiquity, and paleontological resources located on Federal lands.

The Archaeological Resources Protection Act of 1979 and its implementing regulations prohibit the excavation, damage, alteration and trade of archaeological resources obtained illegally from public or Indian lands, and authorizes agency permit procedures for archaeological investigations on public lands under agency control.

The Historic Sites Act of 1935 authorizes the designation of national historic sites and landmarks, and interagency efforts to preserve historic resources.

The Historical and Archeological Data-Preservation Act directs Federal agencies to notify the Secretary of the Interior when they find that any Federal construction project or Federally licensed activity or program may cause irreparable loss or destruction of significant scientific, prehistorıc, historical, or archaeological data.

The National Historic Preservation Act of 1966, as amended establishes historic preservation as a national policy, defines its elements, and specifies guidelines for preservation of significant American cultural and historic resources. Regulations (36 CFR 800) pursuant to Section 106 provide direction for Federal agencies whose actions affect properties on or eligible for the National Register. Section 110 requires Federal agencies to locate, inventory, and nominate all properties that may qualify for the National Register.

The Native American Graves Protection and Repatriation Act requires Federal agencies to establish procedures for identifying Native American groups associated with cultural items on Federal lands, to inventory human remains and associated funerary objects in Federal possession, and to return such items, upon request, to the affiliated groups. 


\section{CRITERIA}

A. The facility maintains a current file of applicable Federal, DOE, and state/local regulations for the protection and management of cultural and historic resources.

B. The facility has a program to locate, inventory, and nominate to the Secretary of the Interior all properties under the Department's ownership or control that appear to qualify for inclusion on the National Register of Historic Places.

C. The facility takes measures to identify Native American graves and artifacts, protect them, and cooperate with state- or federally-sanctioned Native American organizations in determining tribal affiliation(s) of the remains and artifacts so they may eventually be returned.

D. The facility consults with the State Historic Preservation Officer (SHPO) during the identification, location, and evaluation of historic properties and in assessing the effect of any undertaking on historic property.

E. If the site contains historic properties that are listed or may be eligible for listing on the National Register, it prepares an Historic Preservation Plan, in consultation with the SHPO, that satisfies applicable federal, state, and local requirements.

F. If the facility does not have any properties eligible for listing on the National Register or that meet the criteria of the National Register, it has obtained a letter from the SHPO agreeing there are no significant historic properties.

G. Facility-specific NEPA docurnents have adequately identified project impacts to archaeological, cultural, and historic resources. Mitigation plans committed to in NEPA documents and/or permits have been successfully implemented by the facility (coordinate review with NEPA specialist).

H. Prior to the start of a new undertaking, the facility takes into account the effects of the undertaking on property included in or eligible for the National Register of Historic Places.

1. The facility has not excavated, removed, or disturbed public lands or Indian lands without obtaining and complying with an appropriate permit.

J. All historic buildings are protected and conserved to mitigate adverse effects of natural deterioration and to eliminate negligence and improper repair.

K. Designated personnel are appropriately qualified and/or adequately trained for the responsibilities of cultural and historic resource preservation and management, and all training is documented.

L. If the facility has responsibilities for the long-term management and preservation of pre-existing and new archeological and paleontological collections, museum conservators inspect the collections periodically for possible deterioration and damage, and inventory the material remains and associated records. 
This page intentionally left blank. 


\section{PERFORMANCE OBJECTIVES AND CRITERIA FOR ENVIRONMENTAL QUALITY ASSURANCE}

\section{Overview}

The responsibility of the quality assurance (QA) specialist is to evaluate a facility's environmental programs, procedures, and practices to ensure quality. Of particular concern is the capability of these programs, procedures, and practices to meet regulatory requirements in an accurate, efficient, and cost-effective manner; and to produce, report, and maintain environmental data that is accurate, representative, and reliable.

DOE 5400.1, General Environmental Protection Program, requires that a quality assurance program (QAP), consistent with DOE 5700.6B, Quality Assurance, be established covering environmental monitoring and surveillance programs. DOE 5700.6B was superseded by DOE 5700.6C, Quality Assurance, on August 21, 1991. The requirements of DOE $5700.6 \mathrm{C}$ are applicable to the work performed by all DOE Elements and Management and Operating (M\&O) contractors as provided by law and or contract and as implemented hy the Contracting Officer. New QAPs require approval by DOE prior to commencement of work. QAPs in existence prior to August 21, 1991 should have been revised to conform to DOE 5700.6C and submitted to DOE for approval by February 21, 1992. Specific DOE orders, segments of the Code of Federal Regulations (CFR), and other guidance that are pertinent to the quality assurance assessment are shown in Table QA-1.

The general approach of the QA assessment/audit includes the following: (1) discussions and interviews with all levels of facility staff involved with environmental activities;

(2) review of documentation, including QA policies and procedures, work instructions, field documentation, environmental records, and any Memorandums of Understanding/ Agreement between the facility and regulators or DOE Headquarters; (3) observation of environmental program activities; and (4) evaluation of QA practices and organizational structure.

The QA specialist should interact and work closely with all other technical specialists on the assessment/audit to ensure that all technical issues are examined in sufficient detail to obtain information about prograrnmatic $Q A$ issues.

Performance Objectives and Criteria (POC) documents have been prepared to guide the $\mathrm{QA}$ specialist in conducting a programmatic assessment or audit. These POC, listed in Table QA-2, have as their common basis the requirements of DOE 5400.1 and DOE 5700.6C. Each of the POC includes a stated objective; citations of applicable DOE Orders, regulations, and requirements that provide the basis for the POC; and criteria that should be used in evaluating the site's performance against the programmatic objective. 


\begin{tabular}{|c|c|c|}
\hline \multicolumn{3}{|c|}{$\begin{array}{c}\text { TABLE QA-1 } \\
\text { LIST OF QUALITY ASSURANCE } \\
\text { REGULATIONS/REQUIREMENTS/GUIDELINES }\end{array}$} \\
\hline $\begin{array}{l}\text { Regulationst } \\
\text { Requirementsf } \\
\text { outidelines }\end{array}$ & Sections/Title & Authority \\
\hline DOE 1324.5A & Records Management Program & DOE \\
\hline DOE $1330.1 \mathrm{C}$ & Computer Software Management & DOE \\
\hline DOE 5400.1 & General Environmental Protection Program & DOE \\
\hline DOE 5480.19 & $\begin{array}{l}\text { Conduct of Operations Requirements for DOE } \\
\text { Facilities }\end{array}$ & DOE \\
\hline DOE 5482.1B & $\begin{array}{l}\text { Environmental, Safety and Health Appraisal } \\
\text { Program }\end{array}$ & DOE \\
\hline DOE $5700.6 \mathrm{C}$ & Quality Assurance & DOE \\
\hline DOE/EH-0173T & $\begin{array}{l}\text { Environmental Regulatory Guide for } \\
\text { Radiological Effluent Monitoring and } \\
\text { Environmental Surveillance }\end{array}$ & DOE \\
\hline 40 CFR 261 & Identification and Listing of Hazardous W-ste & EPA \\
\hline EPA-570/9-90-008 & Manual for the Certification of Laboratories & EPA \\
\hline EPA-600/4-79-019 & $\begin{array}{l}\text { Guidelines Establishing Test Procedures for } \\
\text { the Analysis of Pollutants }\end{array}$ & EPA \\
\hline QAMS-005/80 & $\begin{array}{l}\text { Interim Guidelines and Specifications for } \\
\text { Preparing QA Project Plans }\end{array}$ & EPA \\
\hline QAMS-004/80 & $\begin{array}{l}\text { Guidelines and Specifications for Preparing } \\
\text { QA Program Plans }\end{array}$ & EPA \\
\hline SW-846 & $\begin{array}{l}\text { Test Methods for the Evaluation of Solid } \\
\text { Waste, Physical/Chemical Methods }\end{array}$ & EPA \\
\hline AL 5700.6B, Rev. II & General Operations Quality Assurance & $A L$ \\
\hline ASME NQA-1-1989 & $\begin{array}{l}\text { Quality Assurance Program Requirements for } \\
\text { Nuclear Facilities }\end{array}$ & ASME \\
\hline
\end{tabular}


TABLE QA-2

\section{PERFORMANCE OBJECTIVES AND CRITERIA FOR}

ENVIRONMENTAL QUALITY ASSURANCE

QA.1 Quality Assurance Program

QA.2 Audits/Appraisals/Surveillance

QA.3 Procedures

QA.4 Laboratory and Field Quality Assurance 


\section{QA.1 QUALITY ASSURANCE PROGRAM}

\section{PERFORMANCE OBJECTIVE}

An effective environmental quality assurance (QA) program and a $Q A$ organization addressing all environmental protection programs and activities should be in effect.

DOE 5400.1, General Environmental Protection Program, Chapter IV, Section 10, requires that a quality assurance program consistent with DOE 5700.6B (superseded by DOE $5700.6 \mathrm{C}$ on August 21,1991 with an implementation period of 180 days) be established covering each element of environmental monitoring and surveillance programs commensurate with its nature and complexity. The quality assurance program is required to include, but not be limited to, eleven key elements defined in the Order.

DOE 5700.6C, Quality Assurance, requires that quality assurance programs be established for DOE activities. It describes 10 Quality Assurance Criteria that must be included in a quality assurance program, and states that ANSI/ASME Nuclear Quality Assurance-1 (NQA-1) is the preferred standard for quality assurance in the nuclear area. New quality assurance programs (QAP) require approval of DOE prior to the commencement of work and existing QAPs are required to be revised to conform to DOE 5700.6C and submitted to DOE for approval by February 21, 1992.

DOE 5820.2A, Radioactive Waste Management, requires that radioactive wastes be managed in a manner consistent with the quality assurance provisions of DOE $5700.6 \mathrm{E}$ (superseded by DOE 5700.6C on August 21, 1991 with an implementation period of 180 days) and ANSI/ASME NQA-1.

DOE 1324.5, Records Management Program.

th the DOE policy for records management programs. Section 5.b. 2 requires jevelopment and application of standards, procedures, techniques, and technology designed to ensure the maintenance, security, and preservation of and access to records of continuing value. Section 6.b.2 requires that departmental records be maintained and used in an effective, efficient, and authorized manner.

\section{CRITERIA}

A. The maintenance, security, preservation of, and appropriate access to records is ensured. The environmental quality assurance program is formalized in a controlled set of documents such as quality assurance manuals, quality assurance plans, and implementing procedures.

B. The program documentation addresses the elements listed in DOE 5400.1 and DOE 5700.6C.

¿. The organizational structure, functional responsibilities, and lines of authority are clearly defined. 
D. Quality assurance personnel report to a level of management that provides the required authority and organizational freedom, including sufficient independence from cost and schedule considerations.

E. Personnel have received training in their responsibilities for environmental quality assurance, and continue to be provided with training to ensure that job proficiency is maintained. All training is documented.

F. Program documents identify the activities and organizational units to which they apply.

G. Program documentation has a level of detail appropriate for the organizational unit or activity to which it applies.

H. The quality assurance program covers all environmental protection programs and activities to an extent consistent with their importance.

I. The quality assurance program includes a system for formal document control governing such activities as document transmittal, distribution, maintenance, and disposition.

J. Environmental records are managed in accordance with a formal program that satisfies the requirements of DOE 1324.5A.

K. Computer software used to support environmental protection activities is subjected to verification and validation.

L. The QA program is designed to provide effective control of procured items and services.

M. Sound engineering/scientific principles and appropriate standards are used in performing design activities that have environmental impacts. The design activities incorporate applicable requirements and are independently verified or validated prior to implementation.

N. Inspection and acceptance testing is conducted of items that have environmental impact. The tests employ established acceptance and performance criteria, and equipment that is calibrated and maintained. 


\section{QA.2 AUDITS/APPRAISALS/SURYEILLANCE}

\section{PERFORMANCE OBJECTIVE}

A program should be in place to provide verification of the effectiveness of the environmental protection activities and adherence to the quality assurance program.

DOE 5400.1, General Environmental Protection Program, Chapter IV, Section 10, requires that audits and performance reporting be included in quality assurance programs governing environmental monitoring and surveillance programs.

DOE 5700.6C, Quality Assurance, requires internal quality assurance audits as part of a quality improvement process. It further requires independent assessment and management assessment of the quality program, its effectiveness, and performance.

\section{CRITERIA}

A. Quality assurance audits, appraisals, and surveillances are conducted on a regular, planned schedule, and cover all environmental protection programs, organizations, and activities.

B. Audits, appraisals, and surveillances are conducted in accordance with formal, controlled procedures.

C. Responsibility, authority, and accountability for the conduct of these activities are clearly defined.

D. Audits, appraisals, and surveillances are conducted by trained, qualified personnel.

E. Findings and observations are formally documented and communicated to appropriate management and staff personnel for corrective action.

F. Root causes of significant deficiencies are identified and corrected to prevent recurrence.

G. A formal system is in place to document responses, investigations, and corrective actions related to findings.

H. A formal mechanism is in place to follow-up, track, and trend findings.

I. A formal lessons-learned system is in place to distribute information gained from audit activities.

J. Management at all levels reviews the results of audits and the corrective action program to assess and ensure the effectiveness of the corrective action process and the Quality Assurance Program. 


\section{QA.3 PROCEDURES}

\section{PERFORMANCE OBJECTIVE}

Key environmental activities should be conducted in accordance with formal procedures.

DOE 5400.1, General Environmental Protection Program, Chapter IV, Section 10, requires that written procedures be included among the elements of a quality assurance program governing environmental monitoring and surveillance programs.

DOE 5480.19, Conduct of Operations Requirements for DOE Facilities, requires that operations at DOE facilities be managed with a consistent and auditable set of requirements, standards, and responsibilities.

DOE 5700.6C, Quality Assurance, requires that work be performed to establish technical standards and administrative controls using approved instructions, procedures, or other appropriate means.

\section{CRITERIA}

A. Written procedures are in place for critical activities.

B. There is a formal system for procedure control, including preparation, review, approval, and amendment.

C. The technical adequacy of procedures has been verified.

D. Procedures reflect current practices and equipment.

E. Standard format and content have been established for procedures.

F. Periodic surveillances of procedures are performed, and resulting findings and observations are provided to the appropriate personnel.

G. Procedures are reviewed periodically by personnel with appropriate expertise.

H. Formal requirements establish the level of approval authority for procedures. 


\section{QA.4 LABORATORY AND FIELD QUALITY ASSURANCE}

\section{PERFORMANCE OBJECTIVE}

Sampling and analysis of environmental media should be conducted in such a way as to provide representative defensible data and support environmental management decisions.

DOE 5400.1, General Environmental Protection Program, requires that a quality assurance program consistent with DOE 5700.6B, Quality Assurance, (superseded by DOE 5700.6C on August 21, 1991 with an implementation period of 180 days) be established to cover each element of the environmental monitoring program. Required elements of the program include procedures, laboratory and field quality control, recordkeeping, audits, and use of chain-of-custody. The Order also requires that laboratories confirm the need and apply for certification with appropriate Federal, state, and local agencies.

DOE 5700.6C, Quality Assurance, provides additional interpretive guidance for the development and implementation of a QA program, including ASME NQA-1 and EPA guidance documents that apply to environmental protection and/or remediation.

DOE 5820.2A, Radioactive Waste Management, requires that radioactive wastes be managed in a manner consistent with the quality assurance provisions of DOE $5700.6 \mathrm{~B}$ (superseded by DOE 5700.6C) and ANSI/ASME NQA-1.

\section{CRITERIA}

A. Quality assurance plans are developed in which the organizational structure, responsibility, authority, and accountability for laboratory quality assurance activities are clearly defined.

B. Field and laboratory activities are conducted under controlled conditions using approved instructions, procedures or other appropriate means.

C. Sampling is conducted in a manner to ensure collection of samples representative of the media and conditions being measured, and to ensure precautions are taken to maintain sample integrity.

D. Legally defensible sample chain-of-custody is maintained.

E. Field and laboratory personnel have received adequate training and are qualified to perform their work. All training is documented.

F. The frequency and types of quality control samples (e.g., blanks, spikes, and duplicates) are defined in controlled documents or procedures, and are in conformance with Federal, state, and/or local requirements.

G. Data from the anaiysis of quality control samples are tracked and trends are assessed in accordance with formal procedures that include acceptance criteria and corrective actions. 
H. Acceptance criteria for sample parameters (e.g., chemical yields) and quality control data are defined in controlled documents.

I. Raw analytical data are recorded in bound notebooks or in a manner that assures positive control.

J. A formal program for the control and proper use of standards and reagents has been implemented.

K. The handling and storage of field samples is controlled to prevent damage or loss, and to minimize deterioration.

L. Data receive independent, documented review and validation (qualified, accepted or rejected) based on set acceptance criteria.

M. An instrument control program for equipment used for monitoring and data collection, including such requirements as calibration, preventive maintenance, and efficiency, functional, and background checks, is in place.

N. Instrument logs are maintained in a manner that assures positive control.

O. The laboratory has certifications, as needed, with the appropriate Federal, state, and local agencies.

P. The laboratory and vendor laboratories participate in cross-check programs, and their performance is formally evaluated, tracked, and assessed for trends, on a regularly scheduled basis.

Q. The facility verifies that subcontractor laboratories have QA programs that satisfy DOE requirements. 
This page intentionally left blank. 


\section{PERFORMANCE OBJECTIVES AND CRITERIA FOR THE NATIONAL ENVIRONMENTAL POLICY ACT (NEPA)}

\section{Overview}

NEPA establishes a national policy to ensure that consideration is given to environmental values and factors in Federal planning and decision-making. The Department of Energy's policy is to comply fully with the letter and spirit of NEPA. To ensure that environmental factors are considered in the decision-making process and to promote environmentally responsible decisions, DOE will incorporate NEPA requirements early in the planning process for proposed actions. DOE also will coordinate its NEPA activities with the states and tribes that host DOE actions. The Department is committed to complete assessment and full disclosure of the environmental consequences of its proposed actions.

The primary requirements for compliance with NEPA include the following:

- $\quad$ Council on Environmental Quality (CEQ) Regulations, 40 CFR Parts 1500-1508 (as amended 7-1-86)

- DOE National Environmental Policy Act Implementing Procedures, 10 CFR Part 1021 (DOE NEPA Regulations) (5-26-92)

- DOE Compliance with Floodplains/Wetlands Environmental Review Requirements, 10 CFR Part 1022

- DOE 5400.1, General Environmental Protection Program (11-9-88)

- DOE 5400.4, Comprehensive Environmental Response, Compensation, and Liability Act Requirements (10-6-89)

- DOE 5440.1E, National Environmentai Policy Act Compliance Program (11-10-92)

- National Environmental Policy Act, 42 U.S.C 4321 et seq. (1-1-70)

In addition, if the following related environmental laws are applicable, then compliance with their requirements must be reviewed during the NEPA audit:

- $\quad$ American Indian Religious Freedom Act, 42 U.S.C. 1996

- Archeological and Historic Preservation Act, as amended, 16 U.S.C. $469-469 \mathrm{c}$

- Coastal Barriers Resources Act, 16 U.S.C. 3501 et seq.

- Coastal Zone Management Act, 16 U.S.C. Section 1451 et seq.

- $\quad$ Endangered Species Act, 16 U.S.C. 1531 et seq. 
- Farmland Protection Policy Act, 7 U.S.C. 4201 et seq.

- Fish and Wildlife Coordination Act, 16 U.S.C. 661 et seq.

- $\quad$ Migratory Bird Treaty Act, 16 U.S.C. 701-718

- National Historic Preservation Act, 16 U.S.C. 470

- Wild and Scenic Rivers Act, 16 U.S.C. 271 et seq.

- Wilderness Act, 16 U.S.C. 1131 et seq.

The responsibility of the NEPA auditor is to review the DOE office and operating contractor NEPA procedures, documentation, and operations for compliance with applicable Federal and state statutes and regulations, DOE regulations and orders, and other relevant memoranda and guidance. The NEPA auditor should also review the DOE and operating contractor activities for adherence to best management practices (BMPs). BMPs are discretionary procedures that enhance overall compliance when specific requirements do not exist, do not apply, or do not go far enough.

The scope of the NEPA audit is programmatic. It is designed to gain a broad understanding and awareness of DOE and operating contractor systems for compliance with NEPA in order to describe the range of issues and problems that may exist. It does not include detailed evaluation of compliance with specific requirements of the CEO and DOE NEPA Regulations and the DOE NEPA Order.

The general approach to the NEPA audit includes the following activities: (1) review of policy statements, program plans, standard operating procedures for consistency with DOE Headquarters NEPA requirements and guidance; (2) review of previous NEPA audits and action plans to determine progress toward resolution of findings; $(3)$ interviews with DOE and operating contractor personnel to determine the depth of understanding and compliance with DOE NEPA procedures; and (4) site observation to ensure that the appropriate level of NEPA determination and documentation exists for ongoing and proposed actions. Since NEPA applies to all site activities and utilizes baseline and impact information from all of the environmental media, it is useful for the NEPA auditor to coordinate his/her activities with the other environmental auditors.

Performance objectives and criteria (POC) have been developed to provide general guidance for the NEPA auditor arid to ensure that relevant aspects of NEPA regulations, Orders, and guidance are considered during the audit. A list of the POC is provided in Table NEPA.1. The POC are intentionally brief and depend on the auditor's thorough familiarity with NEPA requirements, DOE guidance for implementing NEPA, and the requirements of the related environmental laws. The emphasis should be on evaluation of a formally documented NEPA program and its implementation. Findings can result from lack of a documented program and/or prosedures and from inadequate or incomplete implementation of an existing program. 


\section{TABLE NEPA-1}

\section{PERFORMANCE OBJECTIVES AND CRITERIA FOR THE NATIONAL ENVIRONMENTAL POLICY ACT (NEPA)}

NEPA.1 NEPA Program Structure and Elements

NEPA. 2 NEPA Program Formality 


\section{NEPA. 1 NEPA PROGRAM STRUCTURE AND ELEMENTS}

\section{PERFORMANCE OBJECTIVE}

The NEPA program should be designed to effectively address and comply with the requirements of the National Environmental Policy Act.

40 CFP 1500.2, CEQ Regulations, requires Federal agencies to interpret and administer the policies, regulations, and public laws of the United States in accordance with the policies set forth in NEPA and in the CEO regulations.

10 CFR 1021.101, DOE Regulations, requires DOE to follow the letter and spirit of NEPA; comply fully with the CEQ regulations; and apply the NEPA review process early in the planning stages for DOE proposals.

DOE 5440.1E, DOE NEPA Order, establishes DOE responsibilities and procedures for implementation of NEPA and coordination of its NEPA activities with the states and tribes that host DOE actions. The Order states that DOE is committed to complete assessment and full disclosure of the environmental consequences of its proposed actions.

\section{CRITERIA}

A. NEPA compliance programs have been developed and formally documented by DOE and the operating contractor following NEPA requirements and guidelines established by DCE Headquarters.

B. NEPA program olements have been reviewed and concurred with by DOE and operating contractor senior management and legal staff.

C. DOE and operating contractor responuibilities, authorities, and accountabilities for the NEPA compliance program are clearly defined, and each individual responsible for action is identified.

D. NEPA compliance programs have sufficient resources to accomplish their missions.

E. Formal programs are in place to ensure that DOE and operating contractor NEPA staff and those responsible for NEPA oversight are appropriately trained.

F. A formal system is in place to ensure that DOE determination of the level of NEPA review for a proposed action is appropriate.

G. A formal system is in place to ensure that DOE NEPA review, determination, and documentation is integrated with planning and budgetary processes for proposed actions such that all processes develop concurrently rather than consecutively.

H. A system is in place to provide oversight and to assess the acceptability of contractors preparing NEPA documentation for DOE. 
I. There is a mechanism to ensure the technical accuracy and adequacy of NEPA documents.

J. DOE has a system to coordinate NEPA-related activities and decisions with states and tribes that host DOE facilities.

K. DOE has a policy that states the conditions under which it seeks the cooperation of Federal, state, and local agencies and American Indian tribes that have jurisdiction by law or special expertise for preparation of NEPA documentation.

L. Systems are in place to ensure follow-up by DOE and the operating contractor of mitigation action plans. 


\section{NEPA. 2 NEPA PROGRAM FORMALITY}

\section{PERFORMANCE OBJECTIVE}

A formal program, supported by controlled documentation, should be in place to ensure NEPA review, determination, and documentation for ongoing and proposed actions.

DOE 5480.19, Conduct of Operations Requirements for DOE Facilities, provides requirements and guidelines for the development of directives, plans, and procedures relating to the conduct of operations. This Order states that it is the policy of DOE that the conduct of operations at DOE facilities be managed with a consistent and auditable set of requirements, standards, and responsibilities. The policy statement also addresses the use of procedures to control conduct of operations, review of programs, and assessment of program effectiveness.

\section{CRITERIA}

A. There are formal written procedures that are consistent with DOE Headquarters requirements and guidance to ensure appropriate DOE NEPA documentation for all ongoing and proposed actions.

B. A recordkeeping system is in place to track the status of NEPA review, determination, and documentation for (as appropriate) the planning, funding, approval, design and construction, and mitigation for all proposed actions.

C. A formal document control system exists for NEPA documentation that is consistent with the document control system used for all other environmental records but also includes the following specific NEPA requirements for:

- public availability of NEPA documentation and supporting information (e.g., in DOE reading rooms and/or public libraries), and

- $\quad$ procedures for restricted public availability of classified information. 


\section{PERFORMANCE OBJECTIVES AND CRITERIA FOR ENVIRONMENTAL MANAGEMENT SYSTEMS}

\section{Overview}

The environmental management systems POC are intended to serve as a guideline in establishing environmental programs that meet the objectives of DOE policy on environmental protection. They are also intended for use in assessing these programs through self-assessment and oversight programs. These POC are based on sound management principles that are widely utilized in the management of environmental activities. With sound management principles, strong environmental management systems can be established in the pursuit of excellence in environmental endeavors.

The commitment to strong environmental management systems is implicit in the policy defined in DOE 5400.1 which states ". . . it is DOE policy to conduct the Department's operations in compliance with the letter and spirit of applicable environmental statutes, regulations, and staridards. In addition, DOE is committed to good environmental management of all its programs and at all its facilities to correct existing environmental problems, to minimize risks to the environment or public health, and to anticipate and address potential environmental problems before they pose a threat to the quality of the environment or the public welfare. Finally, it is DOE's policy that efforts to meet environmental obligations be carried out consistently across all operations and among all field organizations and programs."

Further support for establishing formal environmental management systems is provided by DOE 5480.19, Conduct of Operations Requirements for DOE Facilities, and DOE 5700.6C, Quality Assurance, which establish general requirements for the formality of operations and the assurance of quality achievement for DOE programs. Although environmental management is not explicitly identified in these policies, their intent is to provide more formality and better quality assurance in all DOE activities.

The POC focus on the objectives that must be achieved for effective environmental management rather than prescribing a specific management system. This nas been done to acknowledge that more than one management approach or system may be used to meet the objectives. The intent of the POC is not to endorse any particular management system but rather to evaluate whether the systems in place to provide the discipline and control needed to achieve the performance objective.

It should be noted that these POC are also applicable to contractors. DOE 5400.1 states ". . . it is DOE policy that contractors will share the Department's commitment to good environmental management. DOE expects its management and operating contractors to conduct their operations in an enviror. nentally sound manner that limits the risks to the environment and protects the public health. DOE will actively oversee contractors' activities to assure compliance with this policy."

Unlike the other POC contained within this document, the environmental management POC are not all specifically referred to in DOE Orders or Federal and state regulations. Many of these POC are based on best management practices, which are followed at Department of Energy organizations, other government organizations, and industry. 


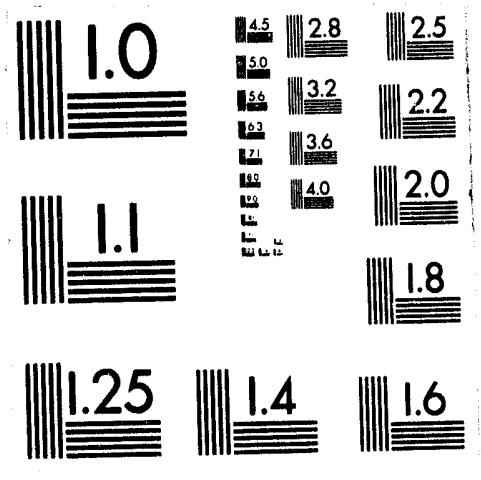




In an assessment of environmental management systems, the responsibility of the environmental management specialist is to assess these systems to determine whether they effectively meet the performance objectives and whether they have sufficient structure and formality to assure that activities are conducted in a manner that is consistent with environmental regulations and DOE policy.

The assessment is based on a combination of staff interviews and document reviews. Interviews are exceptionally important in conducting an environmental management assessment. They provide the primary means of understanding the organizational relationships, roles and responsibilities, policies, and systems that form the framework for the management of environmental matters. More importantly, they often reveal differences in the actual versus the documented practices. Document review is important to verify the formality of the system and confirm interview information.

Environmental management findings are often best-management-practices findings rather than compliance findings because they are not specifically required by DOE Orders or regulations. However, their significance is not diminished by this distinction since an environmental management finding may indicate a root cause of more specific compliance findings. No distinction, therefore, is made between co:npliance and BMP in the writing of the performance objectives for environmental management findings. 
TABLE EM-1

PERFORMANCE OBJECTIVES AND CRITERIA FOR

ENVIRONMENTAL MANAGEMENT SYSTEMS

EM. $1 \quad$ Organizational Structure

EM.2 Environmental Commitment

EM.3 Environmental Protection Programs

EM.4 Formality of Environmental Programs

EM.5 Internal and External Communication

EM.6 Staff Resources, Training, and Development

EM.7 Program Evaluation, Reporting and Corrective Action

EM.8 Environmental Planning and Risk Management 


\section{PERFORMANCE OBJE_TIVE}

The structure of the organization being assessed should be such that environmental management systems are congruent and effectively integrated with other functions and processes. Roles, responsibilities, and accountabilities should be well defined and clearly communicated to effectively manage environmental issues. Authorities should be delegated to organizational levels that can ensure the effective implementation of environmental programs.

\section{CRITERIA}

\section{Management Organization}

A. The organizational structure of the environmental management function is characterized by clear lines of authority and responsibility.

B. The environmental management function is organized in such a way that managers can be leveraged effectively, without being spread too thinly.

C. Reporting relationships within the environmental management function are well defined, clearly communicated, and effectively integrated into the overall organizational structure.

D. Environmental managers are positioned high enough in the organization and have sufficient organizational stature, independence, and authority to effectively implement environmental programs and make decisions related to environmental protection.

E. The integrity and effectiveness of the organizational structure is periodically reviewed and revisions are made when warranted.

II. Roles and Responsibilities

A. Environmental roles and responsibilities are well defined, clearly communicated, and understood by all personnel whose activities may impact environmental performance.

B. Roles, responsibilities, and accountabilities are supported by management systems and documentation such as job descriptions, performance standards and performance appraisals.

C. Personnel responsible for environmental management are held accountable for their performance and the performance of those they manage. 
D. A group independent of line management with responsibility for policy and standards development and oversight and technical support has been established. This group has the authority and management support to implement their responsibilities. 


\section{EM.2 ENVIRONMENTAL COMMITMENT}

\section{PERFORMANCE OBJECTIVE}

The organization should exhibit a commitment to environmental excellence demonstrated by top management support, formal environmental policy, and line management accountability for environmental performance.

\section{CRITERIA}

\section{Top Management Support}

A. Top management clearly communicates its commitment to environmental protection through the issuance of formal statements and policies that explicitly state environmental goals and expectations, with full compliance as a minimum goal.

B. Top management demonstrates its commitment to environmental excellence through personal and managerial actions.

C. Top management's commitment is demonstrated through required routine reporting on environmental performance and the status of environmental initiatives.

D. Senior managers have a basic understanding of and appreciation for environmental requirements relevant to the scope of the operations for which they are responsible.

E. Top management encourages openness and is receptive to input on environmental issues from all employees, as well as from the public at large.

F. Top management has created a culture of compliance, awareness, teamwork, and line responsibility for environmental management.

II. Environmental Policy

A. A formal environmental policy statement has been issued from a high enough level of authority within the organization to communicate its importance.

B. Environmental policy places priority for environmental protection above production. Environmental compliance is formally established as the minimum acceptable standard.

C. The organization has established issue-specific policies for the major environmental issues consistent with the scope of its operations.

D. Environmental policies are widely distributed, easily accessible, and understood throughout the organization. 


\section{Line Management Support}

A. Individuals throughout the organization recognize the environmental aspects of their job responsibilities, and take personal responsibility for and demonstrate a sense of "ownership" of environmental protection.

B. Managers at all levels have formally stated and demonstrated their commitment to environmental excellence.

C. Managers at all levels and in all functions, whose activities may impact environmental performance, take responsibility and interest in limiting the environmental impacts of their operations.

D. Management and staff cooperate fully and openly with internal and external oversight groups. 


\section{EM.3 ENVIRONMENTAL PROTECTION PROGRAMS}

\section{PERFORMANCE OBJECTIVE}

Programs should be in place to ensure compliance with (1) applicable Federal, state, and local environmental protection laws and regulations, (2) Executive Orders, and (3) internal DOE policies and Orders that are designed to protect the environment and public health and welfare.

DOE 5400.1, General Environmental Protection Program, establishes environmental protection program requirements, authorities, and responsibilities for assuring compliance with applicable environmental protection laws and regulations, Executive Orders, and internal Department policies. The Order states "it is DOE policy to conduct the Department's operations in compliance with the letter and spirit of applicable environmental statutes, regulations, and standards. In addition, DOE is committed to good environmental management of all its programs. . ." Criteria are provided below that address programs to ensure compliance with all applicable environmental laws, regulations and DOE policies.

\section{CRITERIA}

\section{Specific Environmental Protection Prograins}

A. Effective environmental protection programs are in place to identify, control, and monitor air emissions.

B. The organization has a program for the protection of surface waters, including identification of point and non-point discharge sources, applicable discharge permits, wetland permits monitoring program, an effective Spill Prevention, Control, and Countermeasures Plan, and reporting and recordkeeping systems.

C. The organization has a program for the protection of potable water supplies, (including backflow prevention systems).

D. The organization has determined and documented the need for site-specific groundwater protection programs. Where necessary, a groundwater monitoring program has been established to address the needs of specific sites.

E. Programs are in place for the proper management and control of toxic and chemical materials to prevent or minimize their release into the environment, including programs for:

- procurement, handling, and storage of toxic and chemical materials;

- management and control of polychlorinated biphenyls;

- management and control of pesticides; 
- management and control of petroleum, petroleum products, and chemicals in aboveground or underground storage tanks; and

- containment or removal of asbestos.

F. The organization has a program for the management of solid, hazardous, and radioactive and mixed waste, including:

- $\quad$ waste source identification;

- $\quad$ waste characterization;

- waste acceptance criteria, where appropriate;

- treatment, storage and disposal practices;

- $\quad$ contingency plans;

- recordkeeping systems;

- training; and

- waste minimization.

G. Programs are in effect that provide for environmental radiation protection through incorporation of guidelines contained in the DOE General Design Criteria and adherence to ALARA principals. Additional programs are in place that require radiological environmental surveillance, evaluation of unplanned releases of radioactive materials, and evaluation of radiation exposure to the public.

H. The organization has a program to identify, remove, and/or routinely monitor underground storage tanks.

I. The organization has a program for compliance with DOE requiremients for implementing NEPA, including screening/review and determination of the appropriate level of NEPA documentation for each proposed action.

II. Specific Program Plans

A. The responsible field organization has prepared, and updated annually, an Environmental Protection Implementation Plan.

B. The responsible field organization has prepared and updated formal program plans for the following:

I. Groundwater Protection Management;

2. Waste Minimization; and

3. Pollution Prevention Awareness. 
C. The organization has developed an environmental monitoring and surveillance plan as specified in DOE 5400.1.

\section{Other Programs Related to Environmental Protection}

A. A program is in place to plan and effectively implement all actions required to manage responses to releases of hazardous substances to the environment from inactive waste sites or to releases of reportable quantities of hazardous materials.

B. The organization has developed and implemented preventive maintenance programs to ensure proper operation of pollution control equipment.

C. The organization has emergency preparedness plans such as contingency plans, Spill Prevention, Control, and Countermeasures plans, and a general emergency plan that addresses any potential hazard including natural disasters, fire, explosions, etc. Emergency response plans and programs include all applicable elements, including roles and responsibilities, procedures, training, and equipment.

D. A Quality Assurance Program (QAP) and organization is in place to assure that environmental programs provide adequate protection to the environment and to public health, and that environmental data are representative and defensible. The QAP shall include the minimum criteria noted in DOE 5700.6C. 


\section{EM.4 FORMALITY OF ENVIRONMENTAL PROGRAMS}

\section{PERFORMANCE OBJECTIVE}

Formal systems and procedures should be in place to manage day-to-day environmental protection activities to ensure environmental compliance. This includes systems to track and understand regulatory requirements, procedures for implementation of policies and programs, routine inspections, and systems for recordkeeping and reporting.

DOE 5480.19, Conduct of Operations Requirements for DOE Facilities, provides requirements and guidelines for the development of directives, plans, and procedures relating to the conduct of operations. This Order states that it is the policy of DOE that the conduct of operations at DOE facilities be managed with a consistent and auditable set of requirements, standards, and responsibilities. The policy statement also addresses the use of procedures to control conduct of operations, review of programs, and assessment of program effectiveness.

\section{CRITERIA}

\section{Regulatory Tracking and Translation}

A. A formal system is in place to routinely track and interpret new and/or changes to Federal, state and local regulations and DOE Orders and policies for the organization.

B. There is a process to ensure that guidance on new regulatory requirements is incorporated into organization or site-specific standard operating procedures, as appropriate.

C. Relevant regulatory information is routinely distributed to field organizations in a timely manner.

D. Field organizations are provided sufficient guidance for compliance with new regulations or policies in the form of guidance documents, sample plans and procedures.

\section{Procedures}

A. The organization has a formal, controlled process for reviewing, creating, updating, and approving new procedures.

B. Procedures and standards are issued from an organizational level with the authority to mandate implementation.

C. Formal standards and procedures have been developed for the implementation of specific environmental protection programs.

D. There are procedures to ensure that any activities that might impact the environment are reviewed for environmental protection considerations. 
E. Procedures are part of a formal, auditable document control system designed to ensure that personnel have ready access to current versions of procedures containing environmental requirements.

F. The organization has implemented a system to periodically review and update environmental procedures.

III. Routine Facility Inspections

A. The organization has a program for routine site and equipment inspections and compliance checks, including appropriate documentation.

B. The organization has a formal system for follow-up of exceptions noted in inspections, which is supported by management review.

\section{Recordkeeping and Reporting}

A. Systems are in place for the appropriate documentation and recordkeeping of environmental performance.

B. The organization has a document control system and record retention policy.

C. There are systems in place to ensure that environmental reports required by Federal and state regulations and DOE are routinely prepared and submitted on a timely basis.

D. Environmental status reports with the appropriate level of detail are routinely prepared for internal management purposes and for reporting environmental concerns to higher levels of management in a timely manner.

E. There are formal mechanisms to investigate, report, correct, track, and monitor trends in environmental problems and "incidents." The types and magnitudes of the problems that should be reported are well defined. 


\section{EM.5 INTERNAL AND EXTERNAL COMMUNICATION}

\section{PERFORMANCE OBJECTIVE}

Formal and informal channels of communication should be utilized to facilitate implementation of all environmental management systems and programs; to emphasize management commitment to envirnnmental protection; to generate a sense of environmental awareness throughout the organization; and to manage relationships with external oversight organizations and others who are likely to be concerned with the success of the organization's environmental protection efforts.

\section{CRITERIA}

I. Internal Communications

A. Environmental information is effectively communicated through formal or informal means throughout the organization (top-down, bottom-up, and lateral).

B. There is a formal system in place to allow personnel to anonymously iwithout retribution) communicate environmental concerns to upper levels of management for resolution.

C. Informal channels of internal communication are encouraged as a means of developing cooperation and commitment to environmental protection.

D. Environmental awareness is continually reinforced throughout the organization via the use of newsletters, bulletin boards, videotapes, office-wide programs, or other means.

E. Formal communication of environmental protection directives is timely, and effectively reaches all responsible elements of the organization.

F. Employee environmental concerns are solicited and addressed. Both the concerns and responses are documented.

G. The effectiveness of communication is demonstrated by a widespread awareness and acceptance of the organizational commitment to environmental protection.

H. Effective working relationships exist between headquarters and field environmental staff as well as between staff and line personnel whose functional responsibilities impact environmental performance.

\section{External Communication}

A. The organization has a good working relationship and cooperates fully and openly with external oversight organizations. 
B. The organization has defined who will be the internal points of contact with external parties, and has identified the points of contact within appropriate external parties.

C. A program exists for communicating with external parties such as regulatory agencies, environmental groups, and the local community to provide them with information and the opportunity to be involved in key decisions related to environmental protection.

D. Formal communication of environmental risks and protection efforts occurs frequently, is timely, and effectively reaches external organizations, including regulatory agencies, environmental groups, and representatives of the local community.

E. The environmental concerns of external parties are solicited and addressed. Both the concerns and responses are documented.

F. The effectiveness of communication is demonstrated by a widespread external recognition of the organization's commitment to environmental protection.

G. The organization periodically assesses the effectiveness of external communications, makes changes as necessary, and documents the results of the evaluations and changes made. 


\section{EM.6 STAFF RESOURCES, TRAINING, AND DEVELOPMENT}

\section{PERFORMANCE OBJECTIVE}

Programs should be in place to ensure that staff resources are sufficient to effectively develop and implement the organization's environmental protection programs. The organization should have a formal program in place to ensure that all personnel have received environmental protection training appropriate for their job responsibilities. The organization should also provide staff development and career advancement opportunities for environmental staff.

\section{CRITERIA}

\section{Environmental Staffing}

A. Environmental staffing levels are sufficient to achieve environmental performance goals. This includes dedicated environmental support staff and others with collateral environmental duties (e.g. line managers with other support functions).

B. Personnel with environmental responsibilities have the relevant background and training to carry out their responsibilities.

C. Staffing for environmental protection activities is provided in a timely manner.

D. A system is in place to identify both short-term and long-term environmental staffing requirements, both within the environmental support group and within line units with environmental responsibilities.

II. Job Descriptions and Performance Evaluations

A. Appropriate job descriptions are established and maintained for environmental positions.

B. Performance standards used in the performance appraisal process include the environmental aspects of individual job responsibilities, including line management responsibilities for environmental performance. Environmental factors are given comparable emphasis to safety and productivity factors.

C. Good environmental performance is rewarded in practice, and poor performance is penalized.

III. Environmental Training Programs

A. Environmental training programs are defined in controlled documents such as a training program manual.

B. There is a process in place to identify and evaluate environmental training needs for all personnel. These needs are incorporated into individual professional development plans. 
C. The environmental training program is supported by appropriate training materials and qualified trainers.

D. There is a formal process to ensure that training courses are developed at an appropriate depth and provide adequate coverage of DOE Orders, Federal and state regulations, and internal policies and procedures.

E. All levels of personnel -- from operators to lower, middle, and upper management -undergo some level of environmental awareness training.

F. Environmental protection training is included in new employee and contractor orientation training, and environmental protection training requirements have been established for temporary employees and visitors.

G. Training activities are documented and the training recordkeeping system is auditable, complete, and current.

H. There is a formal documented process for the periodic evaluation of the effectiveness of training programs.

\section{Staff Development Opportunities}

A. The organization provides career opportunities and advancement for environmental staff within the program, where possible, or in other DOE programs/facilities.

B. In staff development efforts, environmental support staff are encouraged to acquire management and professional skills in order to build their supervisory and management potential.

C. Cross-functional training is available and encouraged to maintain and expand staff capabilities. 


\section{EM.7 PROGRAM EVALUATION, REPORTING AND CORRECTIVE ACTION}

\section{PERFORMANCE OBJECTIVE}

The organization should have self-assessment and oversight programs in place to effectively evaluate environmental protection activities, anticipate and report environmental concerns, and implement corrective actions.

Numerous DOE Orders, including DOE 5480.19, Conduct of Operations Requirements for DOE Facilities.

DOE 5480.1B, Environment, Safety, and Health Program for Department of Energy Operations.

DOE 5482.IB, Environment, Safety, and Health Appraisal Program, establish requirements for self-assessment and appraisal programs at all levels of the organization.

The December 1992 ES\&H Self-Assessment guidance document provides guidance on establishing effective ES\&H self-assessment functions within DOE and contract organizations. The major objective of self-assessment programs is to establish accountability and excellence at the "grassroots" level, thereby involving people who are the most familiar with the operations and their management. Self-assessment is a continual line management activity that acquires, assimilates, documents, and reports through all levels of an organization on the effectiveness, adequacy, efficiency, and economy of its activities. Self-assessment should establish a culture of accountability and continuous improvement as well as foster excellence in all program activities.

\section{CRITERIA}

\section{Self-Assessment and Appraisal Programs}

A. Facilities and departments have implemented ongoing formal, written programs which include both internal self-assessments and independent oversight appraisals.

B. Responsibilities and authorities for self-assessmerit activities are clearly defined.

C. Frequency of self-assessments and appraisals is congruent with the program's goals and inherent risks.

D. Focused functional appraisals are conducted on specific issues to reduce the organization's long-term environmental liabilities.

E. Audits/appraisals are conducted by professionals who are trained and qualified.

F. Audits/appraisals are conducted using formal, written guidance documents and are documented.

G. Self-assessment program implementation is addressed in budget planning and budget requests. 
H. The systems used for environmental program evaluations are periodically critiqued and modifications are made as necessary.

I. Audits are conducted to verify the effectiveness of the environmental protection quality assurance activities and adherence to the quality assurance program.

\section{Reporting and Follow-up}

A. Assessment results are documented in formal reports distributed in a timely manner to appropriate levels of management.

B. Corrective actions to address root causes of findings are developed and implemented by line management.

C. Corrective actions are independently tracked to ensure their completion, objectively verified at completion, and formally closed out.

D. "Lessons learned" programs are implemented to seek out improvement opportunities for environmental performance.

E. Trend analysis of findings is conducted on a periodic basis to identify underlying programmatic or management root causes.

F. Performance indicators for environmental protection have been defined and are tracked and analyzed for trends. 


\section{EM.8 ENVIRONMENTAL PLANNING AND RISK MANAGEMENT}

\section{PERFORMANCE OBJECTIVE}

The organization should plan for environmental management activities to ensure that environmental resources needs are adequately addressed and the organization's environmental goals can be met. Planning for environmental protection should be integrated with planning for other organizational functions. In the planning and budget allocation process, environmental protection should receive equal priority and weight as production activities.

The organization should have a formal system to identify environmental hazards, assess the resulting environmental risks of those hazards, and mitigate risks.

\section{CRITERIA}

1. Environmental Planning and Budgeting

A. Environmental planning is conducted with comparable formality to planning for other organizational functions and includes both short- and long-term planning.

B. Environmental protection considerations are adequately included in planning for other organizational functions.

C. Environmental issues are represented by qualified personnel in key strategic and operations planning meetings/ committees.

D. In the planning process, the organization has a system for establishing priorities and weighing competing factors, with environmental protection receiving equal weight to production.

E. Commitment of funds for environmental-related activities is satisfactory to serve the organization's environmental performance goals, through both capital and maintenance projects.

F. Environmental protection is an integral part of the budget and planning process.

G. The organization has assessed its needs for pollution control technologies and other technical equipment to achieve its performance goals.

H. The organization has a system in place for the control and oversight of purchased materials, equipment, and services supporting environmental protection activities to ensure that they meet environmental specifications.

\section{Risk Management}

A. A formal environmental risk management program has been established and is operational. This program includes objectives, approach, procedures and risk evaluation criteria. 
B. A formal, systematic review of the organization's operations/activities is periodically conducted to identify and manage environmental risks.

C. The organization has developed programs or standards to manage environmental risks not covered by regulatory requirements.

D. All new projects, programs, or activities that may impact the environment are carefully reviewed to identify and address environmental risks as early as possible. A formal project/program review and approval process, which includes environmental considerations, has been established. 

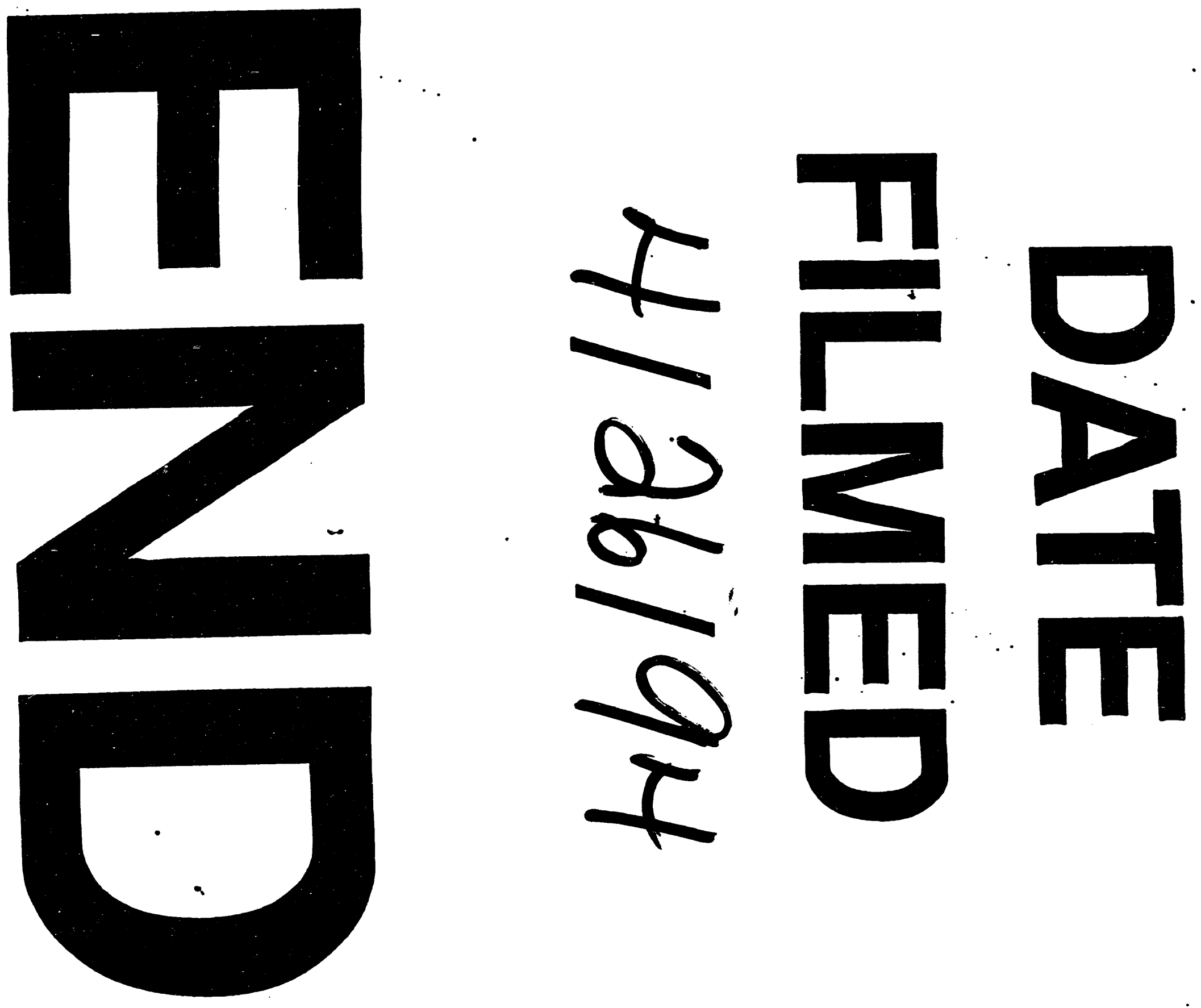


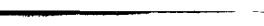

